Aus dem Institut für Zelluläre und Molekulare Immunologie (Prof. Dr. rer. nat. Wienands)

der Medizinischen Fakultät der Universität Göttingen

\title{
Suszeptibilität parthenogenetischer Stammzellen und ihrer Derivate gegenüber zytotoxischen Effektormechanismen
}

\author{
INAUGURAL-DISSERTATION \\ zur Erlangung des Doktorgrades \\ der Medizinischen Fakultät der \\ Georg-August-Universität zu Göttingen
}

vorgelegt von

Hannah Johannsen

aus

Bad Oldesloe

Göttingen 2016 
Dekan:

Referent:

Ko-Referent/in:

Promotor-Vertretung

Tag der mündlichen Prüfung:
Prof. Dr. Heyo K. Kroemer

Prof. Dr. Ralf Dressel

Prof. Dr. Gerald Wulf

Prof. Dr. Thomas Meyer

30. März 2017 
Inhaltsverzeichnis

$\begin{array}{ll}1.1 \text { Stammzellen } & 7\end{array}$

$\begin{array}{ll}\text { 1.1.1 Herkunft und Eigenschaften von Stammzellen } & 7\end{array}$

1.1.1.1 Embryonale Stammzellen (ESC)

1.1.1.2 Induzierte pluripotente Stammzellen (iPSC) 8

1.1.1.3 Multipotente adulte Stammzellen der Keimbahn (maGSC) 9

1.1.1.4 Parthenogenetische Stammzellen (PSC) 9

1.1.2 Schwierigkeiten in der Arbeit mit Stammzellen 11

1.2 Zytotoxische T-Zellen, ihre Effektormechanismen und Auswirkungen auf Stammzellen $\quad 13$

1.2.1 Entwicklung zytotoxischer T-Lymphozyten 13

$\begin{array}{ll}\text { 1.2.2 Aktivierung zytotoxischer T-Lymphozyten } & 13\end{array}$

1.2.3 Effektormechanismen zytotoxischer T-Lymphozyten 14

1.2.4 Protektionsmechanismen gegen Effektormechanismen von CTL $\quad 15$

$\begin{array}{ll}\text { 1.2.5 Auswirkungen von CTL auf Stammzellen } & 16\end{array}$

1.3 NK-Zellen, ihre Effektormechanismen und deren Auswirkungen auf $\begin{array}{lr}\text { Stammzellen } & 19\end{array}$

$\begin{array}{ll}\text { 1.3.1 Herkunft natürlicher Killerzellen } & 19\end{array}$

$\begin{array}{ll}\text { 1.3.2 Aktivierung von NK-Zellen } & 19\end{array}$

1.3.3 Effektormechanismen natürlicher Killerzellen 20

1.3.4 Auswirkungen von NK-Zellen auf Stammzellen 21

$\begin{array}{ll}1.4 \text { Fragestellung } & 23\end{array}$ 
2.1 Material 25

2.1.1 Verwendete Geräte 25

2.1.2 Chemikalien und Reagenzien 26

2.1.3 Analysesets 28

2.1.4 Nährmedien 28

2.1.5 Puffer und Stammlösungen 28

2.1.6 Gele 31

2.1.7 Antikörper 31

2.1.7.1 Primäre Antikörper 31

2.1.7.2 Sekundäre Antikörper, Isotypenkontrolle und Sekundärreagenzien 32

2.1.7.3 Rekombinante Ig-Fusionsproteine 33

2.1.8 Proteinmarker 33

2.1.9 Zytokine 33

2.1.10 Enzyme und Enzyminhibitoren 33

2.1.11 Primer 34

2.1.12 Zelllinien 35

2.1.13 Versuchstiere 36

2.1.14 Einwegartikel 36

2.1.15 Computeranalyse $\quad 37$

$\begin{array}{lll}2.1 .16 & \text { Herstellerliste } & 37\end{array}$

$\begin{array}{ll}2.2 \text { Methoden } & 39\end{array}$

2.2.1 Zellkulturmethoden 39

2.2.1.1 Allgemeines zur Arbeit mit Zellkulturen 39

2.2.1.2 Bestimmung der Zellzahl 39

2.2.1.3 Einfrieren und Auftauen von Zellen 40

2.2.1.4 Ablösung adhärent wachsender Zellen 40

2.2.1.5 Isolierung von Lymphozyten aus Mäusemilzen 41

2.2.1.6 Stimulation zytotoxischer T-Lymphozyten aus OT-I-Mäusen 41

2.2.1.7 Stimulation alloreaktiver zytotoxischer T-Lymphozyten 41

2.2.1.8 Stimulation Lymphokin-aktivierter NK-Zellen (LAK) 42

2.2.2 Magnetische Separation von NK-Zellen 42

2.2.2.1 Allgemeines zur MACS 42 
2.2.3 Zytotoxizitätstest $\quad 43$

2.2.3.1 Allgemeines zur Arbeit mit radioaktiven Stoffen 43

2.2.3.2 Prinzip des ${ }^{51}$ Chrom-Freisetzungstests 43

2.2.3.3 Durchführung des ${ }^{51}$ Chromfreisetzungstests 44

2.2.4 Durchflusszytometrie 46

2.2.4.1 Allgemeines zur Durchflusszytometrie 46

2.2.4.2 Bestimmung verschiedener Oberflächenliganden mittels

Durchflusszyto-metrie $\quad 46$

$\begin{array}{lll}2.2 .5 & \text { Westernblot } & 47\end{array}$

2.2.5.1 Allgemeines zum Westernblot $\quad 47$

2.2.5.2 Herstellung von Zell-Lysaten 47

2.2.5.3 SDS-Polyacrylamid-Gelelektrophorese 47

2.2.5.4 Westernblot 48

2.2.5.5 Immunfärbung der transferierten Proteine 48

2.2.6 Quantitative Echtzeit-PCR 49

2.2.6.1 Allgemeines zur quantitativen Echtzeit-PCR (real-time-PCR, rtPCR) 49

2.2.6.2 Erstellen von Primern 50

2.2.6.3 Isolierung und Aufreinigung von RNA 50

2.2.6.4 Synthese von cDNA 51

2.2.6.5 Durchführung der quantitativen Echtzeit-PCR 51

\section{ERGEBNISSE $\quad 52$}

3.1 Auswirkungen von LAK-Zellen auf parthenogenetische Stammzellen 52

3.1.1 Lysierbarkeit parthenogenetischer Stammzellen durch LAK-Zellen 52

3.1.2 Expression von MHC-Klasse-I-Molekülen auf parthenogenetischen Stammzellen in der Durchflusszytometrie 56

3.1.3 Expression von MHC-Klasse-I-mRNA in der rtPCR 59

3.1.4 Expression NK-Zell-aktivierender Liganden auf parthenogenetischen $\begin{array}{ll}\text { Stammzellen in der Durchflusszytometrie } & 60\end{array}$

\subsection{Auswirkungen Peptid-spezifischer CTL auf parthenogenetische} Stammzellen $\quad 64$

3.2.1 Lyse parthenogenetischer Stammzellen durch CTL aus OT-I-Mäusen 64 
3.2.2 Lyse parthenogenetischer Stammzellen durch OT-I-Zellen nach Behandlung mit Interferon- $\gamma$

3.2.3 Hinweise auf protektive Faktoren parthenogenetischer Stammzellen gegen CTL 68

\subsection{Auswirkungen von CTL und NK-Zellen auf parthenogenetische} Stammzellen im Vergleich zu differenzierten Zellen

3.3.1 Lysierbarkeit undifferenzierter parthenogenetischer Stammzellen durch LAK-Zellen im Vergleich zur Lysierbarkeit differenzierter parthenogenetischer Stammzellen

3.3.2 Lysierbarkeit undifferenzierter parthenogenetischer Stammzellen durch CTL im Vergleich zur Lysierbarkeit ihrer differenzierten Derivate

3.3.3 MHC-Klasse-I-Expression differenzierter Zellen

3.3.4 Veränderung der Expression NK-Zell-aktivierender Liganden während der Differenzierung der parthenogenetischen Stammzellen

4 DISKUSSION

4.1 Parthenogenetische Stammzellen und NK-Zellen

4.2 Parthenogenetische Stammzellen und CTL

4.3 Differenzierte Derivate

5 ZUSAMMENFASSUNG

6 LITERATURVERZEICHNIS 
Abkürzungsverzeichnis

\begin{tabular}{|c|c|}
\hline Abb. & Abbildung \\
\hline APC & Antigen-präsentierende Zelle \\
\hline APS & Ammoniumpersulfat \\
\hline CD & cluster of differentiation \\
\hline CDR & komplementaritätsbestimmende Region \\
\hline $\mathrm{cm}$ & Zentimeter \\
\hline CTL & zytotoxische T-Zelle / CD8+ T-Zelle \\
\hline d.h. & das heißt \\
\hline DMEM & dulbecco modified eagle medium \\
\hline DMSO & Dimethylsulfoxid \\
\hline DNA & Desoxyribonukleotidsäure \\
\hline dsDNA & Doppelstrang-Desoxyribonukleotidsäure \\
\hline EDTA & Ethylendiamintetraessigsäure \\
\hline EGTA & Ethylenglycol bis(2-aminoethylether)-N,N,N',N'-tetraessigsäure \\
\hline ESC & embryonale Stammzelle \\
\hline FACS & fluorescence activated cell sorting \\
\hline FCS & fetales Kälberserum \\
\hline$g$ & Gramm \\
\hline Gy & Gray \\
\hline $\mathrm{HCl}$ & Salzsäure \\
\hline HSP & Hitzeschockprotein \\
\hline Hepes & 2-(4-(2-Hydroxyethyl)- 1-piperazinyl)-ethansulfonsäure \\
\hline IFN & Interferon \\
\hline IL & Interleukin \\
\hline iPSC & induzierte pluripotente Stammzelle \\
\hline $\mathrm{KHCO}_{3}$ & Kaliumhydrogencarbonat \\
\hline MACS & magnetic activated cell sorting \\
\hline maGSC & multipotente adulte Stammzelle der Keimbahn \\
\hline $\mathrm{MHC}$ & Haupthistokompatibilitätskomplex \\
\hline$\mu g$ & Mikrogramm \\
\hline $\mathrm{mg}$ & Milligramm \\
\hline & Minute \\
\hline
\end{tabular}




$\begin{array}{ll}\mu l & \text { Mikroliter } \\ \mathrm{ml} & \text { Milliliter } \\ \mathrm{mRNA} & \text { messenger RNA } \\ \mathrm{NaCl} & \text { Natriumchlorid } \\ \mathrm{NaOH} & \text { Natronlauge } \\ \mathrm{NH} 4 \mathrm{Cl} & \text { Ammoniumchlorid } \\ \mathrm{NK}-Z \text { elle } & \text { natürliche Killerzelle } \\ \text { PBS } & \text { Phosphat-gepufferte Salzlösung } \\ \text { pH } & \text { potentia Hydrogenii } \\ \mathrm{PCR} & \text { Polymerasekettenreaktion } \\ \text { PSC } & \text { parthenogenetische Stammzelle } \\ \mathrm{RNA} & \text { Ribonukleinsäure } \\ \text { rtPCR } & \text { realtime-polymerase chain reaction /Echtzeit- } \\ \text { SDS } & \text { Polymerasekettenreaktion } \\ \text { SIINFEKL } & \text { Natriumdodecylsulfat } \\ \text { SPI-6 } & \text { Peptid aus Ovalbumin (aa 257-264) } \\ & \text { Serinprotease-Inhibitor 6 } \\ \text { SSC } & \text { spermatogoniale Stammzelle } \\ \text { TCR } & \text { T-Zellrezeptor } \\ \text { TGF } \beta & \text { Tumorwachstumsfaktor } \beta \\ \text { TNF } & \text { Tumornekrosefaktor } \\ \text { x g } & \text { x Erdbeschleunigung } \\ & \end{array}$




\section{Einleitung}

\subsection{Stammzellen}

\subsubsection{Herkunft und Eigenschaften von Stammzellen}

Stammzellen können sich selbst erneuern oder in verschiedene Gewebe differenzieren (Klimanskaya et al. 2007). Ihre Erzeugung und gerichtete Ausdifferenzierung bietet vielfältige Anwendungsmöglichkeiten in der regenerativen Medizin, der Evaluation von Medikamenten-Effekten und -Sicherheit, aber auch als Modellsystem embryonaler Entwicklung oder von Krankheiten (Zimmermann 2011). Die verschiedenen heute bekannten Stammzelltypen unterscheiden sich im Wesentlichen durch die Art ihrer Gewinnung aus embryonalem oder adultem Gewebe sowie hinsichtlich ihres Entwicklungspotentials.

\subsubsection{Embryonale Stammzellen (ESC)}

Murine embryonale Stammzellen (ESC) wurden erstmals 1981 aus Embryoblasten gewonnen (Evans und Kaufman 1981, Martin 1981). 1998 gaben Thomson und Kollegen die Erzeugung humaner ESC bekannt. Es folgten zahlreiche Experimente zur Ausdifferenzierung von ESC sowie der Transplantation der Stammzellen und ihrer Derivate in verschiedene Gewebe. So konnten aus humanen ESC gewonnene Kardiomyozyten die Funktion infarzierten Herzgewebes in Ratten und Mäusen verbessern (Caspi et al. 2007). Im Meerschweinchenmodell konnte gezeigt werden, dass sich aus humanen ESC gewonnene Kardiomyozyten auch bezüglich der elektrischen Aktivität integrierten und zu einer Reduktion von Arrhythmien führten (Shiba et al. 2012). Die Entwicklung von Patchs zur Integration von Stammzellderivaten in infarziertes Herzgewebe ist weiterhin Gegenstand der Forschung (vgl. Ye et al. 2013). Auch bei der Erzeugung neuronalen Gewebes wurden Fortschritte erzielt, so führten im Parkinson-Modell bei Ratten neuronale Progenitorzellen aus humanen ESC nach Injektion in das Striatum zu einer signifikanten Verbesserung der Symptomatik (Ben-Hur et al. 2004). 2007 gelang zudem die Ausdifferenzierung humaner ESC zu Motoneuronen, welche für Erkrankungen wie die Amyotrophe Lateralsklerose Hoffnungen wecken (Lee et al. 2007). Hinsichtlich neuer Therapieansätze in der Alzheimer-Forschung konnten aus humanen ESC cholinerge 
Neurone gewonnen werden, welche in hippocampalem Gewebe von Mäusen funktionsfähige Synapsen bildeten (Bissonnette et al. 2011).

Dennoch bleiben ethische Bedenken, die sich vor allem mit der Zerstörung von Embryonen zur Erzeugung von ESC beschäftigen. Auch die Frage, wie im Falle einer klinischen Anwendung ggf. innerhalb kurzer Zeit immunkompatible ESC für den Erkrankten gewonnen und anschließend gerichtet differenziert werden sollen, stellt ein bisher nicht hinreichend gelöstes Problem dar.

\subsubsection{Induzierte pluripotente Stammzellen (iPSC)}

Um somatische Zellen in einen pluripotenten Zustand zu versetzen, bediente man sich ursprünglich des Transfers ihres Nucleus in Oozyten (Wilmut et al. 1997) oder der Fusion mit ESC (Cowan et al. 2005, Tada et al. 2001). 2006 gelang dies durch Transfektion von nur vier Transkriptionsfaktoren (Takahashi und Yamanaka 2006). Diese Methode stellt nach Weiterentwicklung und Modifikation eine der gebräuchlichsten Vorgehensweisen dar.

Die Generation von iPSC erfordert keine Destruktion eines Embryos. Zudem wird diskutiert, dass aus iPSC gewonnenes Gewebe weitgehend dem des Donors entspricht und daher eine immunologische Akzeptanz erwartet werden kann. Diese Auffassung war zuletzt Gegenstand von Diskussionen, nachdem berichtet worden war, dass eine iPSC-Linie, anders als die verglichene ESC-Linie, keine Teratome bildete (Zhao et al. 2011). Diese Ergebnisse ließen sich jedoch nicht auf andere Zelllinien übertragen, im Gegenteil zeigte eine Arbeitsgruppe um Araki, dass bei iPSC nur mit einer geringen Immunogenität zu rechnen sei und sie bezüglich Teratom-Ausbildung und T-Zell-Infiltration ESC-Linien weitestgehend ähnelten (Araki et al. 2013). Ein gewisser Grad an Immunogenität der iPSC durch zuletzt gezeigte genetische Aberrationen konnte jedoch nicht sicher ausgeschlossen werden (Puri und Nagy 2012, Martins-Taylor und Xu 2012).

Die Einsatzmöglichkeiten der iPSC-Derivate werden zurzeit intensiv erforscht. So gelang beispielsweise die Reprogrammierung somatischer Zellen von an FanconiAnämie Erkrankten (Raya et al. 2009) und die Integration von aus iPSC gewonnenen neuronalen Vorläuferzellen in das fetale Gehirn von Ratten. Wurden diese dazu angeregt, sich in dopaminerge Neuronen zu differenzieren, konnten sie Symptome der Parkinsonerkrankung im Rattenmodell mildern (Wernig et al. 2008). Ebenso konnten Kardiomyozyten, Hepatozyten, Insulin-sezernierende Zellen u.a. aus iPSC generiert 
werden (vgl. Ho et al. 2012). Auch zum Studium von Krankheiten und deren Beeinflussung durch Medikamente können iPSC genutzt werden. So gelang beispielsweise die Generierung von iPSC von Patienten, die an Parkinson oder Huntington erkrankt waren (Park et al. 2008).

Allerdings kann bei der Transduktion der Transkriptionsfaktoren durch Viren eine Veränderung des Genoms nicht ausgeschlossen werden. An Möglichkeiten, die Effizienz der iPSC-Protokolle zu verbessern, wird intensiv geforscht (Stadtfeld et al. 2008, Okita et al. 2008, Ma et al. 2013).

\subsubsection{Multipotente adulte Stammzellen der Keimbahn (maGSC)}

Aus männlichen Embryonen können Urkeimzellen der Keimdrüsenleiste (embryonal germline stem cells, EGC) gewonnen und zu Zellen aller drei Keimblätter differenziert werden (Rohwedel et al. 1996).

Spermatogonien lassen sich auch aus adulten männlichen Tieren isolieren (spermatogonial stem cells, SSC) und durch geeignete Kulturbedingungen in einen ESCähnlichen Zustand bringen (multipotent adult germline stem cells, maGSC; Guan et al. 2006). Murine maGSC konnten zu Kardiomyozyten und Gliazellen differenziert werden (Guan et al. 2007, Streckfuss-Bömeke et al. 2008, Glaser et al. 2008).

\subsubsection{Parthenogenetische Stammzellen (PSC)}

Parthenogenetische Stammzellen (PSC) werden aus künstlich aktivierten Oozyten gewonnen. Zur Erzeugung diploider PSC sind zwei Methoden bekannt: Meist werden Oozyten der Metaphase II durch Behandlung mit Strontium zu Kalzium-Oszillationen angeregt (Zhang et al. 2005) und dadurch aktiviert. Cytochalasin B verhindert anschließend die Ausstoßung des zweiten Polkörperchens (Balakier und Tarkowski 1976). Eine zweite, weniger gebräuchliche Methode, bei welcher mittels Cytochalasin D zunächst tetraploide Oozyten erzeugt werden, die sich anschließend teilen, wurde 1991 durch Kubiak und Kollegen etabliert (Kubiak et al. 1991). Da PSC aus Zellen mit haploidentem Chromosomensatz erzeugt werden, sind sie überwiegend homozygot (Klimanskaya et al. 2007). Heterologe Abschnitte im Erbgut erklären sich durch Crossing-Over in der Meiose I (Kim et al. 2007).

Wie auch bei der Erzeugung von iPSCs und maGSCs müssen zur Generierung von PSC keine Embryonen zerstört werden. Ein weiterer Vorteil von PSC liegt in der Reduktion der Immunkomplexität durch den homologen Genotyp. Dadurch könnte sich die Anzahl immunkompatibler Empfänger von Linien parthenogenetischer 
Stammzellen im Vergleich zu ESC-Linien deutlich erweitern, sodass Hoffnungen in den Aufbau von PSC-Banken gesetzt werden (Klimanskaya et al. 2007, Taylor et al. 2005, Nakajima et al. 2007). Zudem kann die Homozygotie zu einer einfacheren experimentellen Ermittlung von Onkogenen sowie Bezügen zwischen MedikamentenWirkmechanismen oder -Toxizität und -Genetik führen (Lin et al. 2003).

Erste murine PSC wurden bereits 1983 erzeugt (Kaufman et al. 1983). 2002 gelang einer Arbeitsgruppe um José Cibelli die Generierung von PSC aus Primaten und deren Ausdifferenzierung unter anderem zu neuronalen Zellen, Kardiomyozyten, Adipozyten und glatten Muskelzellen (Cibelli et al. 2002). Auch humane PSC wurden mittlerweile in verschiedenen Laboren etabliert (Mai et al. 2007; Revazova et al. 2007). Diese riefen in SCID-Mäusen Teratome hervor, sodass von ihrer Pluripotenz ausgegangen werden kann. Da sie über viele Passagen einen normalen Karyotyp behielten, kann auf eine weitere Verwendbarkeit in der regenerativen Medizin gehofft werden (Mai et al. 2007). Mittels Komplementierung tetraploider Embryonen konnten voll entwickelte Mäuse aus PSC gewonnen werden (Chen et al. 2009).

Die in dieser Arbeit verwendeten parthenogenetischen Stammzellen der Linien A3 und A6 wurden von Peter Christalla im Labor von Prof. W. H. Zimmermann etabliert. Hierzu wurden weiblichen Mäusen der F1-Generation, einer Kreuzung von C57BL/6- und DBA/2-Mäusen, Eizellen entnommen und künstlich aktiviert. Die Zelllinie A3 zeigte einen homozygoten $\left(\mathrm{H}^{\mathrm{d} / \mathrm{d}}\right)$, die Zellinie $A 6$ dagegen einen heterozygoten MHCGenotyp $\left(\mathrm{H}^{\mathrm{b} / \mathrm{d}}\right)$. Die Zellen riefen in immundefizienten Mäusen und solchen mit demselben Haplotyp Teratome hervor, während keine Teratome bei allogener Transplantation in Mäuse mit unterschiedlichem Haplotyp gefunden wurden. Daraus konnte geschlossen werden, dass das Immunsystem der Mäuse PSC desselben Haplotyps weitestgehend akzeptierte (Didié et al. 2013). Trotz Verlustes der Heterozygotie und der dadurch möglichen Kompensationsmechanismen bei Aberrationen des Allels sowie der Unterschiede im Imprinting konnte - anders als teilweise erwartet (Eckardt et al. 2008) - gezeigt werden, dass es zwischen dem Differenzierungspotenzial zu Kardiomyozyten gegenüber ESC wenig Unterschiede zu geben schien. Auch bezüglich Morphe, Expression von Stammzellmarkern, Wachstumscharakteristika und in der Transkriptomanalyse ähnelten diese PSC den ESC- bzw. maGSC- und iPSC-Linien weitestgehend (Didié et al. 2013). 


\subsubsection{Schwierigkeiten in der Arbeit mit Stammzellen}

Einige anfängliche Hürden in der Arbeit mit Stammzellen konnten genommen werden. So kann durch die Erzeugung von iPSC, maGSC und PSC die Zerstörung von Embryonen vermieden werden, welches diesbezügliche ethische Bedenken entkräftet. Verschiedene Ansätze minimieren eine mögliche Kontamination der Stammzellen durch Viren oder den Einsatz xenogener Materialien (vgl. Amit und ItskovitzEldor 2006, Zhou et al. 2009, Okita et al. 2008). Auch eine einfachere Vermehrung und Differenzierung der Stammzellen ist durch verschiedene Protokolle möglich ge-worden (z. B. Thomas et al. 2009, Fu et al. 2011, Bernstein und Hyun 2012). Aller-dings müssen vor einem weitreichenden Einsatz von Stammzellen in der regener-ativen Medizin und Medikamentenforschung noch weitere Probleme gelöst werden.

Eng mit der Pluripotenz von Stammzellen verbunden ist ihre Neigung zur Ausbildung von Tumoren aus Derivaten aller drei Keimblätter, sogenannten Teratomen (Hentze et al. 2009, Blum und Benvenisty 2009). Wenn auch zuletzt zunehmend überdacht (Buta et al. 2013), wird die Plutipotenz von Stammzellen weiterhin häufig durch TeratomBildung in immundefizienten Empfängern überprüft. Es genügen schon 2 murine ESC oder 245 humane ESC, um in immuninkompetenten Mäusen Teratome hervorzurufen (Hentze et al. 2009, Lawrenz et al. 2004). Obgleich die Tumoren meist benigner Natur sind, gibt es Berichte über aus ESC hervorgehende maligne, metastasierende Tumoren (Erdö et al. 2003, Amariglio et al. 2009), die zu ernsthaften Bedenken in Bezug auf die Transplantierbarkeit von Stammzellen bzw. ihrer Derivate beitragen.

Die Vorgänge, die zur Ausbildung von Teratomen führen, sind noch nicht im Detail verstanden, eine Neigung zu maligner Entartung wird unter anderem auf genetische Veränderungen während der Kultivierung (Blum und Benvenisty 2009), bei iPSC auch auf vorbestehende somatische Mutationen sowie Mutationen während der Transfektion (Gore et al. 2011) und Erlangen der Plutipotenz (Lister et al. 2011) zurückgeführt.

Eine Grundvoraussetzung der Bildung von Teratomen ist in jedem Fall das Versagen des Immunsystems bei der Bekämpfung der Tumorzellen. Aber auch eine starke Immunantwort birgt Risiken, da sie in der Abstoßung eines Transplantates aus Stammzellen münden kann. Die genauen Ursachen, die der Abstoßung transplantierter Stammzellen und deren Derivaten zugrunde liegen, sind noch nicht hinreichend geklärt. Es scheint verschiedene Mechanismen zu geben, die, abhängig vom Grad der Differenzierung transplantierter Zellen, relevant werden (Dressel 2011). 
Während B-Zellen in diesem Kontext wohl eine untergeordnete Rolle spielen, konnte eine Abstoßung von ESC durch T-Zellen gezeigt werden (Drukker et al. 2006). CD8 ${ }^{+}-$ T-Zellen (CTL) interagieren mit MHC-Klasse-I-Molekülen, welche zytosolische Peptide präsentieren (Kapitel 1.2.2). Werden die Peptide von aktivierten CTL als fremd erkannt, induzieren diese die Apoptose der Peptid-präsentierenden Zelle. Mit dem Grad der Differenzierung steigt die Zahl der MHC-Klasse-I-Moleküle auf der Oberfläche der Stammzellen (Drukker et al. 2002). Allerdings exprimieren in vitro differenzierte Stammzell-Derivate zum Teil andere Peptide als voll differenzierte Zellen, was die verstärkte Lyse von Derivaten der Stammzellen durch CD8 ${ }^{+}$-Zellen im Vergleich zu ihren Vorläufern erklären könnte (Swijnenburg et al. 2005). Zudem wurde berichtet, dass einige Stammzelllinien in der Lage sind, sich durch Expression von SPI6, TGF- $\beta$ oder Arginase I gegen CTL zu schützen (Abdullah et al. 2007, YachimovichCohen et al. 2010, Koch et al. 2008).

Natürliche Killerzellen (NK-Zellen) lysieren Stammzellen effektiv (Dressel et al. 2010). Ihre Aktivierung beruht vermutlich auf einem Zusammenspiel zweier Faktoren: zum einen exprimieren Stammzellen nur ein sehr geringes Maß an MHC-Klasse-IMolekülen (Drukker et al. 2002). Dies könnte nach der missing-self-Hypothese NKZellen aktivieren (Kärre 1985). Zum anderen exprimieren Stammzellen verschiedene NK-Zell-aktivierende Liganden (Dressel et al. 2008, Frenzel et al. 2009). Jedoch sind NK-Zellen, anders als T-Zellen, in der Regel nicht alleine in der Lage, die Ausbildung von Teratomen nach Injektion von Stammzellen zu verhindern (Drukker et al. 2006, Tian et al. 2006, vgl. Kapitel 1.2.5).

Auch das Komplementsystem scheint in der Lage, über den alternativen Aktivierungsweg die Bildung von Teratomen nach Injektion kleiner Mengen von ESC zu verhindern (Koch et al. 2006). 


\subsection{Zytotoxische T-Zellen, ihre Effektormechanismen und Auswirkungen auf Stammzellen}

\subsubsection{Entwicklung zytotoxischer T-Lymphozyten}

CD8+ T-Lymphozyten (zytotoxische T-Lymphozyten, CTL) spielen eine wichtige Rolle in der Abwehr intrazellulärer Pathogene und Tumoren. Über T-Zell-Rezeptoren (TCR) interagieren sie mit den MHC-Klasse-I-Molekülen ihrer Zielzellen, die i.d.R. zytosolische Peptide präsentieren (Garcia et al. 1999). Ein verändertes Präsentationsmuster kann so z. B. auf eine Infektion der Zelle durch Viren hinweisen. Wird dies von CTL erkannt, können sie über die Exozytose zytotoxischer Granula oder die Aktivierung sogenannter Todesrezeptoren die Apoptose dieser Zellen induzieren (Lowin et al. 1994).

CTL entstammen als Untergruppe der T-Lymphozyten der hämatopoetischen Reihe des Knochenmarks. Sie differenzieren im Thymus, wo sie ihren spezifischen T-ZellRezeptor erlangen (Bhandoola und Sambandam 2006). Bevor die Zellen in die Peripherie wandern, werden sie hinsichtlich der Bindung an MHC-Moleküle überprüft: binden sie diese zu stark und bergen somit eine Gefahr zur Autoreaktivität, wird ihre Apoptose induziert (negative Selektion; Kappler et al. 1987). Sind sie andererseits in der Lage, die Moleküle zu erkennen, ohne gleichzeitig eine zu starke Bindung einzugehen, erhält die Zelle ein überlebenssicherndes Signal (positive Selektion, Anderson et al. 1996). T-Lymphozyten, die diesen Reifungsprozess überstehen, treten als sogenannte naive T-Lymphozyten in das Blut über.

\subsubsection{Aktivierung zytotoxischer T-Lymphozyten}

MHC-Moleküle sind in der Lage, fragmentierte Proteine auf ihrer Oberfläche zu präsentieren. MHC-Klasse-II-Moleküle werden auf professionellen antigenpräsentierenden Zellen (APC) exprimiert und präsentieren extrazelluläre Proteine, die zuvor über Endozytose aufgenommen wurden. MHC-Klasse-I-Moleküle werden dagegen auf nahezu allen kernhaltigen Zellen des Organismus beobachtet und präsentieren vor allem zytosolische Proteine (Grommé und Neefjes 2002). Über eine sogenannte Kreuzpräsentation können jedoch auch extrazelluläre Proteine über MHC-Klasse-I- 
Moleküle antigenpräsentierender Zellen präsentiert werden (Ackerman und Cresswell 2004, Bevan 1976).

CTL interagieren über den T-Zell-Rezeptor (TCR) mit MHC-Klasse-I-Molekülen (Garcia et al. 1999). Dieser besteht in diesem Fall aus einer $\alpha$ - und einer $\beta$-Kette, welche je eine variable $(\mathrm{V} \alpha / V \beta)$ und eine konstante $(C \alpha / C \beta)$, in der Zellmembran verankerte, Region aufweisen. Für die Erkennung des MHC-Moleküls und des prozessierten Antigens besitzen $\alpha$ - und $\beta$-Kette jeweils drei sehr variable, komplementaritätsdeteminierende Regionen (CDRs).

Der TCR bildet einen Komplex mit CD3, einem signaltransduzierenden Proteinkomplex (Davis et al. 1998). Die Bindung eines MHC-Klasse-I- bzw. Klasse-IIMoleküls durch den TCR wird durch CD8- bzw. CD4-Korezeptoren stabilisiert (Gao und Jakobsen 2000).

Erkennt eine zytotoxische T-Zelle ein ihr durch professionelle APC präsentiertes Peptid und erhält ein zusätzliches costimulatorisches Signal, wird sie aktiviert. Gut untersucht ist z. B. die Gruppe der B7-Proteine (z. B. CD80, CD86), die auf aktivierten APC vermehrt exprimiert werden, an CD28 auf T-Zellen binden und ein costimulatorisches Signal vermitteln. Ein zusätzliches Signal ist insofern wichtig, als dass es hilft, eine T-Zell-Antwort nur dann hervorzurufen, wenn diese auch wirklich vonnöten ist (Lenschow et al. 1996, Green et al. 1994). Erkennt eine T-Zelle zwar ein Antigen, erhält jedoch kein costimulatorisches Signal, wird sie anerg. Dieser Mechanismus, der zu „peripherer Toleranz" führt, verhindert, dass seltene autoreaktive Zellen, die die Selektion im Thymus überlebt haben, eine Zerstörung körpereigenen Gewebes induzieren (Schwartz 2003).

\subsubsection{Effektormechanismen zytotoxischer T-Lymphozyten}

Nach Antigen-Erkennung und -Bindung sowie Erhalt costimulativer Signale proliferieren CTL (Groscurth und Filguiera 1998). Anschließend können sie über die Aktivierung sogenannter Todesrezeptoren oder über Exozytose zytotoxischer Granula die Apoptose ihrer Zielzellen hervorrufen (Lowin et al. 1994).

Eine Möglichkeit der CTL, die Apoptose der Zielzellen einzuleiten, besteht in der Kalzium-abhängigen Exozytose zytotoxischer Granula. Nach Erkennen des Antigens formiert sich innerhalb weniger Minuten die sogenannte immunologische Synapse. Um 
den TCR-Komplex stabilisieren vor allem CD2 und LFA1 (leukozyte-functionassociated-antigen-1) die Bindung zwischen TCR und MHC-Molekül der Zielzelle (Grakoui et al. 1999). Entlang von Mikrotubuli werden die Granula anschließend gen immunologischer Synapse geführt und fusionieren dort mit der Zellmembran, sodass die lytischen Proteine in die Synapse entlassen werden (Kuhn und Poenie 2002), während die umgebenden Moleküle die Adhäsion ermöglichen.

Die Granula enthalten vor allem Perforin und Granzyme. Perforin polymerisiert und ist in der Lage, Poren in der Membran der Zielzellen zu formen. Die Poren führen zu einem unkontrolliertem Ein- und Ausstrom von Flüssigkeit in die Zelle, welches zum Zelltod führen kann (Voskoboinik et al. 2010).

Granzyme sind Serin-Proteasen. Es gibt verschiedene Subgruppen von Granzymen, welche auf unterschiedliche Weisen die Apoptose der Zielzellen einleiten. Granzym B ist z. B. in der Lage, über Interaktion mit dem Bid-Protein eine Freisetzung von Cytochrom C zu veranlassen und somit den Zelltod einzuleiten (Lieberman 2003). Granzyme scheinen auf Perforin angewiesen zu sein, um in das Zytosol der Zielzellen zu gelangen (Kägi et al. 1994).

Eine zweite Möglichkeit die Apoptose einzuleiten, besteht in der Aktivierung von Todesrezeptoren der Zielzelle, die schließlich zu deren Apoptose führt. Gut erforscht ist beispielsweise der Rezeptor Fas (CD95), ein Mitglied der TNF-Familie, der durch den Fas-Liganden auf CTL, aber auch auf $\mathrm{T}_{\mathrm{H} 1}$-Zellen, aktiviert werden kann und die Apoptose Caspasen-abhängig vermittelt (Wajant 2002). Dieser zweite Mechanismus scheint vor allem in der Regulation der Immunantwort und dem Verhindern von Autoimmunität eine Rolle zu spielen (Lieberman 2003). Da aber in einzelnen zytotoxischen T-Zellen zum Teil sehr unterschiedliche Mengen von Granula vorhanden sind, könnte die zusätzliche Aktivierung der Todesrezeptoren auch eine größere Sicherheit bei der Elimination der veränderten Zellen bedingen (Hassin et al. 2011).

\subsubsection{Protektionsmechanismen gegen Effektormechanismen von CTL}

Es gibt verschiedene Mechanismen mit denen sich zum einen CTL selbst, zum anderen Zellen, die einer CTL-vermittelten Lyse entgehen wollen, vor zytotoxischen Effektormechanismen schützen können. So entgehen verschiedene Tumoren der TZell-Kontrolle durch Herabregulation stimulierender Liganden (v.a. MHC-Klasse-I- 
Moleküle), Veränderung der Antigenexpression oder Sekretion immunsupprimierender Zytokine wie TGF- $\beta$ oder IL-10 (Pawelec 2004). CTL selbst exprimieren auf ihrer Oberfläche Cathepsin B, welches Perforin abbaut (Balaji et al. 2002). Zudem werden die Granula polarisiert in die immunologische Synapse ausgeschüttet, was einen zusätzlichen Schutz der CTL ermöglicht (Stinchcombe und Griffiths 2007).

\subsubsection{Auswirkungen von CTL auf Stammzellen}

Im Hinblick auf die Transplantierbarkeit von Stammzellen und deren Derivaten müssen unterschiedliche Effektormechanismen des Immunsystems berücksichtigt werden. Verschiedene Studien zeigen, dass T- (Drukker et al. 2006) und NK-Zellen (Dressel 2010) sowie der alternative Weg des Komplementsystems (Koch et al. 2006) bei der Lyse von Stammzellinien in vitro und in vivo eine Rolle spielen können. Das Ausmaß, in welchem diese Zellen/Systeme auf die Stammzellen wirken, hängt vom Grad der Differenzierung der Stammzellen sowie den Transplantations-bedingungen (xeno-/ allo-/ syngen) ab (Dressel 2011).

Die Auswirkungen von CTL auf Stammzellen werden teils sehr kontrovers diskutiert. Im Allgemeinen scheinen CTL in der Lage, Stammzellen zu lysieren (Dressel et al. 2009). So sind verschiedene Stammzellinien aus maGSC, ESC und iPSC durch aktivierte CTL in vitro lysierbar und dementsprechend nicht generell gegen CTLvermittelte Lyse geschützt. Dies ist insofern relevant, da durchflusszytometrisch auf allen bisher bekannten murinen Stammzelllinien MHC-Klasse-I-Moleküle nicht detektiert werden konnten und so die Frage aufgeworfen wurde, ob CTL überhaupt in der Lage seien, Stammzellen zu erkennen (z. B. Bonde und Zavazava 2006). Im Gegensatz zu murinen Stammzellinien weisen humane Stammzellen in der Durchflusszytometrie ein geringes $\mathrm{Maß}$ an MHC-Klasse-I-Molekülen auf ihrer Oberfläche auf (Drukker et al. 2002, Draper et al. 2002).

Die Expression von MHC-Klasse-I-Molekülen steigt i.d.R. mit dem Grad der Differenzierung der Stammzellen, wobei das Maß, in welchem MHC-Klasse-I-Moleküle vermehrt exprimiert werden, in den einzelnen Studien sehr unterschiedlich ausfällt ( $z$. B. Drukker et al. 2002, v.d.Brink und Burakoff 2002, Frenzel et al. 2009). Durch die vermehrte Expression können T-Zellen vermutlich Stammzellen bzw. deren Derivate 
im Laufe des Differenzierungsprozesses besser erkennen und deren Lyse hervorrufen (Karabekian et al. 2011). Zudem exprimieren Stammzell-Derivate teils andere Peptide als voll differenzierte Zellen oder Stammzellen, eine Tatsache, die ebenfalls in die Interpretation der unterschiedlichen Lysierbarkeit durch CTL von Derivaten der Stammzellen gegenüber ihren Vorläufern einbezogen werden sollte (Swijnenburg et al. 2005).

Wie bereits erwähnt, scheinen CTL unter verschiedenen Transplantationsbedingungen unterschiedliche Bedeutung zuzukommen. So fanden Drukker und Kollegen 2006 im xenogenen Modell heraus, dass nach Injektion von hESC in Mausmodelle, die entweder keine B-Zellen, T-Zellen, NK-Zellen oder T- und B-Zellen bilden konnten, ausschließlich in T-Zell-defizienten Modellen Teratome hervorgerufen wurden. Sie schlossen daraus, dass die Teratom-Ausbildung, also das Versagen des Immunsystems bei der Abwehr xenogener Stammzellen, vor allem von der T-ZellAntwort des Empfängers abhängig sei.

Wird humane Haut auf Mäuse transplantiert, wird bei CD4-Knockout-Mäusen eine verlangsamte Abstoßung im Vergleich zu CD8-Knockout- und immunkompetenten Mäusen festgestellt (Uchida et al. 1999). CTL scheinen dementsprechend unter xenogenen Transplantationsbedingungen eine eher untergeordnete Rolle zu spielen. Swijnenburg und Kollegen stellten daher die These auf, dass auch bei der Transplantation von Stammzellen CD4+-Zellen wichtiger als CD8 ${ }^{+}$-Zellen seien. Tatsächlich überlebten hESC nach Injektion in Mäuse mit CD8-Knockout länger als nach Injektion in Mäuse mit CD4-Knockout (Swijnenburg et al. 2008). In beiden Fällen waren die Stammzellen jedoch nicht in der Lage, Teratome zu bilden, sodass davon auszugehen ist, dass sowohl $\mathrm{CD}^{+}{ }^{+}$- als auch CD8+-Zellen in der xenogenen Situation genügen, um transplantierte Stammzellen abzuwehen. Eine mögliche Erklärung für die untergeordnete Rolle von CTL gegenüber CD4+-Zellen könnte darin liegen, dass in der xenogenen Transplantation keine direkte Allorekognition durch CTL möglich ist.

Verschiedene Studien zeigen, dass auch unter allogenen Bedingungen eine Abwehr der transplantierten Stammzellen oder deren Derivate stattfindet, wobei auch hier das Ausmaß der Abstoßung in den einzelnen Studien recht unterschiedlich ausfällt (z. B. Bonde und Zavazava 2006, Yachomovik-Cohen et al. 2010, Dressel 2011). In einigen Studien riefen allogene ESC zunächst Teratome hervor, wurden später jedoch abgestoßen (Nussbaum et al. 2007). Als mögliche Erklärung gilt die zunehmende Differenzierung der Zellen und somit verbesserte Erkennung durch CTL (siehe oben). 
Wu und Kollegen zeigten 2008, dass die allogene Abwehr von Stammzellen mit ihrer Infiltration durch $\mathrm{CD}^{+}{ }^{+}$und $\mathrm{CD}^{+}$-Zellen sowie Makrophagen einherging und dass das Teratom-Wachstum durch CTL unterbunden werden konnte, wenn diese durch APC aktiviert wurden. Dies unterstützt die Vermutung, dass CTL eine entscheidende Rolle in der Abwehr allogener Stammzellen spielen. Lui und Kollegen schreiben außerdem regulatorischen T-Zellen (Treg) eine bedeutende Rolle in der Akzeptanz der Stammzellen zu (vgl. Lui et al. 2010). Weiterhin scheinen bereits Unterschiede in Nebenhistokompatibilitätsantigenen auszureichen, um ein Wachstum von Tera-tomen nach Injektion von Stammzellen zu verhindern (Dressel et al. 2008).

Über immunologische Mechanismen bei der Abwehr oder Annahme syngener Stammzellen bei Transplantationen ist erstaunlich wenig bekannt. Bei syngenen Transplantationen kommt es zum Wachstum von Teratomen. Eine Immunsuppression mit Cyclosporin A zeigte hierauf keine Auswirkungen (Dressel 2011). Die sich in syngenen Empfängern bildenden Teratome sind gelegentlich mit T-, B- und NKZellen infiltriert, diese reichten jedoch nicht aus, um deren Auftreten zu unterbinden (Dressel 2011).

Lawrenz und Kollegen stellten 2004 fest, dass es in immundefizienten Mäusen nur zweier ESC bedarf, um Teratome hervorzurufen. Allerdings können u.U. kleinere Mengen von Stammzellen abgewehrt werden. Vermutlich kommt hier vor allem das angeborene Immunsystem zum Tragen (Kapitel 1.3.4).

Inwieweit Stammzelllinien generell in der Lage sind, sich gegen CTL zu schützen, bleibt zu klären. Ergebnisse, die nahelegten, dass sie hierzu z. B. durch Expression von SPI-6, TGF- $\beta$ oder Arginase I fähig seien, wurden bisher nur vereinzelt publiziert und ließen sich nicht regelmäßig auf andere Stammzellinien übertragen (Yachimovich-Cohen et al. 2010, Koch et al. 2008, Abdullah et al. 2007). Weiter diskutiert wird die Rolle das FAS-Liganden, dessen Expression zu einer Toleranz gegen T-Zellen führen könnte. Dieser konnte - wenn auch nicht regelhaft (Grinnemo et al. 2006, Drukker et al. 2006) in einigen Studien auf verschiedenen Stammzellinien nachgewiesen werden (Fändrich et al. 2002). Auch die Expression von CD80 und CD 86, zwei costimulatorischen Molekülen, wurde untersucht. CD86 konnte z. B. auf murinen ESC detektiert (Robertson et al. 2007) und mRNA von CD80 in humanen ESC nachgewiesen werden (Grinnemo et al. 2006). 
Zusammenfassend kommen bei der Abwehr von Stammzellen verschiedene Effektormechanismen des Immunsystems zum Tragen. T-Zellen scheinen vor allem unter xeno- und allogenen Transplantationsbedingungen von Bedeutung zu sein.

\subsection{NK-Zellen, ihre Effektormechanismen und deren Auswirkungen auf Stammzellen}

\subsubsection{Herkunft natürlicher Killerzellen}

Natürliche Killerzellen (NK-Zellen) sind Teil des angeborenen Immunsystems und ein wichtiger Bestandteil bei der Bekämpfung intrazellulärer Pathogene. Sie sind in der Lage, verschiedene Virusinfektionen (z. B. durch Herpes-Viren) so lange zu bekämpfen, bis das adaptive Immunsystem durch spezifische Maßnahmen dafür sorgen kann, dass die Erreger eliminiert werden. NK-Zellen sind jedoch auch bei der Abwehr von Tumorzellen, der Bekämpfung von Protozoen (z. B. Leishmanien oder Listerien) und vermutlich an einigen hypersensiblen und autoimmunen Vorgängen beteiligt (Vivier et al. 2008, Flodström-Tullberg 2009).

Als Teil der lymphoiden Reihe entwickeln sich NK-Zellen im Knochenmark und zirkulieren anschließend im Blut. Sie sind größer als T- oder B-Lymphozyten und weisen, ähnlich wie CTL, zytoplasmatische Granula auf, welche sie exozytieren und mit deren Hilfe sie die Apoptose anderer Zellen einleiten können (Lettau et al. 2007).

\subsubsection{Aktivierung von NK-Zellen}

Besteht in einem Organismus eine Entzündung, können NK-Zellen über Chemokine angelockt werden (Gregoire et al. 2007). Zudem werden in der Frühphase eines Infektes potente Stimulatoren der NK-Zellen produziert. Bekannte Beispiele sind IFN- $\alpha$ als Antwort verschiedener Zelltypen auf virale oder bakterielle Nukleinsäuren oder IL12, welches von aktivierten Makrophagen produziert wird.

NK-Zellen tragen auf ihrer Oberfläche aktivierende und inhibierende Rezeptoren (Pegram et al. 2011). Aktivierende Rezeptoren lösen jeweils unterschiedliche Signalwege aus, welche zurzeit Gegenstand der Forschung sind. Abhängig vom Typ des aktivierenden Rezeptors und dem nachfolgenden Signalweg, folgen der Interaktion mit einem entsprechenden Liganden unterschiedliche Effektor- 
mechanismen der NK-Zelle. So können virale Infektionen die Expression von MICA und MICB, zwei Liganden von NKG2D auf humanen Zellen, induzieren, auf diesem Wege deren Lyse durch NK-Zellen hervorrufen und so den Organismus schützen (Mistry und O'Callaghan 2007).

Eine Stimulation von NKG2D kann zu aktivem Rollen der NK-Zelle auf Endothelien führen, während Liganden von CD244 (die aktivierende Isoform von 2B4, einem NK-Zell-Rezeptor) die Invasivität der Zellen steigern und eine Zytokin-Antwort hervorrufen (Bryceson et al. 2011).

NK-Zellen exprimieren zudem CD16, welches an die Fc-Region von IgG-Antikörpern bindet. Somit können NK-Zellen andere, durch Antikörper markierte, Zellen lysieren (Trinchieri und Valiante 1993). CD16 selbst fördert die Degranulation von NK-Zellen (Bryceson et al. 2011).

Überwiegen aktivierende Signale im Vergleich zu inhibierenden Signalen, kommt es zu einer vermehrten Expression von LFA-1 auf der Oberfläche der NK-Zellen. Die durch LFA-1 vermittelte Adhäsion (vgl. Bryceson et al. 2009) kann jedoch auch wieder durch Signale inhibierender NK-Rezeptoren unterbrochen werden (Burshtyn et al. 2000).

Anders als die Signalwege der aktivierenden Rezeptoren, sind diejenigen der inhibierenden Rezeptoren recht gut verstanden. Ihnen gemein ist, dass sie ihre Wirkung vor allem über die Aktivierung von Thyrosinphosphatasen entfalten (Long 2008).

Ein wichtiges inhibierendes Signal für NK-Zellen ist die Präsenz von MHC-Klasse-IMolekülen. Werden diese, z. B. im Rahmen einer Infektion mit Herpesviren, herunterreguliert, kommt es über eine verminderte Inhibition sogenannter KIRRezeptoren oder CD94-NKG2A auf den NK-Zellen zu einer Aktivierung der NK-Zelle (Hewitt 2003).

\subsubsection{Effektormechanismen natürlicher Killerzellen}

Natürliche Killerzellen zeigen ähnliche Effektormechanismen wie zytotoxische T-Lymphozyten. Auch NK-Zellen enthalten Granula mit Perforin und Granzymen (Lettau et al. 2007), die nach Stimulation ausgeschüttet werden können und die Apoptose ihrer Zielzellen einleiten (Lieberman 2003).

Nach ihrer Aktivierung formiert sich zunächst das Zytoskelett der NK-Zelle neu. Entlang von Mikrotubuli polarisieren sich die Granula an der neu entstandenen 
Synapse, bevor sie mit der Zellmembran fusionieren und ihre Enzyme auf die Zielzellen wirken können. (Topham und Hewitt 2009 und Kapitel 1.2.3).

Neben den offensichtlichen Ähnlichkeiten der Effektormechanismen von CTL und NKZellen bestehen jedoch auch Unterschiede. So entsteht die zytosklelettale Polarität der CTL meist schneller als bei NK-Zellen, bei welchen sie teils sogar inkomplett bleibt (Wulfing et al. 2003). Zudem scheint der Kontakt zwischen CTL und Zielzelle deutlich stabiler als zwischen NK- und Zielzelle zu sein (Deguine et al. 2010, Sinai et al. 2010). Neben der Induktion der Apoptose ihrer Zielzellen, sind NK-Zellen zudem in der Lage, verschiedene Chemokine und Zytokine zu produzieren und somit Einfluss auf die Entzündungsreaktion zu nehmen (Bryceson et al. 2011).

Für die unterschiedlichen Effektormechanismen der NK-Zellen müssen zum einen verschiedene Signale, zum anderen aber auch ein unterschiedlicher Grad an aktivierenden Stimuli gegeben sein (Fauriat et al. 2010). Werden Chemokine wie MIP1 $\alpha$ und MIP1 $\beta$ vergleichsweise früh und mittels weniger Stimuli ausgeschüttet, verlangt die Degranulation, mehr aber noch die Ausschüttung von entzündungsfördernden Substanzen wie TNF- $\alpha$ oder Interferonen, ein höheres Maß aktivierender Stimuli.

\subsubsection{Auswirkungen von NK-Zellen auf Stammzellen}

Über die Auswirkungen von NK-Zellen auf Stammzellen sind teils sehr unterschiedliche Ergebnisse publiziert worden. So kamen beispielsweise Koch und Kollegen $2008 \mathrm{zu}$ dem Schluss, dass murine Stammzellen nicht durch aktivierte syngene oder allogene NK-Zellen lysiert werden könnten.

Dagegen kamen andere Gruppen zu gegenteiligen Ergebnissen. So wurden murine hämatopoetische Vorläuferzellen nach Transplantation in Mäuse durch NK-Zellen lysiert (Rideout et al. 2002). Bonnevie und Kollegen zeigten 2007, dass die Abwehr einer xenogenen Transplantation von ESC in Affen zum Teil NK-Zell-abhängig war (vgl. auch Bonde und Zavazava 2006). Mit diesen Ergebnissen steht im Einklang, dass Teratome nach Injektion humaner Stammzellen in einem T- und B-Zell-defizienten Mausmodell langsamer wuchsen als in einem T-, B- und NK-Zell-defizienten Mausmodell oder wenn die NK-Zellaktivität T- und B-Zell-defizienter Mäuse zusätzlich inhibiert wurde (Tian et al. 2006). Hieraus wurde geschlossen, dass NK-Zellen an der 
Rejektion von Stammzellen beteiligt waren. Ähnliche Ergebnisse konnten für die allogene Situation demonstriert werden (Dressel 2011). Umgekehrt konnte durch die Aktivierung von NK-Zellen ein langsameres Wachstum der Teratome erreicht werden (Dressel et al. 2010). In vitro konnte gezeigt werden, dass z. B. durch IL-2 aktivierte NK-Zellen in der Lage waren, einzelne Stammzellinien teils effektiver als die entsprechenden Kontrollzelllinien zu lysieren (Dressel et al. 2008, Frenzel et al. 2009). Dennoch scheinen funktionstüchtige NK-Zellen in der Regel alleine nicht auszureichen, um eine Teratomausbildung zu verhindern. NK-Zellen können also für die vollständige Rejektion von in größeren Mengen applizierten undifferenzierten Stammzellen keine ausreichende Immunrejektion hervorrufen (Drukker et al. 2006). Eine mögliche Erklärung der in den meisten Studien sehr effektiven Lyse von Stammzellinien durch NK-Zellen könnte in dem Zusammenspiel zweier Faktoren liegen: zum einen zeigen murine Stammzellen in der Durchflusszytometrie keine Expression von MHC-Klasse-I-Molekülen, sodass nur von einer sehr geringen Menge an MHC-Klasse-I-Molekülen auf murinen Stammzellen ausgegangen werden kann. Auch humane ESC zeigen nur eine sehr geringe Anzahl von MHC-Klasse-I-Molekülen (Kapitel 1.2.5). Im Einklang mit der missing-self-Hypothese könnten die Stammzellen so zu Zielzellen der NK-Zellen werden (Kärre 1985).

Zum anderen wurden auf Stammzellen verschiedene NK-Zell-aktivierende Liganden nachgewiesen. So exprimieren verschiedene Stammzelllinien Rae-1, einen Liganden von NKG2D, einem potenten NK-Zell-Aktivator. Auch CD112 und CD155, Liganden von DNAM-1, welcher ebenfalls NK-Zellen aktivieren kann, konnten durchflusszytometrisch erfasst werden. Bisher konnten noch keine Liganden der ebenfalls aktivierenden Rezeptoren NKp46 oder 2B4 auf Stammzellen detektiert werden (Dressel et al. 2008 und 2010). Frenzel und Kollegen zeigten 2009 die Expression von ICAM-1, welcher für die Interaktion von NK-Zellen mit ihren Zielzellen vonnöten ist. Auf humanen Stammzellen konnten MICA und MICB, ebenfalls Liganden von NKG2D, nachgewiesen werden (Suárez-Alvarez et al. 2010).

In vitro konnte zudem gezeigt werden, dass eine Lyse von Stammzellinen durch NKZellen durch die Zugabe von rekombinanten NKG2D vermindern kann (Dressel et al. 2010), die Lyse von Stammzelllinien daher von NKG2D-Liganden abhängig ist.

So könnte das geringe Maß an MHC-Klasse-I-Molekülen und das Fehlen inhibierender Liganden zusammen mit NK-Zell-aktivierenden Liganden eine Erklärung für die gute Lysierbarkeit verschiedener Stammzellinien durch NK-Zellen darstellen. 
In verschiedenen Studien konnte zudem gezeigt werden, dass die Lysierbarkeit von Stammzellderivaten durch NK-Zellen mit dem Grad ihrer Differenzierung sinkt (Koch et al. 2006, Dressel et al. 2008, Frenzel et al. 2009). Dies ließe sich durch die Hochregulation von MHC-Klasse-I-Molekülen erklären (siehe Kapitel 1.3.4). Dressel et al. schlossen aus ihren Ergebnissen, dass die zunehmende Resistenz gegenüber NK-Zellen durch eine Herunterregulation NK-Zell-aktivierender Liganden während des Differenzierungsprozesses zu erklären sei, Frenzel und Kollegen kamen im Hinblick auf ICAM-1 zu ähnlichen Schlüssen (Frenzel et al. 2009).

Auch das angeborene Immunsystem scheint Auswirkungen auf die Transplantierbarkeit von Stammzellen zu haben: so publizierten Koch und Kollegen 2006, dass murine ESC - im Gegensatz zu ihren Derivaten - durch den alternativen Komplementweg sehr gut lysierbar seien.

Zusammengefasst scheinen NK-Zellen in der Lage, verschiedene Stammzellinien sehr effektiv zu lysieren, wobei zum einen die Menge der MHC-Klasse-I-Moleküle, zum anderen aktivierende Liganden eine große Rolle spielen. Dass die Lyse differenzierter Derivate dieser Linien sinkt, ist vermutlich auf die Herauf- bzw. Herabregulation dieser beiden Parameter zurückzuführen.

\subsection{Fragestellung}

Ziel dieser Arbeit war es, die Auswirkungen zytotoxischer Effektormechanismen auf parthenogenetische Stammzellen sowie auf deren Derivate zu untersuchen, um sie mit anderen Stammzellinien zu vergleichen.

Parthenogenetische Stammzellen lassen sich ohne die Zerstörung von Embryonen aus adulten Organismen gewinnen. Zudem könnte ihr homologer Genotyp die Anzahl immunkompatibler Empfänger im Vergleich zu ESC-Linien deutlich erweitern. Dennoch ist über die Auswirkungen des Immunsystems auf parthenogenetische Stammzellinien kaum etwas bekannt.

Um diese näher zu untersuchen, haben wir murine parthenogenetische Stammzellen der Linien A3 und A6, welche zuvor durch P. Christalla etabliert worden waren (Didié et al. 2013), sowie deren Derivate nach Behandlung in Differenzierungsmedium im ${ }^{51}$ Chrom-Freisetzungstest hinsichtlich ihrer Lysierbarkeit durch CTL und NK-Zellen untersucht. Mithilfe von Durchflusszytormetrie, Westernblot und rtPCR wurden die 
Zellen auf verschiedene immunologisch relevante Proteine sowie mögliche Protektionsmechanismen untersucht. 


\section{Material und Methoden}

2.1 Material

2.1.1 Verwendete Geräte

\section{Gerät}

Autoklav

Blot-Kammer
Durchflusszytometer
Echtzeit-PCR
Elektrophoresekammer
und Zubehör
Hamiltonspritze
Homogenisator
Inkubator
Flüssigszintillatorzähler
Kanüle
MACS-Separator
Magnetrührer

Mikroskop

Netzteile

Neubauerzählkammer
Typ

Fedegari FVS/3

Fedegari FVS/2

FACSCalibur

7500 Real Time PCR

System

Hamilton Mikroliter

Spritze

Tenbroek

Hera Cell 150

1450 MicroBeta Trilux

0,45mm 100 Sterican

Nr. M2/93/817

$\mathrm{RH}$ basic 2

Axiovert 35

Pipetboy acu

\section{Firma}

Integra Biosciences

$\mathrm{GmbH}$

Integra Biosciences

$\mathrm{GmbH}$

Bethesda Research

Laboratories

Becton Dickinson $\mathrm{GmbH}$

Applied Biosystems

$\mathrm{GmbH}$

Boskamp Pherostat

Hamilton Bonaduz AG

über Schütt Labortechnik

$\mathrm{GmbH}$

Heraeus Holding GmbH

Wallac

Braun Melsungen AG

Miltenyi Biotec $\mathrm{GmbH}$

IKA Werke GmbH \&

Co. KG

Carl Zeiss Microlmaging

$\mathrm{GmbH}$

Orion Integrated

Biosciences Inc.

über Omnilab 


\begin{tabular}{|c|c|c|}
\hline Pipetten & $\begin{array}{l}2 \mu \mathrm{l}, 2,5 \mu \mathrm{l}, 20 \mu \mathrm{l}, 200 \mu \mathrm{l}, \\
1000 \mu \mathrm{l}, 300 \mu \mathrm{l} \text { 8-Kanal }\end{array}$ & Eppendorf AG \\
\hline Pipettierhilfe & pipete boy acu & $\begin{array}{l}\text { Orion Integrated } \\
\text { Biosciences Inc. }\end{array}$ \\
\hline Rotoshake & Genie & Scientific Industries Inc. \\
\hline sterile Werkbank & KS 18 & Heraeus Holding GmbH \\
\hline Thermocycler & Tpersonal & Biometra GmbH \\
\hline Thermomixer & $\begin{array}{l}\text { Thermomixer comfort } \\
1,5 \mathrm{ml}\end{array}$ & Eppendorf AG \\
\hline Trockenschrank & T6120 & Heraeus Holding GmbH \\
\hline Vortexer & MS1 Minishaker & $\begin{array}{l}\text { IKA Werke GmbH \& } \\
\text { Co.KG }\end{array}$ \\
\hline \multirow[t]{2}{*}{ Waagen } & H95 & Sartorius AG \\
\hline & BP 61 & Sartorius AG \\
\hline \multirow[t]{5}{*}{ Zentrifugen } & $3 K 30$ & $\begin{array}{l}\text { Sigma-Aldrich Chemie } \\
\text { GmbH }\end{array}$ \\
\hline & Multifuge $1 \mathrm{~L}$ & Heraeus Holding GmbH \\
\hline & Multifuge 3 S-R & Heraeus Holding GmbH \\
\hline & Mikro 22 & Hettich GmbH \& Co.KG \\
\hline & Mikroliter & Hettich GmbH \& Co. KG \\
\hline
\end{tabular}

2.1.2 Chemikalien und Reagenzien

\section{Chemikalie}

Acrylamid 30\% (Rotiphorese Gel 30;

29:1)

APS (Ammoniumpersulfat)

$\beta$-Mercaptoethanol

Bromphenolblau

Chloroform

Concanavalin A

DAB (Diaminobenzidin)
Hersteller

Roth GmbH \& Co.

Sigma-Aldrich Chemie GmbH

Sigma-Aldrich Chemie GmbH

Merck Bioscience GmbH

Merck Bioscience GmbH

Sigma-Aldrich Chemie GmbH

Roth GmbH \& Co. 
DMEM (dulbecco modified Eagle

medium) - GIBCO (Pulver)

DMSO (Dimethylsulfoxid)

EDTA (Ethylendiamintetraessigsäure)

EGTA (Ethylenglycol bis(2-

aminoethylether)-N,N,N',N'-

tetraessigsäure)

Essigsäure 100\%

Ethanol absolut

FCS (fetales Kälberserum)

Glycerin

Glycin

$\mathrm{HCl}$ (Salzsäure)

Hepes (2-(4-(2-Hydroxyethyl)- 1-

piperazinyl)-ethansulfonsäure)

Isoamylalkohol

Isopropanol (100\%)

$\mathrm{KHCO}_{3}$ (Kaliumhydrogencarbonat)

Methanol

$\mathrm{MgCl}_{2}$ (Magnesiumchlorid) Hexahydrat

$\mathrm{Na}_{2}{ }^{51} \mathrm{CrO}_{4}$ (radioaktives

Natriumchromat)

$\mathrm{NaCl}$ (Natriumchlorid)

$\mathrm{NaOH}$ (Natronlauge)

$\mathrm{NH}_{4} \mathrm{Cl}$ (Ammoniumchlorid)

PBS (Phosphat-gepufferte Salzlösung)

PenStrep (Penicillin G 10000U/ml;

Streptomycin $10000 \mu \mathrm{g} / \mathrm{ml}$ )

Perhydrol $30 \% \mathrm{H}_{2} \mathrm{O}_{2}$

Phenol

Ponceau S

SDS (Natriumdodecylsulfat)

SIINFEKL (Ovalbumin aa 257-264)
Invitrogen $\mathrm{GmbH}$

Merck Bioscience GmbH

Roth $\mathrm{GmbH} \&$ Co.

Sigma-Aldrich Chemie GmbH

Merck Bioscience GmbH

AppliChem

Biochrom AG

Roth $\mathrm{GmbH} \&$ Co.

AppliChem

Merck Bioscience GmbH

Roth $\mathrm{GmbH} \&$ Co.

Merck Bioscience GmbH

Roth $\mathrm{GmbH} \&$ Co.

Merck Bioscience GmbH

Roth $\mathrm{GmbH}$ \& Co.

Merck Bioscience $\mathrm{GmbH}$

Hartmann Analytic GmbH

Merck Bioscience GmbH

Merck Bioscience GmbH

Merck Bioscience $\mathrm{GmbH}$

Biochrom AG

Invitrogen $\mathrm{GmbH}$

Merck Bioscience GmbH

Merck Bioscience GmbH

Sigma-Aldrich Chemie GmbH

Roth GmbH \& Co.

Bachem Distribution Services GmbH 
TEMED

(N,N,N',N'-Tetramethylethylendiamin)

Tris (Tris-(hydroxymethyl)-aminomethan)

Triton X-100

TRIzol Reagent

Trypanblau

Trypsin

Tween-20 (Polyoxyethylen(20)-sorbitanmonolaurat)

\subsubsection{Analysesets}

NK Cell Isolation Kit II

Sybr-Green-Kit (Power SYBR green

PCR master mix)

\subsubsection{Nährmedien}

Name

DMEM-Komplett-Medium

Hepes-gepuffertes DMEM

2.1.5 Puffer und Stammlösungen

Name

DAB-Lösung
AppliChem

Roth $\mathrm{GmbH}$ \& Co.

Serva Electrophoresis $\mathrm{GmbH}$

Invitrogen $\mathrm{GmbH}$

Merck Bioscience $\mathrm{GmbH}$

Biochrom AG

AppliChem
Miltenyi Biotec $\mathrm{GmbH}$

Applied Biosystems GmbH

\section{Zusammensetzung}

500 ml DMEM-Medium

$5 \mathrm{ml}$ 100x PenStrep

$50 \mathrm{ml}$ FCS

13,54 g/l DMEM (Pulver)

$4,77 \mathrm{~g} / \mathrm{l}$ Hepes

dest. $\mathrm{H}_{2} \mathrm{O}$

$\mathrm{pH}$ mit $\mathrm{NaOH}$ auf 7.2 einstellen
Zusammensetzung

$50 \mathrm{ml} \mathrm{PBS/Tween}$

$25 \mathrm{mg}$ DAB 
EDTA/Trypsin

EGTA/MgCl 2

Einfriermedium

Erythrozytenlyse-Puffer

PBS

PBS/Tween

Probenpuffer (reduzierend)

Sammelgelpuffer
$50 \mu \mathrm{H}_{2} \mathrm{O}_{2}$

$0.05 \%$ Trypsin

$0.02 \%$ EDTA

in PBS

4 mM EGTA

$8 \mathrm{mM} \mathrm{MgCl}_{2}$

$10 \%$ FCS

Hepes-gepuffertes DMEM

$\mathrm{pH}$ auf 7.2 mit $0,5 \mathrm{M} \mathrm{NaOH}$ einstellen

$80 \%$ FCS

$20 \%$ DMSO

$155 \mathrm{mM} \mathrm{NH}_{4} \mathrm{Cl}$

$10 \mathrm{mM} \mathrm{KHCO}_{3}$

0,1 mM EDTA

in dest. $\mathrm{H}_{2} \mathrm{O}$

9,55 g/l PBS

in dest. $\mathrm{H}_{2} \mathrm{O}$

0,05\% Tween-20

in PBS

0,02 M Tris/HCl pH 8,0

20\% Glycerin

$2 \%$ SDS

2 mM EDTA

$10 \% \beta$-Mercaptoethanol

0,1\% Bromphenolblau

in dest. $\mathrm{H}_{2} \mathrm{O}$

0,5 M Tris/HCl pH 6,8 
$0,4 \%$ SDS

in dest. $\mathrm{H}_{2} \mathrm{O}$

SDS-Laufpuffer

3,02 g Tris

$14,41 \mathrm{~g}$ Glycin

$10 \mathrm{ml} \mathrm{10 \%} \mathrm{SDS}$

ad $5 \mathrm{I}$ dest. $\mathrm{H}_{2} \mathrm{O}$

Triton-Lyse-Puffer

$10 \%$ Triton X-100

in PBS

Transferpuffer

9,084 $\mathrm{g}$ Tris

43,23 g Glycin

20\% Methanol

in dest. $\mathrm{H}_{2} \mathrm{O}$

Trenngelpuffer

1,5 M Tris/HCL pH 8,8

$0,4 \%$ SDS

in dest. $\mathrm{H}_{2} \mathrm{O}$

Trypanblau

$0.2 \%$ Trypanblau

in dest. $\mathrm{H}_{2} \mathrm{O}$

$4.25 \% \mathrm{NaCl}$

in dest. $\mathrm{H}_{2} \mathrm{O}$

Tryanblau mit $\mathrm{NaCl}$ in einem Verhältnis von 4:1 mischen 
2.1.6 Gele

\section{Name}

Sammelgel

Trenngel

\subsubsection{Antikörper}

2.1.7.1 Primäre Antikörper

\section{Antikörper}

Anti-Cathepsin B

Anti-HSC70

Anti-SPI9

Anti-CD112

Anti-CD155

Anti-CD48

\section{KIon/Isotyp}

Ziege lgG (polyklonal)

Klon: 1B5

Isotyp: Ratte IgG2a

Maus lgG1 (polyklona)

Klon: 502-57

Isotyp: Ratte IgG2a

Klon: TX56

Isotyp: Ratte IgG2a

Klon: 331504

Isotyp: Ratte IgG1

\section{Hersteller}

R \& D Systems GmbH

Biomol GmbH

MBL Internat. Coop.

R \& D Systems GmbH

BioLegend Inc.

R \& D Systems GmbH 


\begin{tabular}{|c|c|c|}
\hline Anti-H2Db (PE-konjugiert) & Klon: KH95 & BioLegend Inc. \\
\hline & Isotyp: Maus IgG2b & \\
\hline Anti-H2D (PE-konjugiert) & Klon: 34-2-12 & BioLegend Inc. \\
\hline & Isotyp: IgG2a & \\
\hline Anti-H2Kb (PE-konjugiert) & Klon: AF6-88.5 & BD Biosciences \\
\hline & Isotyp: IgG2a & \\
\hline Anti-H2Kd (PE-konjugiert) & Klon: SF 1-1.1 & BD Biosciences \\
\hline & Isotyp: IgG2a & \\
\hline Anti-H60 & Klon: 205326 & R \& D Systems GmbH \\
\hline & Isotyp: Ratte IgG2a & \\
\hline Anti-Mult1 & Klon: 237104 & R \& D Systems GmbH \\
\hline & Isotyp: Ratte IgG2a & \\
\hline Anti-Rae1 & Klon: 186107 & R \& D Systems GmbH \\
\hline & Isotyp: Ratte IgG2a & \\
\hline Anti-Qa1b & Klon: 6A8.6F10.1AG & BD Biosciences \\
\hline
\end{tabular}

2.1.7.2 Sekundäre Antikörper, Isotypenkontrolle und Sekundärreagenzien

\section{Name}

Kaninchen anti-Ziege IgG;

HRP-konjugiert

Ziege anti-Maus IgG ; HRP-konjugiert

Ziege anti-Ratte IgG; FITC-konjugiert

Ziege anti-Maus IgG; FITC-konjugiert

Ziege anti-Mensch IgG/M/A; FITC-

konjugiert

Streptavidin Tricolor-konjugiert

Maus-IgG2a; FITC-konjugiert

Maus-IgG2b; PE-konjugiert

\section{Hersteller}

Dianova

Dianova

Dianova

Dianova

Dianova

BioLegend Inc.

ImmunoTools $\mathrm{GmbH}$

ImmunoTools $\mathrm{GmbH}$ 


\section{Rekombinante Ig-Fusionsproteine}

2B4

DNAM-1

NKG2D

NKp46

\subsubsection{Proteinmarker}

Proteinmarker

SDS-6H

\author{
Beschreibung \\ Molekulargewicht:
}

$30,000-200,000$
Hersteller

Anteils

Isotyp: human IgG1 R \& D Systems $\mathrm{GmbH}$

Isotyp: Maus IgG2a R \& D Systems GmbH

Isotyp: humanes $\quad R \& D$ Systems $\mathrm{GmbH}$

$\lg \mathrm{G} 2 \mathrm{a}$

Isotyp: humanes IgG1 R \& D Systems GmbH

\subsubsection{Zytokine}

\section{Zytokin}

rekombinantes murines Interferon-

Gamma (rm IFN-y)

rekombinantes murines IL-2 (rm IL-2)

humanes IL-2 (hu IL-2)
Hersteller

ImmunoTools $\mathrm{GmbH}$

R\&D Systems GmbH

Novartis GmbH
Hersteller

Sigma-Aldrich-Chemie

$\mathrm{GmbH}$

\subsubsection{Enzyme und Enzyminhibitoren}

\section{Enzym/Enzyminhibitor}

Taq-Polymerase

M-MLV (Moloney murine leukemia virus) reverse Transkriptase

\section{Hersteller}

New England Biolabs AG

New England Biolabs AG 
DNAse $(10 \mathrm{U} / \mu \mathrm{l})$

RNAse Inhibitor $(40 \mathrm{U} / \mu \mathrm{l})$
New England Biolabs AG

New England Biolabs AG

\subsubsection{Primer}

\begin{tabular}{|c|c|}
\hline \multirow[t]{2}{*}{$\begin{array}{l}\text { untersuchte Gene } \\
\text { Arginase }\end{array}$} & $\begin{array}{l}\text { Primer } \\
\text { forward 5' acctggccttatgtcc } 3 \text {, }\end{array}$ \\
\hline & reverse 5' agcaccacacccattc $3^{\prime}$ \\
\hline \multirow[t]{2}{*}{ B2Mikroglobulin } & forward 5' ctcacactgaattcaccccc 3' \\
\hline & reverse 5' cagtagacggtattgggctc 3' \\
\hline \multirow[t]{2}{*}{ Dnam-1 } & forward 5' tcgttggaggtttcac 3 \\
\hline & reverse 5' gctaccttactccctg 3' \\
\hline \multirow[t]{2}{*}{$H 2 D^{b}$} & forward 5' ggaacctgctcggctactac 3' \\
\hline & reverse 5' gccttgtaatgctctgc $3^{\prime}$ \\
\hline \multirow[t]{2}{*}{$H 2 D^{d}$} & forward 5' agtggatggctggctgtgac 3 ' \\
\hline & reverse 5' cgtagcattcccgttattcag 3' \\
\hline \multirow[t]{2}{*}{$H 2 K^{b}$} & forward 5 ' agcagacctgaagataaagtcac 3 ' \\
\hline & reverse 5' gatgcccacttctggaaggt 3' \\
\hline \multirow[t]{2}{*}{$H 2 K^{d}$} & forward 5' cacacgttccagcggatgttc 3' \\
\hline & reverse 5 ' tccacgtttcaggtcttcg $3^{\prime}$ \\
\hline \multirow[t]{2}{*}{ H6O } & forward 5' gtggettctccagcaaaga 3' \\
\hline & reverse 5' gccaccactctcatgggttc 3' \\
\hline \multirow[t]{2}{*}{ Hprt } & forward 5' gtcctgtggecatctgccta 3' \\
\hline & reverse 5' gggacgcagcaactgacatt 3' \\
\hline \multirow[t]{2}{*}{ ldo1 } & forward 5' ccacactgagcacggacgg 3' \\
\hline & reverse 5' tgcggggcagcacctttcg $3^{\prime}$ \\
\hline \multirow[t]{2}{*}{ Mult-1 } & forward 5' ggggcttcctcttgctctgt 3' \\
\hline & reverse 5 ' ttagagaccatgccctgcttg 3' \\
\hline \multirow[t]{2}{*}{ NKG2D } & forward 5' gctggttaagcactgg 3' \\
\hline & reverse 5' ttgagccatagcacag 3' \\
\hline
\end{tabular}


Nectin-2 (CD112)

Polyviruslike-Receptor (CD155)

Qa1b

Rae-1

Spi6/Serpinb9

Tap1

Tap2

$T G F \beta$

2.1.12 Zelllinien

forward 5' cgagagtcacccagcacag 3' reverse 5' tgttgtcggcagatgaggatg 3' forward 5' gatgttcttgccgtcgtcct 3' reverse 5' agttgccgtcatagccagaga 3' forward 5' gatgttgcttttgccac 3' reverse 5 ' tagcccgacaatgatgaacc 3 ' forward 5' ccaaggacaggccagagcag 3' reverse 5' tgctgttcttggagacctcctc 3 ' forward 5' tgcagacaaaacttgtgaagtcctc 3 ' reverse 5' tgcctggacacctctgcttc $3^{\prime}$ forward 5' ctgctctccctctacccctc 3' reverse 5' ctgcgtggagagcaaggagtc 3 ' forward 5' gcagacgacttcatagggga 3' reverse 5' gttgcttctgtcccacagc 3' forward 5' gcaacaattcaccttg 3' reverse 5' agcaccacacccattc 3'

Name Art

A3

A6

RMA

X63-Ag8.653

YAC homologe parthenogenetische Stammzellinie heterologe parthenogenetische Stammzelline Maus T-Zell-Lymphom-Linie Maus Myelom-Zelllinie Maus T-Zell-Lymphom-Linie

RMA, YAC und 653 sind Suspensionszellen, die parthenogenetische Stammzellen wachsen adhärent auf Feederzellen. 


\subsubsection{Versuchstiere}

Die Versuchstiere wurden in der Zentralen Tierexperimentellen Einrichtung der GeorgAugust-Universität Göttingen gehalten.

\begin{tabular}{|c|c|c|}
\hline $\begin{array}{l}\text { Name } \\
\text { OT-1 }\end{array}$ & $\begin{array}{l}\text { Art } \\
\text { Maus }\end{array}$ & $\begin{array}{l}\text { Beschreibung } \\
\text { Transgen für einen Va2V } \beta 5 \text { T-Zellrezeptor gegen } \\
\text { duch } \mathrm{H}^{2} \mathrm{~K}^{\mathrm{b}} \text { präsentiertes SIINFEKL }\end{array}$ \\
\hline C57BL/6 & Maus (Wildtyp) & Haplotyp: $\mathrm{H} 2^{\mathrm{b}}$ \\
\hline $129 / \mathrm{Sv}$ & Maus (Wildtyp) & Haplotyp: $\mathrm{H} 2^{\mathrm{b}}$ \\
\hline FVB & Maus (Wildtyp) & Haplotyp: H2q \\
\hline DBA & Maus (Wildtyp) & Hapoltyp: H2d \\
\hline
\end{tabular}

2.1.14 Einwegartikel

\begin{tabular}{|c|c|c|}
\hline Artikel & Тур & Firma \\
\hline \multirow[t]{2}{*}{ Eppendorfgefäß } & $1,5 \mathrm{ml}$ & Sarstedt AG \& Co. \\
\hline & $2 \mathrm{ml}$ & Sarstedt AG \& Co. \\
\hline FACS-Röhrchen & BD Falcon $5 \mathrm{ml}$ & Becton Dickinson $\mathrm{GmbH}$ \\
\hline Gefrierröhrchen & Cryo Tube Vialis $1,8 \mathrm{ml}$ & Nunc A/S \\
\hline Gewebekultur-Petrischale & unbeschichtet $94 \times 16 \mathrm{~mm}$ & Greiner Bio-One \\
\hline \multirow[t]{2}{*}{ Handschuhe } & Peha-soft S/M & Hartmann AG \\
\hline & Nitrile S/M & Ansell Healthcare Limited \\
\hline \multirow[t]{2}{*}{ Klebefolie } & Top Seal-A 96-Loch- & PerkinElmer LAS GmbH \\
\hline & Platten & \\
\hline MACS Seperationssäulen & LS & Miltenyi Biotec GmbH \\
\hline Mikrotiterplatte & 96-Loch-Rundboden & Sarstedt AG \& Co. \\
\hline \multirow[t]{2}{*}{ Nitrozellulosemembran } & $200 \times 200 \mathrm{~mm}$ & Schleicher\&Schuell \\
\hline & $0,45 \mathrm{~mm}$ Porengrösse & \\
\hline Pipetten & $\begin{array}{l}2 \mathrm{ml}, 5 \mathrm{ml}, 10 \mathrm{ml}, 25 \mathrm{ml} \\
\text { cellstar }\end{array}$ & Greiner Bio-One \\
\hline Pipettenspitzen & $\begin{array}{l}10 \mu \mathrm{l} \text { weiß, } 200 \mu \mathrm{l} \text { gelb, } \\
1000 \mu \mathrm{l} \mathrm{blau}\end{array}$ & $\begin{array}{l}\text { Greiner Bio-One / Sarstedt } \\
\text { AG \& Co. }\end{array}$ \\
\hline
\end{tabular}




$\begin{array}{lll}\text { Sterilfilter } & \text { Filtropur S } & \text { Sarstedt AG \& Co. } \\ \text { Wallac Messplatte } & 96 \text {-Loch } & \text { PerkinElmer LAS GmbH } \\ \text { Whatmanpapier } & \text { GB 003 } & \text { Schleicher\&Schuell } \\ \text { Zentrifugationsröhrchen } & 13 \mathrm{ml} \text { Röhrchen } & \text { Sarstedt AG \& Co. } \\ & 50 \mathrm{ml} \text { Röhrchen } & \text { Sarstedt AG \& Co. }\end{array}$

\subsubsection{Computeranalyse}

Die Computeranalyse des ${ }^{51} \mathrm{Chrom}$-Freisetzungstest erfolgte mithilfe der MicroBeta Software für den Wallac MicroBeta Trilux Flüssigszintillationszähler und Excel 2007 (Microsoft).

Die Analyse der FACS-Daten wurde mit Cell Quest (BD Biosciences) und Excel 2010 durchgeführt, während die Daten der quantitativen rtPCR mithilfe von 7500 Systems (AB) und Excel 2010 ausgewertet wurden. Die statistische Analyse erfolgte mit GraphPad Prism 5.

\subsubsection{Herstellerliste}

\section{Hersteller}

AppliChem GmbH

Applied Biosystems (AB) GmbH

Bachem Distribution Services GmbH

Becton Dickinson GmbH

BD Biosciences

Biochrom AG

BioLegend

Biometra GmbH

Biotec-Fischer $\mathrm{GmbH}$

Brand $\mathrm{GmbH}+\mathrm{Co} . \mathrm{KG}$

\section{Adresse}

Ottoweg 4, 64291 Darmstadt

Frankfurter Straße 129b, 64291

Darmstadt

Hegenheimer Str. 5, 79576 Weil am

Rhein

Tullastr. 8-12, 69126 Heidelberg

1 Becton Drive, Franklin Lakes, NJ USA

Leonorenstr. 2-6, 12247 Berlin

11080 Roselle Street, San Diego, USA

Rudolf-Wissel-Straße 30, 37079

Göttingen

Daimlerstraße 6, 35447 Reiskirchen

Otto-Schott-Straße 25, 97877 Wertheim 
Braun Melsungen AG

Caltag Laboratories

Carl Zeiss Microlmaging GmbH

Desaga (Sarstedt-Group)

Dianova

Eppendorf AG

GeReSo $\mathrm{GmbH}$

Greiner BioOne AG

Hamilton Bonaduz AG

Hartmann Analytic $\mathrm{GmbH}$

Hettich $\mathrm{GmbH}$ \& Co.KG

Heraeus Holding GmbH

Hewlett-Packard

IKA Werke GmbH \& Co. KG

ImmunoTools $\mathrm{GmbH}$

Integra Biosciences $\mathrm{GmbH}$

Invitrogen $\mathrm{GmbH}$

Merck KGaA

Miltenyi Biotec GmbH

New England Biolabs AG

Nunc A/S

Omnilab (Krannich)

Orion Integrated Biosciences

Phase $\mathrm{GmbH}$

$\mathrm{R} \& \mathrm{D}$ Systems $\mathrm{GmbH}$

Roth GmbH \& Co.

Sarstedt AG \& Co.

Carl-Braun-Straße 1, 34212 Melsungen

Brauhausstieg 15-17, 22041 Hamburg

Carl-Zeiss-Straße 22, 73447 Oberkochen In den Ziegelwiesen 1-7, 69168 Wiesloch Warburgstr. 45, 20354 Hamburg Barkhausenweg 1, 22339 Hamburg Carl-Orff-Str. 33, 37574 Einbeck Bad Haller Straße 32, 4550 Kremsmünster, Österreich Via Crush 8, 7402 Bonadiz, Schweiz Butterberg 1a, 38108 Braunschweig Föhrenstraße 12, 78532 Tuttlingen Heraeusstraße 12-14, 63450 Hanau Herrenbergerstraße 140, 71034 Böblingen Janke \& Kunkel-Str. 10, 79219 Staufen Altenoyther Str. 10, 26169 Friesoythe Ruhberg 4, 35463 Fernwald Frankfurter Straße 129b, 64293 Darmstadt Frankfurter Straße 250, 64293 Darmstadt Friedrich Ebert Straße 68, 51429 Bergisch Gladbach 240 County Road, Ipswich, MA 019382723

Kamstrupvej 90, 4000 Roskilde, Denmark Rooke-Hooke-Straße 8, 28359 Bremen 265 Centre Ave Suite 1R, New Rochelle, New York, USA

Blücherstraße 2, 23564 Lübeck

Borsigstraße 7, 65205 Wiesbaden

Schoemperlenstr. 1-5, 76185 Karlsruhe Rommelsdorfer Straße, Postfach 1220, 51582 Nümbrecht 
Sartorius AG

Schütt Labortechnik GmbH

Scientific Industries, Inc.

Serva Electrophoresis $\mathrm{GmbH}$

Sigma-Aldrich Chemie GmbH

Wallac

Webeco GmbH \& Co.KG
Weender Landstraße $\quad 94-108, \quad 37075$ Göttingen

Rudolf-Wissell-Str. 11, 37079 Göttingen

70 Orville Drive, Bohemia, New York 11716 USA

Carl-Benz-Straße 7, 69115 Heidelberg

Riedstraße 2, 89555 Steinkirchen

Jetzt: PerkinElmer, 940 Winter Street, Waltham, Massachusetts 02451, USA

An der Trave 14, 23923 Selmsdorf

\subsection{Methoden}

\subsubsection{Zellkulturmethoden}

\subsubsection{Allgemeines zur Arbeit mit Zellkulturen}

Um eine mögliche Kontamination durch Pilze oder Bakterien zu vermeiden, wurden alle Arbeiten mit Zellkulturen unter sterilen Bedingungen, d.h. unter einer sterilen Werkbank mit sterilen Materialien durchgeführt.

Bei den Zellen mit denen gearbeitet wurde, handelte es sich um Suspensionszellen und adhärent auf Feeder wachsende Zelllinien. Suspensionszellen wurden in Gewebekultur-Petrischalen für Suspensionskulturen in $10 \mathrm{ml}$ DMEM-Komplettmedium gehalten. Aufgrund der hohen Teilungsrate vieler dieser Kulturen wurde die Zahl der Zellen täglich halbiert. Die auf Feeder wachsenden Stammzelllinien wurden freundlicherweise von Vijay Muppalla im Labor der Pharmakologie der Universitätsmedizin Göttingen in Gewebekultur-Petrischalen zur Verfügung gestellt. Die Zellkulturen wurden bei $37^{\circ} \mathrm{C}$ und $5 \% \mathrm{CO}_{2}$ inkubiert.

\subsubsection{Bestimmung der Zellzahl}

Zur Bestimmung der Zellzahl in einem gegebenen Volumen, wurden diesem $10 \mu \mathrm{l}$ entnommen und in eine Neubauer-Zählkammer überführt. Aus den unter dem 
Mikroskop pro Großquadrat gezählten Zellen ließ sich auf die Gesamtzellzahl rückschließen:

Zellzahl $=$ mittlere Zellzahl $\times$ Verdünnungsfaktor $\times 10^{4}$

Sollten zudem ausschließlich lebende Zellen gezählt werden, wurden die Zellen zuvor in Trypanblau 1:10 verdünnt. Trypanblau dringt nicht durch intakte Zellmembranen, sodass intakte lebende Zellen hell vor dem blau gefärbten Hintergrund erscheinen.

\subsubsection{Einfrieren und Auftauen von Zellen}

Zum Einfrieren von Zellen wurden diese zunächst gezählt und anschließend etwa $5 \times 10^{6}$ Zellen in ein 13-ml-Röhrchen überführt. In diesem wurden sie bei $300 \times g$ min zentrifugiert. Das Zellpellet wurde in 0,5 ml Hepes-gepuffertem DMEM-Medium resuspendiert und anschließend ein gleiches Volumen Einfriermedium hinzugefügt. Die Zellen wurden schnell in Einfrierröhrchen überführt und in einer Styroporbox bei $80^{\circ} \mathrm{C}$ langsam eingefroren.

Zum Auftauen der Zellen wurden die Einfrierröhrchen in warmes Wasser gehalten bis der Inhalt flüssig wurde. Dieser wurde in ein 13-ml-Röhrchen mit $10 \mathrm{ml}$ Hepesgepuffertes DMEM-Medium überführt und bei $300 \times \mathrm{g} 10 \mathrm{~min}$ zentrifugiert. Der Überstand wurde abgenommen und das Zellpellet in Kulturmedium aufgenommen und inkubiert.

\subsubsection{Ablösung adhärent wachsender Zellen}

Die untersuchten parthenogenetischen Stammzellen wuchsen adhärent auf Feederzellen und mussten daher vor allen Versuchen vom Boden der Gewebeplatten gelöst werden. Dazu wurde das Inkubationsmedium entfernt und die Innenfläche der Platten kurz mit sterilem PBS gespült. Anschließend wurden $10 \mathrm{ml}$ PBS/EDTA mit $1 \mathrm{ml} 10 \times$ Trypsin auf die Zellen gegeben. Da Trypsin die Oberflächen der Zellen angreift und Oberflächenproteine zerstören könnte, wurde nur so lang wie unbedingt notwendig (meist zwei bis drei Minuten) abgewartet. Die Stammzellen hatten sich zu diesem Zeitpunkt von den Feederzellen gelöst und konnten abgenommen werden. Das Trypsin wurde durch Zugabe von $200 \mu \mathrm{FCS}$ inaktiviert, die Zellen für $10 \mathrm{~min}$ bei $300 \times \mathrm{g}$ zentrifugiert und das Zellpellet in DMEM-Komplettmedium aufgenommen. 


\subsubsection{Isolierung von Lymphozyten aus Mäusemilzen}

Um Lymphozyten aus Mäusemilzen zu gewinnen, mussten diese zunächst präpariert werden. Die Mäuse wurden hierzu unter Narkose durch $\mathrm{CO}_{2}$ mit einem Genickbruch getötet. Die anschließende Präparation erfolgte mithilfe von autoklavierten chirurgischen Instrumenten. Nach alkoholischer Desinfektion des Fells wurde median ein Bauchschnitt durchgeführt, das Fell abpräpariert und nach Wechsel der Instrumente das Bauchfell eröffnet. Die Milz wurde aufgesucht und isoliert, um anschließend entnommen und in ein 13ml-Röhrchen mit $10 \mathrm{ml}$ Hepes-gepuffertem DMEM-Medium überführt zu werden.

Unter einer sterilen Werkbank wurden die Milzzellen nun mithilfe eines TenbroekHomogenisators homogenisiert und bei $300 \mathrm{xg} 10 \mathrm{~min}$ zentrifugiert. Die Zellen wurden zur Lyse der Erythrozyten in $3 \mathrm{ml}$ Erythrozytenlyse-Puffer resuspendiert. Nach $3 \mathrm{~min}$ wurden die Zellen, um den Puffer auszuwaschen, dreimal mit $10 \mathrm{ml}$ DMEMKomplettmedium bei $300 \mathrm{xg} 10$ min zentrifugiert.

Die weiteren Arbeitsschritte ergaben sich daraus, welche Zellen aus der entnommenen Milz stimuliert werden sollten (s. 2.2.1.7-9).

\subsubsection{Stimulation zytotoxischer T-Lymphozyten aus OT-I-Mäusen}

OT-I-Mäuse besitzen einen transgenen, für über $\mathrm{H} 2 \mathrm{~K}^{\mathrm{b}}$-präsentiertes SIINFEKL spezifischen, T-Zellrezeptor. Sie ließen sich in einem Medium aus $16 \mathrm{ml}$ DMEMKomplettmedium, $20 \%$ ConA-Überstand, $20 \mathrm{ng} / \mathrm{ml}$ murines IL-2 und $1 \mathrm{nM}$ SIINFEKL peptidspezifisch stimulieren. Um die räumliche Nähe von SIINFEKL und CTL zu gewährleisten, wurden die Zellen in einer rundbödigen 96-Loch-Mikrotiterplatte ausgesät. Die Zellen wurden anschließend für vier Tage inkubiert.

\subsubsection{Stimulation alloreaktiver zytotoxischer T-Lymphozyten}

Um alloreaktive CTL zu gewinnen, mussten die Mäuse zunächst über einen Zeitraum von 40 Tagen immunisiert werden (s. 2.2.1.4). Dabei war zu beachten, dass, um eine optimale Stimulation der Zellen zu gewährleisten, vier Tage vor Präparation der Milz noch einmal immunisiert wurde. Nach Präparation und Erythrozyten-Lyse (s. 2.2.1.5) wurden die Zellen restimuliert. Hierzu wurden etwa $5 \times 10^{6}$ Milzzellen der allogenen Linie - also jener, gegen welche zuvor immunisiert worden war - zu den präparierten 
Zellen gegeben und bei $300 \mathrm{xg} 10 \mathrm{~min}$ zentrifugiert. Die so gemischten Zellen wurden in $16 \mathrm{ml} \mathrm{Komplettmedium,} 20 \%$ ConA-Überstand und $10 \mathrm{ng} / \mathrm{ml}$ murinem IL-2 in einer 96-Loch-Mikrotiterplatte ausgesät und anschließend für vier Tage inkubiert.

$\mathrm{Zu}$ beachten war, dass die Milzzellen der allogenen Linie zuvor mit 30 Gy bestrahlt worden waren. Dies inaktivierte die Zellen, sodass sie zwar allogene Lymphozyten stimulieren, jedoch selbst nicht weiter stimuliert werden konnten.

\subsubsection{Stimulation Lymphokin-aktivierter NK-Zellen (LAK)}

Um NK-Zellen zu stimulieren, wurden die Milzzellen in $8 \mathrm{ml}$ DMEM-Komplettmedium, $20 \%$ ConA-Überstand, $20 \mathrm{ng} / \mathrm{ml}$ murinem IL-2 und $2000 \mathrm{U} / \mathrm{ml}$ humanem IL-2 in einer Gewebekulturplatte ausgesät und für vier Tage inkubiert.

\subsubsection{Magnetische Separation von NK-Zellen}

\subsubsection{Allgemeines zur MACS}

MACS (magnetic activated cell sorting) ist eine Methode zur An- oder Abreicherung verschiedener Zellpopulationen aus einer Suspension verschiedener Zelltypen. Hierbei werden die benötigten Zellen selbst (Anreicherung) oder die meisten der umgebenden Zellen (Abreicherung) mittels zellspezifischer Antikörper detektiert. Diese sind entweder direkt gekoppelt, d.h. an innen befindet sich ein Magnetpartikel (micro beat), oder sie sind mit Biotin konjugiert und werden ihrerseits durch an Streptavidin gekoppelte Magnetpartikel erkannt. Lässt man die Zellen nun durch ein magnetisches Feld laufen, verbleiben die Antikörper-gebundenen Zellen im Magneten, sodass sich die verschiedenen Zellpopulationen trennen.

\subsubsection{MACS zur Separation von NK-Zellen}

Zunächst wurde die Milz einer Maus präpariert und homogenisiert (s. 2.2.1.5), die Erythrozytenlyse unterblieb. Zur magnetischen Abreicherung von NK-Zellen wurde das Maus-NK-Zell-Isolations Kit der Firma Miltenyi verwendet.

Zur Herstellung des MACS-Puffers wurde PBS entgast und 0,5\% FCS, sowie $2 \mathrm{mM}$ EDTA hinzugefügt. Alle sich anschließenden Arbeitsschritte erfolgten auf Eis. 
Die folgenden Mengen- und Volumenangaben beziehen sich auf eine Ausgangszahl von $1 \times 10^{7}$ Zellen, bei anderen Zellzahlen wurden die Volumina entsprechend angepasst.

Die Zellen wurden gezählt und bei $300 \times \mathrm{g}$ für 10 min zentrifugiert. Der Überstand wurde abpipettiert, die Zellen in $40 \mu$ MACS-Puffer resuspendiert und $10 \mu \mathrm{l}$ der Biotingekoppelten Antikörper gegen verschiedene Zelltypen aus dem Kit (T-Zellen, dendritische Zellen, B-Zellen, Granulozyten und Erythrozyten) hinzugegeben. Anschließend wurden die Zellen für 10 min bei $4^{\circ} \mathrm{C}$ inkubiert.

$30 \mu \mathrm{l}$ MACS-Puffer sowie $20 \mu \mathrm{l}$ der Anti-Biotin-Magnetpartikel wurden hinzupipettiert und erneut bei $4^{\circ} \mathrm{C}$ für 15 min inkubiert. Die Zellen wurden in $1-2 \mathrm{ml}$ Puffer bei $300 \mathrm{xg}$ für 10 min zentrifugiert und der Überstand abgenommen. Die Zellen wurden in $500 \mu \mathrm{l}$ Puffer aufgenommen.

Eine LS-Säule wurde in den MACS Separator eingesetzt und mit $3 \mathrm{ml}$ Puffer gespült. Die Zellsuspension wurde auf die Säule appliziert und die NK-Zellen, welche nicht in ihr verblieben, aufgefangen. Die Säule wurde dreimal mit je $3 \mathrm{ml}$ Puffer gewaschen. Anschließend wurde sie entnommen und die in ihr verbliebenen Zellen herausgewaschen. Die Reinheit der aufgefangenen NK-Zellen wurde mittels Durchflusszytormetrie überprüft.

\subsubsection{Zytotoxizitätstest}

\subsubsection{Allgemeines zur Arbeit mit radioaktiven Stoffen}

Alle Arbeiten mit radioaktiven Stoffen wurden im Isotopenlabor durchgeführt. Die Werkbank war mit einer bleiernen Schutzmauer umgeben, hinter der die Arbeit mit den radioaktiven Stoffen erfolgte. Fester und flüssiger radioaktiver Abfall wurden getrennt entsorgt.

\subsubsection{Prinzip des ${ }^{51}$ Chrom-Freisetzungstests}

Mittels des ${ }^{51}$ Chrom-Freisetzungstests lässt sich die zytolytische Aktivität verschiedener Killerzellen gegen Zielzellen bestimmen.

Die Zielzellen werden mit radioaktiven ${ }^{51} \mathrm{Chrom}$ inkubiert, welches sie internalisieren und an intrazelluläre Proteine binden. Die Killerzellen werden im Folgenden zu den 
Zielzellen gegeben. Durch die Lyse der Killerzellen erfolgte die Freisetzung von Chrom aus den Zellen. Über die so freigesetzte Menge an radioaktivem Chrom lassen sich daher Rückschlüsse auf die zytolytische Aktivität der Killerzellen ziehen.

\subsubsection{Durchführung des ${ }^{51}$ Chromfreisetzungstests}

Zunächst wurden die Zielzellen, in diesem Fall die parthenogenetischen Stammzellen sowie die jeweiligen Kontrollzellen, gezählt, in $150 \mu \mathrm{l}$ FCS resuspendiert und mit 8-10 $\mu \mathrm{l}$ (abhängig von der Aktivität der verwendeten Charge) des radioaktiven Chroms $\mathrm{Na}_{2}{ }^{51} \mathrm{CrO}_{4}$ inkubiert. Dabei bedurfte es pro getesteter Killerzellsorte 240.000 Zielzellen.

Nach 90 min wurden die Zellen dreimal in $10 \mathrm{ml}$ Hepes-gepuffertem DMEM-Medium für je $10 \mathrm{~min}$ bei $300 \mathrm{x}$ g zentrifugiert und der Überstand verworfen, um das freie Chrom zu entfernen. Die Zellen wurden nun in DMEM-Komplettmedium aufgenommen, sodass sich eine Konzentration von 100.000 Zellen / ml ergab.

Die Effektorzellen wurden in ihrem Medium resuspendiert und anschließend bei 300 x g 10 min zentrifugiert. Der Überstand wurde entfernt, die Zellen in DMEMKomplettmedium aufgenommen und gezählt.

Der weitere Testansatz ist für einen Test mit LAK-Zellen beschrieben. Pro Zielzellsorte

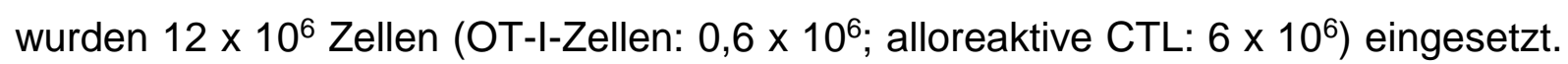
In eine 96-Loch-Mikrotiterplatte wurde pro Zielzellsorte in je drei Reihen $100 \mu$ I DMEMKomplettmedium vorgelegt. Die Effektorzellen wurden in $300 \mu \mathrm{l}$ Medium aufgenommen und je $100 \mu \mathrm{l}$ in jedes der drei Löcher des Tripletts pipettiert. Die Zellen wurden anschließend in diesem Volumen von nun $200 \mu$ resuspendiert. Daraufhin wurden $100 \mu \mathrm{l}$ dieses Gemisches - entsprechend der Hälfte der Zellen - in die zweite Reihe übertragen, gemischt, erneut $100 \mu \mathrm{l}$ in die dritte Reihe übertragen und entsprechend fortgefahren. Resultat dieses Verfahrens war eine Verdünnungsreihe, in der sich zuoberst etwa $2 \times 10^{6}$ Effektorzellen fanden, in der nächsten Reihe nur noch $1 \times 10^{6}$ Zellen/Loch usw. Um die spontane Chromfreisetzung (Spontanrelease) zu bestimmen, blieb die letzte Reihe frei von Effektorzellen.

Die Verdünnungsreihen alloreaktiver CTL sowie von CTL, die aus OT-I gewonnen wurden, wurden prinzipiell ähnlich hergestellt. Dennoch gab es einige Abweichungen, die zu beachten waren: bei alloreaktiven Zellen begann der Ansatz statt mit $2 \times 10^{6}$ mit $1 \times 10^{6}$ Zellen, bei CTL aus OT-I-Mäusen mit 100.000 Zellen. Ein weiterer wichtiger 
Unterschied des Testansatzes mit CTL aus OT-I-Mäusen war, dass die Verdünnungsreihe in $50 \mu$ statt $100 \mu$ durchgeführt wurde. Anschließend wurde zu dieser Verdünnungsreihe pro Loch $50 \mu \mathrm{l}$ DMEM-Komplettmedium mit 0,25 $\mu \mathrm{g} / \mathrm{ml}$ SIINFEKL gegeben, sodass wieder ein Gesamtvolumen von $100 \mu$ entstand. Zudem wurde eine Negativkontrolle angefertigt, die die Peptidspezifität zeigen sollte: ihr wurde kein SIINFEKL zugegeben. Als Nachweis, dass die Lyse über den kalziumabhängigen Granula-Exozytose-Weg vermittelt wurde, wurde zu einem Triplett zudem 2 mM EGTA und $4 \mathrm{mM} \mathrm{MgCl}_{2}$ gegeben.

Je $100 \mu \mathrm{l}$ des Mediums, in welchem die Zielzellen resuspendiert worden waren, wurden nun zu den Effektorzellen gegeben und für 3 min bei 20 x g zentrifugiert, um den Kontakt zwischen Ziel- und Effektorzellen zu gewährleisten. Anschließend erfolgte die Inkubation für 4 Stunden bei $37^{\circ} \mathrm{C}$ und $5 \% \mathrm{CO}_{2}$ in einer feuchten Kammer.

Nach Ablauf dieser Zeit wurden die Zellen wiederum für 3 min bei 20 x g zentrifugiert, um die Zellen und den Überstand, welcher das freigesetzte ${ }^{51}$ Chrom enthielt, zu trennen. Je $50 \mu$ des Überstands wurden abgenommen und in eine 96-Loch-WallacMessplatte pipettiert. Um die Radioaktivität des Überstandes in Relation zur Gesamtmenge des ${ }^{51}$ Chroms in den Zielzellen zu setzen, wurden die verbliebenen Zellen durch $5 \mu \mathrm{l}$ 10\%-Triton lysiert und $50 \mu \mathrm{l}$ des Sediments in eine zweite 96-LochWallac-Messplatte gegeben. Zur Messung der Radioaktivität wurde in jedes der Löcher der 96-Loch-Wallac-Messplatte $200 \mu$ Szintillatorflüssigkeit gegeben. Mittels einer Klebefolie wurden die Messplatten verschlossen und kurz auf einem Schüttler geschüttelt. Mittels eines Wallac-MicroBeta-Trilux-Zählers konnte die Radioaktivität anschließend gemessen werden, wobei die counts per minute (cpm) in jedem Loch der Messplatte ermittelt wurden. Die Lyse wurde anschließend mit folgender Formel berechnet:

[\%] Lyse $=(4$ x cpm Überstand x 100) / (3 x cpm Sediment + cpm Überstand $)$

Um die spezifische Lyse zu ermitteln, wurde von den Werten anschließend der Spontanrelease abgezogen. Dieser ergab sich aus der gemessenen Radioaktivität eines Tripletts, in welches nur Zielzellen, nicht jedoch Effektorzellen vorgelegt worden, entsprach also der Menge an Radioaktivität, die auch ohne Lyse durch Killerzellen aus den Zellen freigesetzt wurde. 


\subsubsection{Durchflusszytometrie}

\subsubsection{Allgemeines zur Durchflusszytometrie}

Mithilfe der Durchflusszytometrie können Zellen hinsichtlich der Expression verschiedener Oberflächenantigene verglichen werden. Hierzu werden die Zellen mit einem Antikörper inkubiert, welcher spezifisch an sein Antigen, z. B. einen Oberflächenrezeptor, bindet. Häufig sind diese Antikörper direkt fluoreszenzmarkiert, ist dies nicht der Fall, müssen die Zellen ein weiteres Mal mit einem fluoreszenzmarkierten Sekundär-Antikörper inkubiert werden, welcher in der Lage ist, an den Primärantikörper zu binden.

Zur Ermittlung unspezifischer Bindungen dient eine Isotypkontrolle, d.h., dass ein Teil der Zellen mit einem Antikörper gleichen Typs inkubiert wird, welcher sich jedoch gegen Strukturen richtet, die die Zellen nicht exprimieren. Bei der Auswertung wird die Messung der Fluoreszenz der Isotypkontrolle von der der untersuchten Zellen abgezogen.

Die Zellen werden einzeln in die Messkammer gesaugt und in einer Spülflüssigkeit an einem Laserstrahl geeigneter Wellenlänge vorbeigeleitet. Das Licht, welches die Akmarkierten Zellen durch Anregung der Fluorochrome dabei emittieren, ist proportional zur Menge der gebundenen Antikörper.

\subsubsection{Bestimmung verschiedener Oberflächenliganden mittels Durchflusszyto- metrie}

Parallel zu jedem Chromfreisetzungstest wurde die Expression der MHC-Klasse-IMoleküle und weiterer Oberflächenantigene auf den untersuchten Zellen gemessen. Ebenso konnte die Reinheit der Auftrennung von Zellpopulationen durch MACS überprüft werden.

Zunächst wurden je etwa $1 \times 10^{6}$ Zellen in FACS-Röhrchen überführt. Diese wurden mit PBS aufgefüllt und 10 min bei $300 \times \mathrm{g}$ zentrifugiert. Der Überstand wurde abgegossen und je $1 \mu \mathrm{g}$ des entsprechenden Antikörpers pro 1 Mio. Zielzellen (1:10 in PBS gelöst) zu den Zellen hinzugefügt. Die Zellen wurden für 30 min bei $4^{\circ} \mathrm{C}$ in Dunkelheit inkubiert. Die Röhrchen wurden erneut mit PBS aufgefüllt, für 10 min bei $300 \times \mathrm{g}$ zentrifugiert und der Überstand wurde wiederum abgegossen, sodass 
ungebundene Antikörper entfernt wurden. Waren die Antikörper direkt fluoreszenzmarkiert, konnten nun $200 \mu \mathrm{l}$ PBS hinzugefügt werden, die Fluoreszenzintensität im FACSCalibur, dem Durchflusszytometer, gemessen und mittels des Programmes Cell Quest Pro ausgewertet werden. Andernfalls schloss sich zuvor noch die Inkubation mit einem Sekundärantikörper (ebenfalls Zugabe von $1 \mu \mathrm{g}$, für $30 \mathrm{~min}$ bei $4^{\circ} \mathrm{C}$ in Dunkelheit inkubiert) und ein erneutes Waschen der Zellen an.

\subsubsection{Westernblot}

\subsubsection{Allgemeines zum Westernblot}

Mittels des Westernblots lassen sich Proteine in einem Zelllysat nachweisen.

Durch eine Gelelektrophorese werden die Proteine abhängig von ihrer Größe aufgetrennt und anschließend durch ein senkrecht zum Gel angelegtes elektrisches Feld auf eine Membran aus Nitrozellulose überführt. Diese wird mit einem spezifischen, gegen das nachzuweisende Protein gerichteten Antikörper inkubiert. Daraufhin erfolgt die Inkubation mit einem zweiten Antikörper, welcher gegen den Primärantikörper gerichtet ist und inn durch Oxidation eines Farbstoffes sichtbar machen kann.

\subsubsection{Herstellung von Zell-Lysaten}

$2 \times 10^{6}$ Zellen wurden in 1,5 ml PBS aufgenommen, in ein Eppendorf-Cup überführt und bei $300 \times \mathrm{g} 5 \mathrm{~min}$ zentrifuiert. Der Überstand wurde sorgfältig abpipettiert und das Zellpellet bei $-20^{\circ} \mathrm{C}$ eingefroren. Zu den Zellpellets wurde $30 \mu \mathrm{l}$ Probenpuffer gegeben. Dann wurden die Pellets 5 min auf $95^{\circ} \mathrm{C}$ erhitzt und im Anschluss 5 min bei $10.000 \mathrm{x}$ g zentrifugiert.

\subsubsection{SDS-Polyacrylamid-Gelelektrophorese}

Zwei Glasplatten $(19 \times 16,5 \mathrm{~cm}$ und $16 \times 16,5 \mathrm{~cm})$ wurden mit Isopropanol gereinigt, die Spacer an drei Seiten der größeren Platte befestigt und die kleinere Platte schließlich mithilfe von drei Klammern befestigt. In den Spalt zwischen den beiden Platten konnte nun bis $3 \mathrm{~cm}$ unter den Rand das Trenngel gegossen werden, welches 
sofort mit $1 \mathrm{ml}$ Isopropanol überschichtet wurde. Anschließend wurde das Trenngel etwa 1 Stunde ausgehärtet.

Das Isopropanol wurde mit destilliertem Wasser ausgespült, das Sammelgel über das Trenngel gegossen, ein Kamm mit Kammern in dieses gesteckt und 1 Stunde aushärten gelassen.

Klammern, Kamm und unterer Spacer wurden entfernt und das Gel an der Elektrophoreseapparatur befestigt. In obere und untere Kammer wurde SDSLaufpuffer gegeben. Eventuell entstandene Luftblasen wurden mithilfe einer Spritze entfernt. Die Kammern wurden nun mit einem Proteinmarker und je $30 \mu \mathrm{l}$ der Zelllysate befüllt. Der Proteinmarker diente als Längenstandard, da er eine Mischung von Proteinen bekannter Größe enthielt. Beim Befüllen der Kammern mit Zelllysaten war darauf zu achten, dass alle Proben doppelt aufgetragen wurden - einmal links, einmal rechts der Mittellinie.

Zunächst wurde eine Stromstärke von $20 \mathrm{~mA}$ angelegt, sobald die Proben das Trenngel jedoch erreicht hatten, wurde diese auf $40 \mathrm{~mA}$ erhöht. Nachdem die Proben am unteren Rand des Gels angekommen waren, wurde das Gel vorsichtig von der Platte gelöst und zugeschnitten.

\subsubsection{Westernblot}

Um die Proteine aus dem Gel zu lösen und auf die Nitrozellulose zu übertragen, wurde senkrecht zu beiden ein elektrisches Feld angelegt. Dabei lag das Gel auf der Nitrozellulose und unter sowie über beiden fand sich mit Blotpuffer angefeuchtetes Wathman-Filterpapier. Es wurde eine Spannung von $16 \mathrm{~V}$ angelegt. Nach 70 Minuten konnte die Nitrozellulose entnommen und in PBS/Tween 1 Stunde auf einem Schüttler gewaschen werden.

\subsubsection{Immunfärbung der transferierten Proteine}

Zur Anfärbung der Proteine wurde die Nitrozellulose in Ponceau-S-Lösung gegeben. Die Marker wurden angezeichnet und die Nitrozellulose längs der Mittellinie zerschnitten. Um die Ponceau-S-Lösung möglichst weitgehend vom Blot zu entfernen, wurde dieser $4 \times$ für je $5 \mathrm{~min}$ in PBS/Tween auf einem Schüttler gewaschen. Zur Detektion unspezifischer Bindungen durch den Sekundärantikörper, wurde eine Hälfte der Nitrozellulose nur mit dem sekundären Antikörper inkubiert. Diese Hälfte blieb 
daher zunächst in PBS/Tween. Die andere Hälfte wurde währenddessen in $5 \mathrm{ml}$ PBS/Tween mit $10 \mu \mathrm{l}$ des Primärantikörper (Anti-Cathepsin-B bzw. Anti-SPI9) und $5 \mu \mathrm{l}$ Anti-HSC70 auf einem Schüttler inkubiert. HSC70 ist ein ubiquitär vorhandenes Hitzeschockprotein, das als Ladekontrolle diente.

Nach 2 Stunden wurde die Nitrozellulose 4 x für 5 min mit PBS/Tween gewaschen. Für die Inkubation mit dem sekundären Antikörper wurden beide Hälften der Nitrozellulose für $90 \mathrm{~min}$ in einer Schale mit $10 \mathrm{ml}$ PBS/Tween und $2 \mu \mathrm{l}$ des entsprechenden Sekundärantikörpers auf einem Schüttler inkubiert. Danach wurde sie 4 x für 5 min in PBS/Tween gewaschen. Anschließend wurde die Nitrozellulose kurz in einen Ansatz mit $50 \mathrm{mg}$ DAB, $50 \mathrm{ml}$ PBS/Tween und $25 \mu \mathrm{l} \mathrm{H}_{2} \mathrm{O}_{2}$ getaucht. Die an den Sekundärantikörper gebundene Peroxidase oxidiert $\mathrm{H}_{2} \mathrm{O}_{2}$ zu Wasser und einem Sauerstoffradikal, welches wiederum DAB zu einem braunen Farbstoff oxidiert, der auf der Nitrozellulose niederschlägt und die Proteinbanden so sichtbar macht.

\subsubsection{Quantitative Echtzeit-PCR}

\subsubsection{Allgemeines zur quantitativen Echtzeit-PCR (real-time-PCR, rtPCR)}

Die quantitative Echtzeit-PCR beruht auf dem Prinzip der herkömmlichen PolymeraseKettenreaktion (PCR), erlaubt aber im Unterschied zu dieser auch die Quantifizierung der gewonnenen Produkte.

Die quantitative Echtzeit-PCR kann in verschiedenen Bereichen zum Einsatz kommen. In den vorliegenden Experimenten wurde mRNA aus den untersuchten Zellen gewonnen, diese zu cDNA umgeschrieben und anschließend mithilfe spezifischer Primer verschiedene Sequenzen amplifiziert. Vor der Amplifikation wurde Sybr-Green hinzugegeben. Sybr-Green interkaliert in dsDNA und bildet dabei einen fluoreszierenden Farbstoff. Die gemessene Fluoreszenz ist somit direkt proportional zur Menge der gebildeten DNA.

Es ist bekannt, dass einige Gene, sogenannte Haushaltsgene, eine vergleichsweise konstante Expression zeigen. Bei der quantitativen Echtzeit-PCR kann man diese als Vergleichswert hinzuziehen. Dabei wird die Fluoreszenz der Probe der untersuchten Sequenz mit der eines Haushaltsgens unter den gleichen Bedingungen verglichen. $\mathrm{Zu}$ beachten ist hierbei, dass die Proben während eines Zykluses verglichen werden, in denen bei beiden die Fluoreszenz exponentiell ansteigt, die Bedingungen also optimal 
sind. Hierzu wird ein Schwellenwert (threshold) definiert. Der Punkt, an welchem die Fluoreszenz diesen überschreitet wird $\mathrm{Ct}$ (threshold cycle) genannt.

\subsubsection{Erstellen von Primern}

Die Primer wurden mithilfe von Datenbanken der Internetseiten http://www.ncbi.nlm.nih.gov und http://eu.idtdna.com erstellt und mithilfe des Programmes GENtle Version 1.9.4 überarbeitet. Mittels PCR und rtPCR wurden die Primer ob ihrer Spezifität und Genauigkeit überprüft.

\subsubsection{Isolierung und Aufreinigung von RNA}

Etwa $1 \times 10^{7}$ Zellen wurden in $30 \mu \mathrm{l}$ PBS gesammelt und $360 \mu \mathrm{l}$ TRIzol hinzupipettiert. TRIzol enthält Guanidiniumthiocyanat, welches Zellen lysiert und Enzyme inaktiviert. Die Suspension wurde $5 \mathrm{~min}$ bei Raumtemperatur inkubiert und anschließend bei $4^{\circ} \mathrm{C}$ und $15000 \mathrm{U} / \mathrm{min}$ für $10 \mathrm{~min}$ zentrifugiert. Das Sediment mit größeren Zelltrümmern wurde verworfen und $72 \mu \mathrm{l}$ Chloroform zur Phasentrennung hinzugegeben. Es wurde $30 \mathrm{~s}$ gevortext und für $5 \mathrm{~min}$ wiederum bei $4^{\circ} \mathrm{C}$ und $15000 \mathrm{U} / \mathrm{min}$ zentrifugiert. Das Sediment wurde erneut verworfen und der Überstand zur Fällung von RNA und DNA in $200 \mu$ Isopropanol resuspendiert. Die Lösung wurde anschließend bei $-80^{\circ} \mathrm{C}$ für 15 min gefällt und im Folgenden bei $4^{\circ} \mathrm{C}$ für $30 \mathrm{~min}$ bei $15000 \mathrm{U} / \mathrm{min}$ zentrifugiert. RNA und DNA befanden sich nun im Sediment und der Überstand konnte verworfen werden. Das Sediment wurde mit 70\% Ethanol in RNAse-freiem Wasser gewaschen, 10 Minuten bei $15000 \mathrm{U} / \mathrm{min}$ zentrifugiert, der Überstand entfernt und das Pellet in 50 $\mu$ I RNAse freiem Wasser gelöst.

Um Reste von DNA zu entfernen, wurde dieses anschließend mit $5 \mu \mathrm{l} 1 \mathrm{M}$ Tris- $\mathrm{HCl}$ (pH 7.5), $1 \mu \mathrm{l} 1 \mathrm{M} \mathrm{MgCl}_{2}, 1 \mu \mathrm{l}$ DNAse $(10 \mathrm{U} \mu \mathrm{l}), 0,5 \mu \mathrm{l}$ RNAse Inhibitor $(40 \mathrm{U} / \mu \mathrm{l})$ und $42,5 \mu \mathrm{l}$ RNAse-freiem Wasser für $20 \mathrm{~min}$ in einem $37^{\circ} \mathrm{C}$ warmen Wasserbad inkubiert. Nun folgte die Aufreinigung. Zu der Suspension wurden $100 \mu \mathrm{l}$ Phenol, Chloroform und Isoamyl-alkohol im Verhältnis 25:24:1 gegeben und kurz gevortext. Anschließend wurde bei Raumtemperatur für 2 min bei $15000 \mathrm{U} / \mathrm{min}$ zentrifugiert, die oberste Phase in ein weiteres Eppendorf-Cup überführt und zu diesem $150 \mu$ l Isopropanol und $15 \mu \mathrm{l}$ $3 \mathrm{M}$ Natriumacetat pipettiert. Daraufhin wurde bei $-80^{\circ} \mathrm{C}$ für 15 min präzipitiert, kurz gevortext und für $15 \mathrm{~min}$ bei $4^{\circ} \mathrm{C}$ und $15000 \mathrm{U} / \mathrm{min}$ zentrifugiert. Die Flüssigkeit wurde entfernt, das Pellet in $1 \mathrm{ml}$ Ethanol (70\%) gewaschen und bei Raumtemperatur und 
maximaler Geschwindigkeit zentrifugiert. Die vorangehenden zwei Schritte wurden zweimal wiederholt. Das Pellet wurde anschließend in $20 \mu \mathrm{l}$ RNAse-freiem Wasser resuspendiert und bei $42^{\circ} \mathrm{C}$ für in ein Wasserbad gestellt.

Um die Güte der Isolierung, sowie das Gelingen der Aufreinigung und die Menge der gewonnenen RNA zu überprüfen, wurde $1 \mu \mathrm{l}$ der Probe mithilfe eines Spektrophotometers analysiert. Hierzu wurde der Quotient der Absorption der Probe bei 260 und $280 \mathrm{~nm}$ herangezogen. Lag dieser bei $\mathrm{A} 280 / \mathrm{A} 260 \approx 2,0$, so konnte davon ausgegangen werden, dass die Probe weitgehend reine RNA enthielt.

\subsubsection{Synthese von cDNA}

Zu $2 \mu \mathrm{g}$ der isolierten RNA wurden $2 \mu$ Zufallsprimer (random primers) gegeben und auf ein Volumen von $15 \mu \mathrm{l}$ mit RNAse-freiem Wasser aufgefüllt. In einem Wasserbad wurde das Gemisch für 10 min bei $70^{\circ} \mathrm{C}$ inkubiert, sodass die Sekundärstruktur zerfiel und sich die Primer anlagern konnten. Anschließend wurden $5 \mu \mathrm{l}$ M-MLV 5x Reaktionspuffer, $2 \mu \mathrm{l}$ dNTP-Mix (10 mM), $1 \mu \mathrm{I}$ DTT $(0,1 \mathrm{M}), 1 \mu \mathrm{l}$ RNAse Inhibitor $(40 \mathrm{U} / \mu \mathrm{l})$ und $1 \mu \mathrm{l}$ M-MLV reverse Transkriptase hinzupipettiert und die Suspension für $60 \mathrm{~min}$ bei $37^{\circ} \mathrm{C}$ inkubiert. Danach konnte mit der quantitativen Echtzeit-PCR fortgefahren oder die Suspension bei $-20^{\circ} \mathrm{C}$ gelagert werden.

\subsubsection{Durchführung der quantitativen Echtzeit-PCR}

Pro Testansatz wurden je drei identische Proben auf eine 96-well-Platte aufgetragen. Diese enthielten 12,5 $\mu \mathrm{l}$ Sybr-Green-Lösung, je $1 \mu \mathrm{l}$ des forward- und des reversePrimers $(5 \mathrm{pmol} / \mu \mathrm{l}) 4 \mu \mathrm{l}$ cDNA (1:50 mit RNAse-freiem Wasser verdünnt) und 6,5 $\mu \mathrm{l}$ RNAse-freies Wasser.

Der Ansatz wurde mithilfe eines 7500 Real Time PCR Systems durchgeführt und erfolgte über 40 Zyklen bei einer Annealingtemperatur von $62^{\circ} \mathrm{C}$. Die Auswertung der Daten erfolgte mithilfe von 7500 RT-Systems (Applied Biosystems).

Die mRNA-Menge wurde unter Verwendung der 2-sct-Formel bestimmt. Mit dieser ließen sich die relativen Änderungen der mRNA-Menge bezogen auf die Kontrolle darstellen. 


\section{Ergebnisse}

3.1 Auswirkungen von LAK-Zellen auf parthenogenetische Stammzellen

3.1.1 Lysierbarkeit parthenogenetischer Stammzellen durch LAK-Zellen

Um das Ausmaß der Lyse parthenogenetischer Stammzellen durch LAK-Zellen zu bestimmen, wurde der ${ }^{51} \mathrm{Chrom}$-Freisetzungstest eingesetzt. Als Zielzellen wurden parthenogenetische Stammzellen der Linien $A 3\left(H 2^{d}\right)$ und $A 6\left(H 2^{b / d}\right)$ sowie zum Vergleich YAC-1-Zellen $\left(\mathrm{H}^{\mathrm{q}}{ }^{\mathrm{q}}\right)$ eingesetzt, welche aufgrund ihrer niedrigen Expression von MHC-Klasse-I-Molekülen gut von LAK-Zellen lysiert werden.

Die LAK-Zellen wurden aus Milzen verschiedener Mauslinien gewonnen (s. Methodenteil). Es wurden Zellen der Stämme 129Sv (H2b), C57BL/6 (H2b), FVB $\left(H 2^{q}\right)$ und DBA $\left(H 2^{d}\right)$ eingesetzt, welche somit entweder beiden, einem oder keinem der Allele des MHC-Klasse-I-Lokus der Zielzellen entsprachen. Es wurde sowohl die spezifische Lyse, also der Mittelwert der absolut gemessenen Werte einer Triplettreihe abzüglich der Spontanfreisetzung von Chrom aus den Zielzellen, als auch die relative Lyse berechnet. Hierfür wurde jeweils die spezifische Lyse der Zielzellen auf die höchste spezifische Lyse der Kontrollzellen (YAC-1 bei einem Effektor- zu Zielzellverhältnis von 200:1) bezogen und prozentual dargestellt. Abb. 3.1 zeigt einen exemplarischen Test. 
A

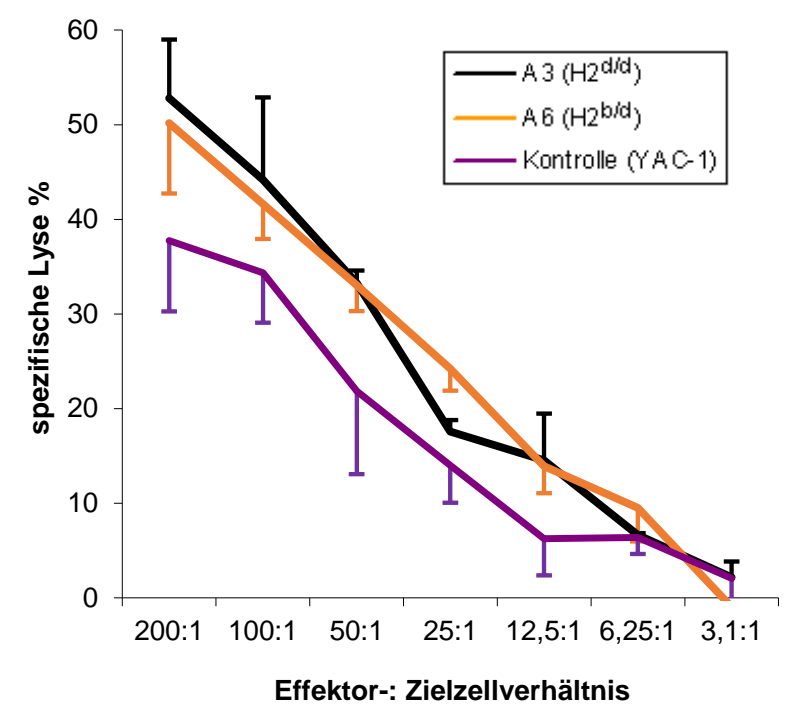

B

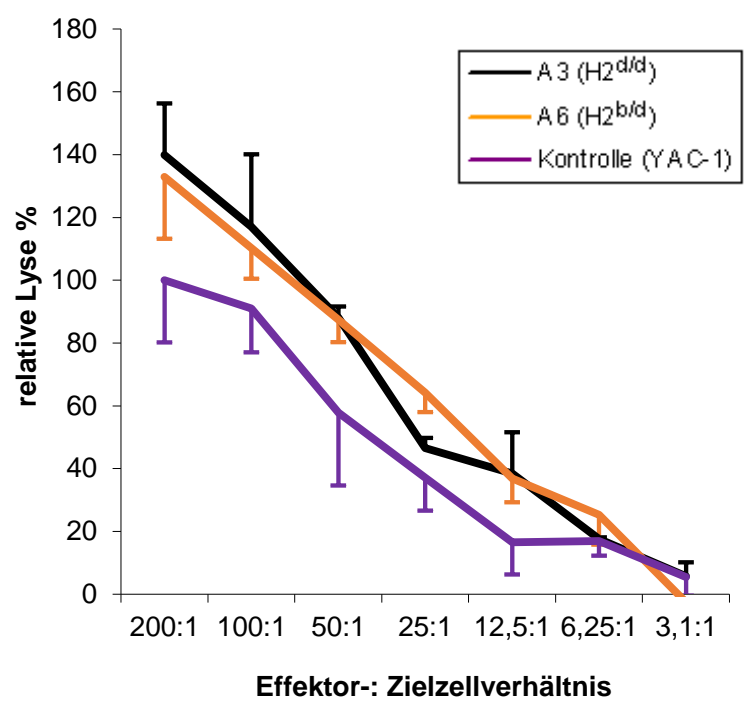

\section{Abb. 3.1 Exemplarischer Test}

Dargestellt sind die Ergebnisse eines ${ }^{51} \mathrm{Chrom}$-Freisetzungstests, bei welchem LAK-Zellen aus Milzen von 129Sv-Mäusen als Effektorzellen verwendet wurden. Als Zielzellen wurden A3-, A6- und YAC-1Zellen eingesetzt. Zur besseren Übersicht sind die Standardabweichungen jeweils nur nach oben oder unten angegeben.

A spezifische Lyse. Dargestellt ist die prozentuale Lyse der Zielzellen, bezogen auf die eingesetzte Gesamtzellzahl. Die mittlere spezifische Lyse berechnete sich aus den absolut gemessenen Werten in Tripletts mit gleichem Testansatz. Gezeigt ist zudem die Standardabweichung zwischen den einzelnen Rundlöchern der Tripletts.

B relative Lyse. Es wurde die spezifische Lyse der Zielzellen auf die höchste spezifische Lyse der Kontrollzellen (YAC-1 bei einem Effektor- zu Zielzellverhältnis von 200:1) bezogen und prozentual dargestellt.

Die Ergebnisse der ${ }^{51}$ Chrom-Freisetzungstests sind in den Abb. 3.2 zusammengefasst. In die Gesamtauswertung wurden hierbei Experimente eingebracht, welche eine spezifische Lyse von $>35 \%$ für die Kontrollzelllinie (YAC-1) bei einem Effektor- zu Zielzellverhältnis von 200:1 aufwiesen. Da davon auszugehen ist, dass die LAK-Zellen bei einer geringeren spezifischen Lyse nicht ausreichend stimuliert wurden, wurden Ergebnisse mit einer geringeren spezifischen Lyse der Kontrollzellen aus der Gesamtauswertung ausgeschlossen. 


\section{A $129 \mathrm{~Sv}\left(\mathrm{H} 2^{\mathrm{b} / \mathrm{d}}\right)$}

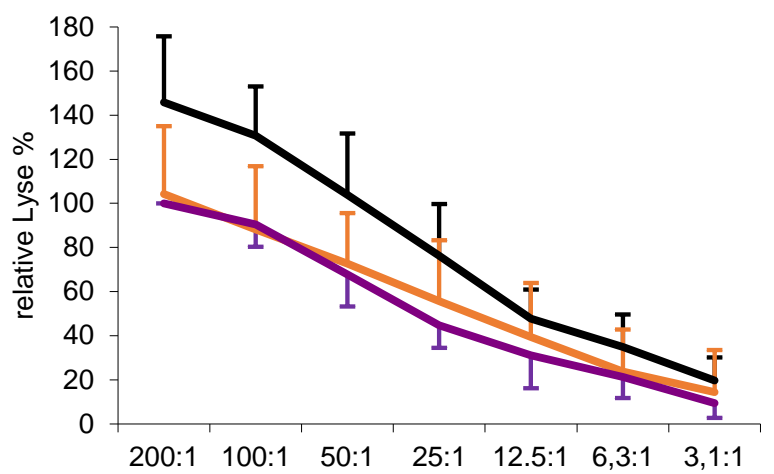

\section{DBA $\left(H 2^{d / d}\right)$}

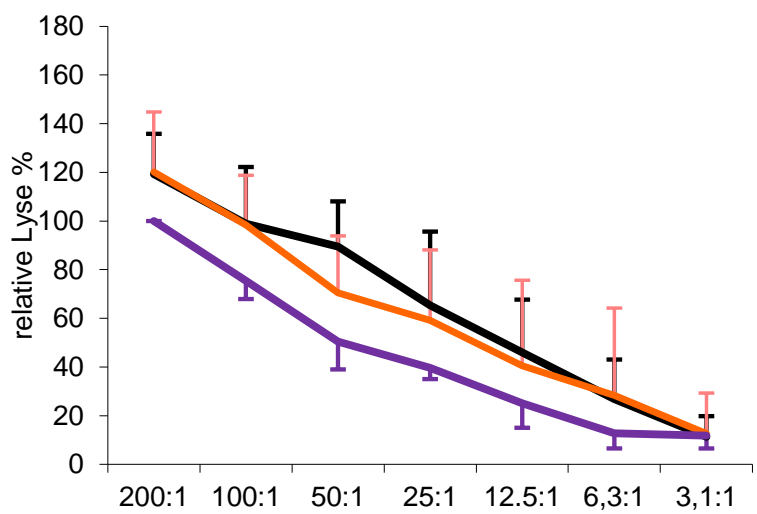

B C57BI/6 (H2 $\left.{ }^{\mathrm{b} / \mathrm{b}}\right)$

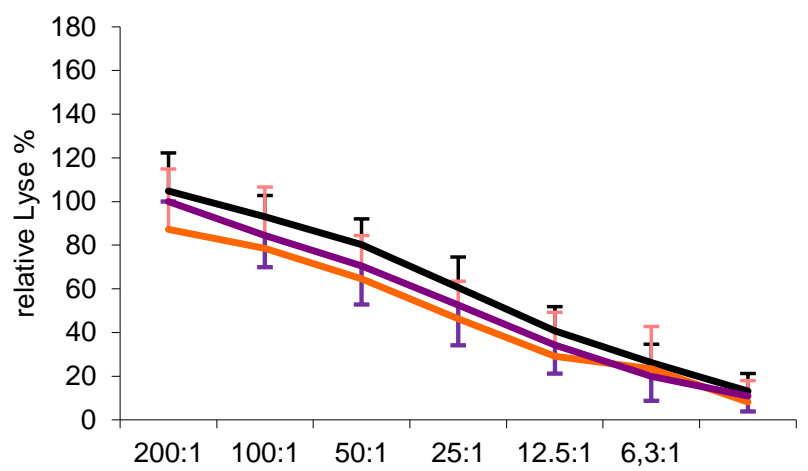

D FVB (H2/ ${ }^{q / q}$

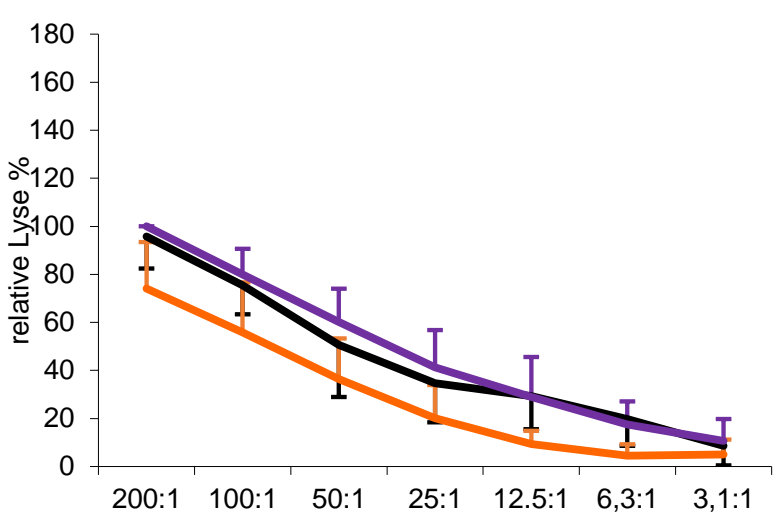

Effektor-: Zielzellverhältnis

\begin{tabular}{llll}
$-\mathrm{A} 3$ & $\mathrm{~A} 6 \quad$ Kontrolle (YAC-1) \\
\hline
\end{tabular}

Abb. 3.2 Gesamtauswertung ${ }^{51}$ Chrom-Freisetzungstests: LAK-Zellen und undifferenzierte PSC Die Überschrift der Diagramme zeigt die Herkunft der Effektorzellen an. Als Zielzellen wurden A3-, A6und YAC-1-Zellen eingesetzt. Dargestellt sind die Mittelwerte der relativen Lyse. Die Balken geben die Standardabweichung (SD) an.

A 129Sv. A3: $n=5 ; A 6: n=5$. Im Vergleich mit Effektorzellen anderer Stämme werden A3-Zellen stärker als Zellen der Linie A6 lysiert. Die spezifische Lyse lag bei einem Effektor- zu Zielzellverhältnis von 200:1 für A3 durchschnittlich bei 66,03\% (SD: 11,1), für A6 bei 48,28\% (SD: 9,89)

B C57BI/6. A3: $n=4 ; A 6: n=6$. Die spezifische Lyse lag für A3 durchschnittlich bei 48,82 \% (SD:18,38), für A6 bei $44,94 \%$ (SD:18,77)

C DBA. A3: $n=4 ; A 6: n=3$. Spezifische Lyse A3: 53,87 \% (SD: 12,26), A6: 53,37\% (SD:15,82)

D FVB. A3: $n=5 ; A 6: n=6$. Die geringste Lyse im Vergleich zu der Kontrollzelllinie zeigten sowohl A3als auch A6-Zellen, die durch LAK-Zellen aus FVB (H2/q) lysiert wurden. Die durchschnittliche spezifische Lyse lag für A3 bei 52,41 \% (SD: 10,26), für A6 bei 36,88 \% (SD: 13,12)

Auffallend ist die gute Lysierbarkeit der parthenogenetischen Stammzellen durch LAKZellen, welche - mit Ausnahme der aus FVB-Mäusen gewonnenen LAK-Zellen stärker als die Kontrollzellen (YAC-1) lysiert werden.

Um zu überprüfen, ob die Lyse der LAK-Zellen vornehmlich durch NK-Zellen vermittelt wurde, wurden NK-Zellen aus Milzen der Mausarten Balb/c $\left(H 2^{d / d}\right)$, DBA $\left(H 2^{d / d}\right)$ und C57/BI6 $\left(\mathrm{H}^{\mathrm{b} / \mathrm{b}}\right)$ angereichert und wie zuvor die LAK-Zellen im ${ }^{51}$ Chrom- 
Freisetzungstest eingesetzt (Abb. 3.3). Auch hier zeigte sich eine gute Lysierbarkeit der PSC. Es sei beachtet, dass das Effektor-: Zielzellverhältnis nur 1\% dessen der Experimente mit LAK-Zellen.
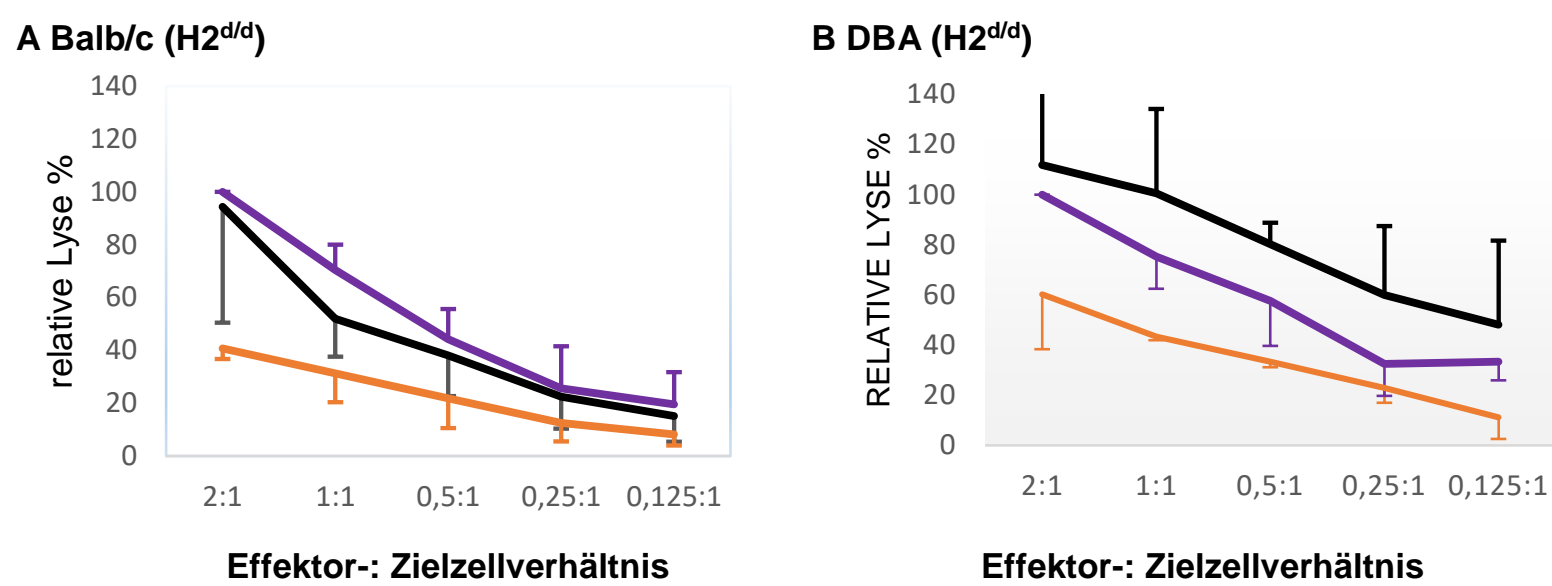

Effektor-: Zielzellverhältnis

\section{C57/BI6 $\left(\mathrm{H} 2^{\mathrm{b} / \mathrm{b}}\right)$}
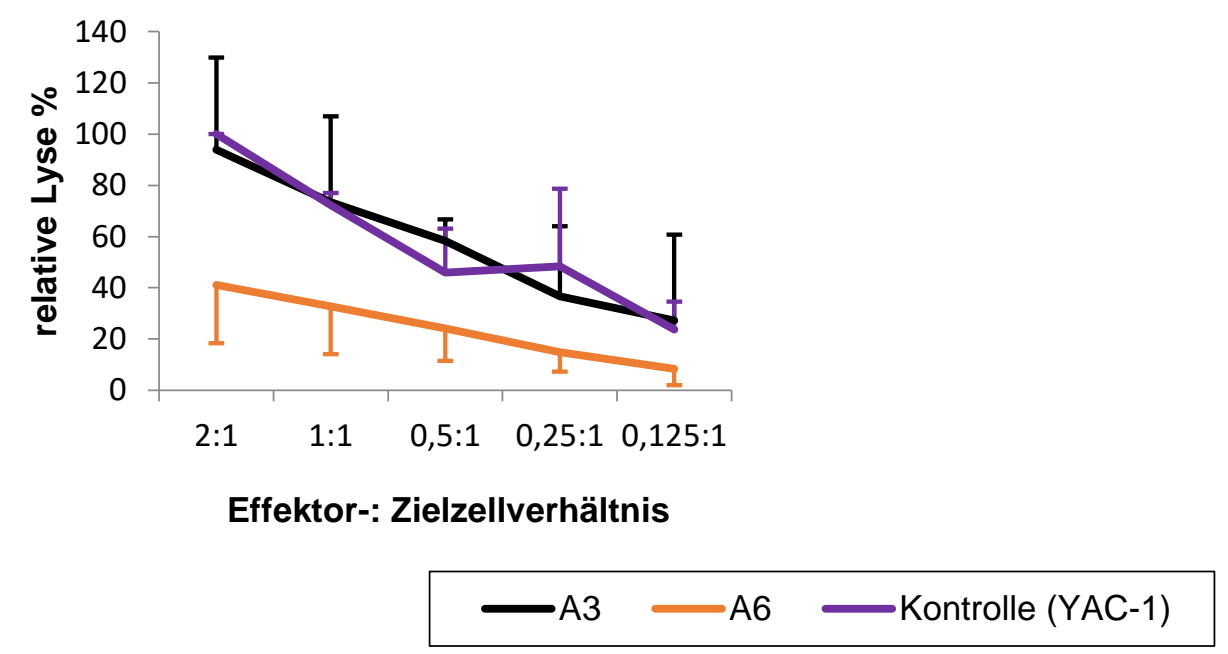

Abb. 3.3 Gesamtauswertung ${ }^{51}$ Chrom-Freisetzungstests: NK-Zellen und undifferenzierte PSC Die Überschrift der Diagramme zeigt die Herkunft der Effektorzellen an. Als Zielzellen wurden A3-, A6und YAC-1-Zellen eingesetzt. Die Balken geben die Standardabweichung (SD) an. Dargestellt ist die relative Lyse.

A Balb/c. A3: $n=3 ; A 6: n=3$. Die spezifische Lyse lag bei einem Effektor- zu Zielzellverhältnis von 200:1 für $\mathrm{A} 3$ durchschnittlich bei $35,6 \%$ (SD: 1,84), für $\mathrm{A6}$ bei $17 \%$ (SD: 7,2)

B DBA. A3: $n=3$; A6: $n=3$. Die spezifische Lyse lag für A3 durchschnittlich bei $71,8 \%(S D: 33,2)$, für A6 bei $36,8 \%(S D: 8,9)$

C C57/BI6 A3: $n=3 ; A 6: n=3$ Die spezifische Lyse lag für A3 durchschnittlich bei 58,7 \% (SD: 22,9), für A6 bei $26,6 \%$ (SD: 11,7 ) 


\subsubsection{Expression von MHC-Klasse-I-Molekülen auf parthenogenetischen}

Stammzellen in der Durchflusszytometrie

MHC-Klasse-I-Moleküle können die Lyse durch NK-Zellen inhibieren. Auf verschiedenen murinen Stammzelllinien konnte jedoch keine Expression von MHCKlasse-I-Molekülen in durchflusszytometrischen Messungen nachgewiesen werden, was die gute Lysierbarkeit von Stammzellen durch NK-Zellen mitbedingen könnte. Auch die parthenogenetischen Stammzellen der Linien A3 und A6 wurden mittels Durchflusszytometrie hinsichtlich einer Expression von MHC-Klasse-I-Molekülen überprüft. Abb. 3.4 zeigt exemplarisch eine Messung von $\mathrm{H}_{2} \mathrm{D}^{\mathrm{d}}$ - und $\mathrm{H} 2 \mathrm{~K}^{\mathrm{d}}$-Molekülen.

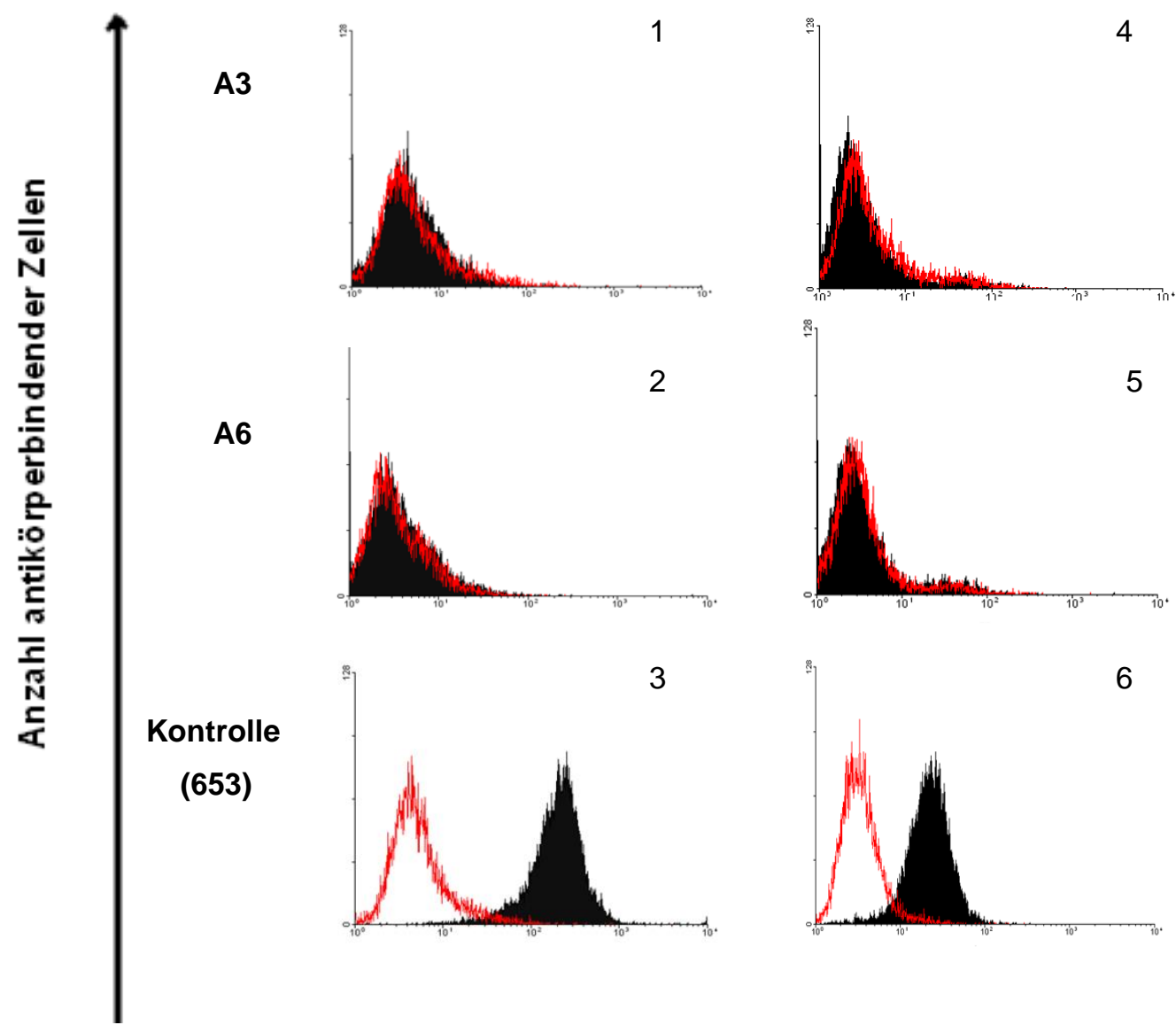

Mittlere Fluoreszenzintensität (MFI)

Abb. 3.4 Expression von MHC-Klasse-I-Molekülen auf parthenogenetischen Stammzellen: exemplarische Grafik einer durchflusszytometrischen Messung

Die Grafiken 1-3 zeigen die durchflusszytometrisch gemessene Expression von H2K ${ }^{d}$, die Grafiken 4-6 die Expression von $\mathrm{H}_{2} \mathrm{D}^{\mathrm{d}}$. Die Isotypkontrollen sind in Rot, die gemessenen antikörperbindenden Zellen in Schwarz dargestellt. 
Es konnte, wie bereits in Abb. 3.4 angedeutet, in der Durchflusszytometrie im Allgemeinen keine Expression von MHC-Klasse-I-Molekülen auf den parthenogenetischen Stammzellen nachgewiesen werden. Allerdings zeigten sich einzelne Messungen schwach positiv. Als Kontrolle für die Funktion der Antikörper wurden parallel MHC-Klasse-I-positive Zellen getestet (RMA-Zellen für $\mathrm{H}^{2} \mathrm{~K}^{\mathrm{b}}$ und $\mathrm{H} 2 \mathrm{D}^{\mathrm{b}}$, sowie 653-Zellen für $\mathrm{H}_{2} \mathrm{~K}^{\mathrm{d}}$ und $\mathrm{H}_{2} \mathrm{D}^{\mathrm{d}}$ ). Eine Zusammenfassung der einzelnen Messungen zeigt Abb. 3.5. 

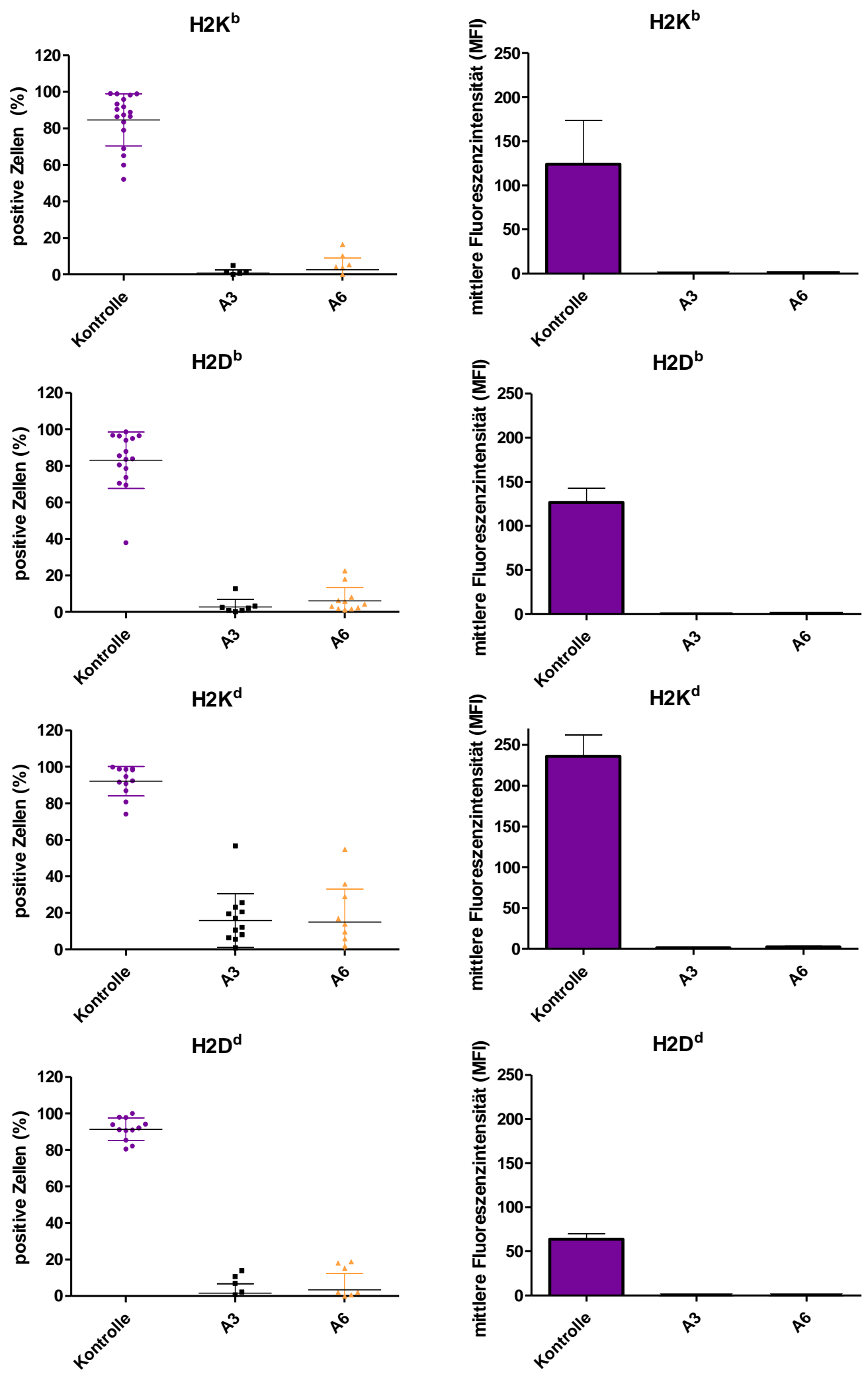

Abb. 3.5 MHC-Klasse-I-Expression auf PSC in der Durchflusszytometrie

Als Kontrolle fungierten Zellen, von welchen eine Expression der MHC-Klasse-I-Moleküle bekannt ist: für $\mathrm{H}_{2} \mathrm{~K}^{\mathrm{b}}$ und $\mathrm{H}_{2} \mathrm{D}^{\mathrm{b}}$ wurden RMA-Zellen, für $\mathrm{H}_{2} \mathrm{~K}^{\mathrm{d}}$ und $\mathrm{H} 2 \mathrm{D}^{\mathrm{d}}$ 653-Zellen eingesetzt. Auf der linken Seite dargestellt ist jeweils die mittlere Anzahl positiv gefärbter Zellen einschließlich der Standardabweichung (SD) der einzelnen Messungen. Rechts wird die mittere Fluoreszenzintensität der Messungen einschließlich der Abweichung vom Mittelwert (SEM) angegeben.

H2K : Kontrolle: $n=18, A 3: n=9, A 6: n=11 ; H 2 D^{b}:$ Kontrolle: $n=16, A 3: n=5, A 6: n=12$;

$\mathrm{H} 2 \mathrm{~K}^{\mathrm{d}}$ :

Kontrolle: $n=12$, A3: $n=13$, A6: $n=11$; H2D : Kontrolle: $n=14, A 3: n=14, A 6: n=12$ 


\subsubsection{Expression von MHC-Klasse-I-mRNA in der rtPCR}

Die Expression verschiedener Gene der parthenogenetischen Stammzellen wurde mittels rtPCR zudem auf Ebene der mRNA untersucht (Abb. 3.6).

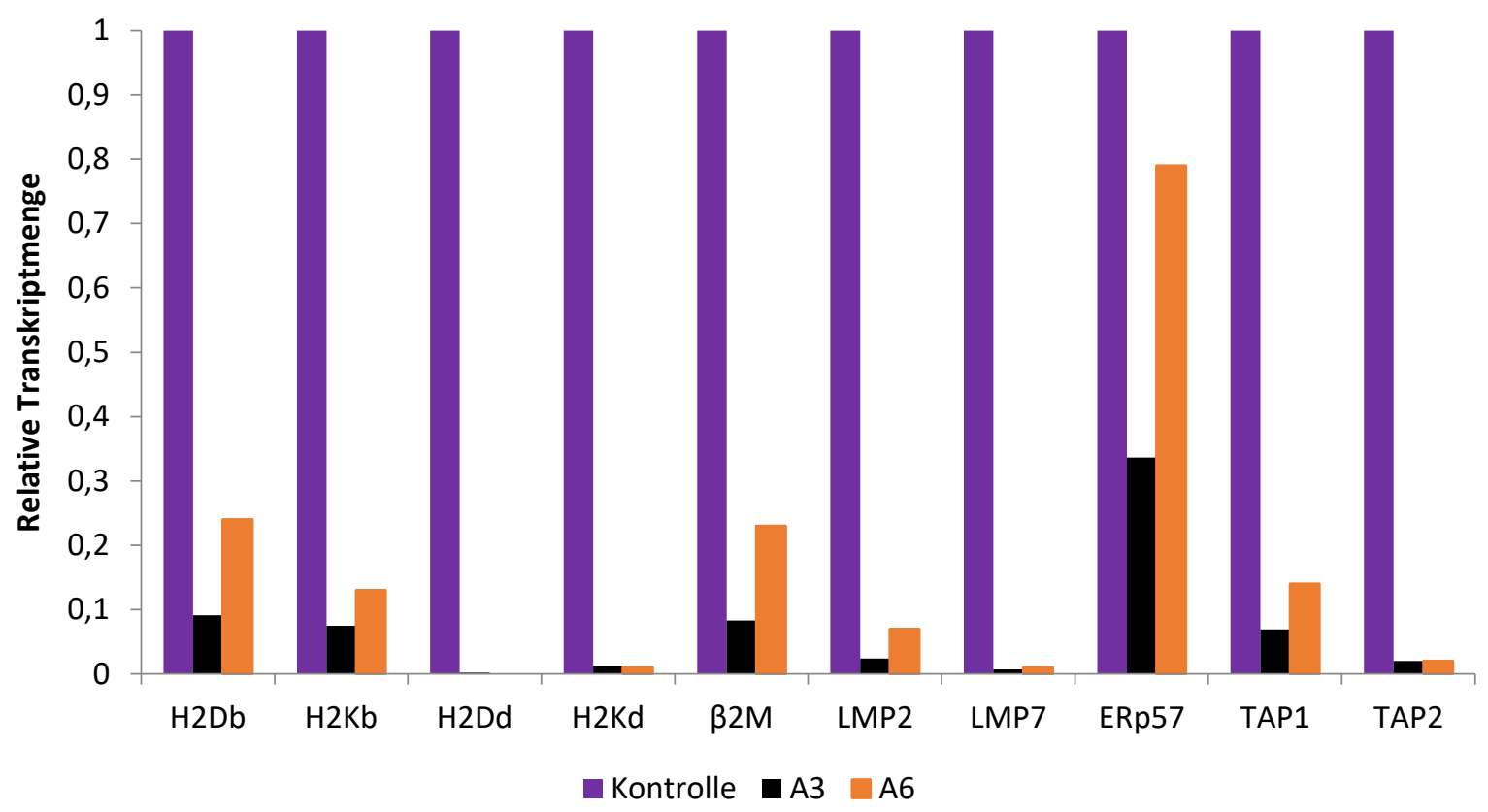

Abb. 3.6 Expression von mRNA des MHC-Klasse-I-Komplexes und assoziierter Proteine In der quantitativen rtPCR wurden die Zelllinien A3 und A6 auf die Expression von mRNA untersucht (Kontrollzelllinien für $\mathrm{H}_{2} \mathrm{~K}^{\mathrm{d}}$ und $\mathrm{H}_{2} \mathrm{D}^{\mathrm{d}}$ : Milzzellen aus DBA, für weitere dargestellte Ergebnisse: RMA). Die Berechnung der Daten erfolgte mithilfe der ${ }^{\triangle \Delta}$ CT-Methoden nach Pfaffl, die Werte sind als relative Transkriptionsmenge in Bezug auf die Kontrollzelllinien als $2^{-\Delta \Delta C T}$ dargestellt. Die Normalisierung erfolgte auf HPRT.

Im Vergleich mit den Kontrollzelllinen zeigten die untersuchten Stammzelllinien eine deutlich geringere Expression von mRNA der meisten analysierten Gene. So lag der relative Expressionsunterschied von MHC-Klasse-I-mRNA der PSC zu RMA- $\left(\mathrm{H} 2^{\mathrm{b}}\right)$ und DBA-Zellen $\left(\mathrm{H}^{\mathrm{d}}\right.$ ) bei durchschnittlich $0,2 \%$ nach Normalisierung auf HPRT. Auch mRNA der MHC-Klasse-I-Komplex assoziierten Moleküle wie den Subeinheiten des Proteasoms LMP2 und LMP7 oder dem Antigentransporter TAP wurde vergleichsweise wenig gebildet. 
3.1.4 Expression NK-Zell-aktivierender Liganden auf parthenogenetischen Stammzellen in der Durchflusszytometrie

Aufgrund der guten Lysierbarkeit der PSC durch LAK stellte sich die Frage, ob PSC NK-Zell-aktivierende Liganden exprimieren. Dies wurde sowohl durchflusszytometrisch wie auch mittels rtPCR untersucht. Die Ergebnisse fassen Abb. 3.7 und 3.8 zusammen.

Hierbei wurde die Bindung von rekombinantem DNAM-1 (CD226), einem aktivierenden Rezeptor auf NK-Zellen, an PSC sowie die Expression der beiden wichtigsten Liganden von DNAM-1, CD112 und CD155 auf PSC analysiert. Als Kontrolle dienten Zellen der Linie YAC-1 (vgl. Abb. 3.7).

Zum anderen wurde die Bindung eines rekominanten NK-Zell-Rezeptors NKG2D an die PSC-Linien untersucht. Auch die Expression der Liganden dieses Rezeptors, Rae1, Mult-1 und $\mathrm{H60}$, wurde überprüft (Abb. 3.8). 


\section{A Bindung an DNAM-1}

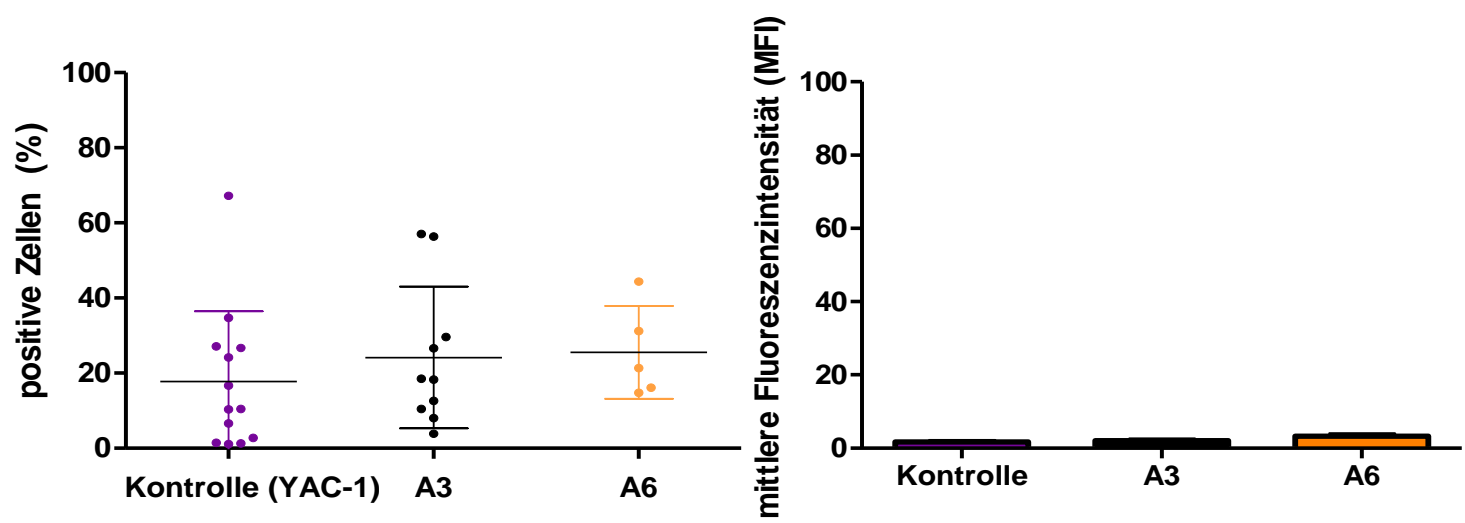

\section{B CD112}
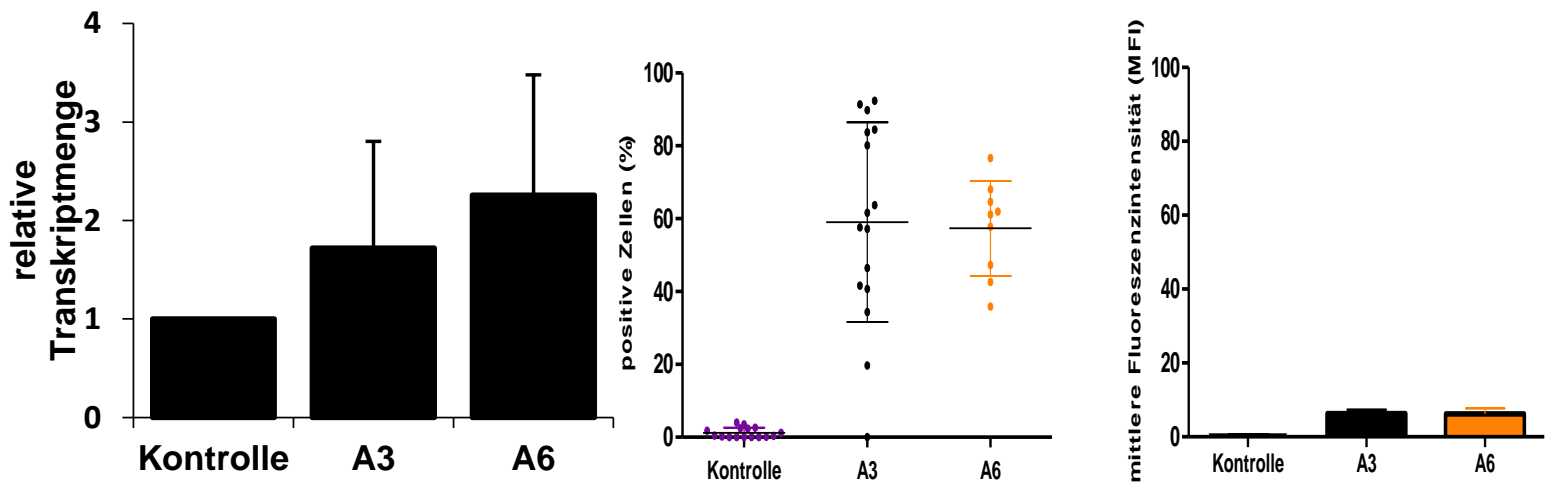

\section{CD155}
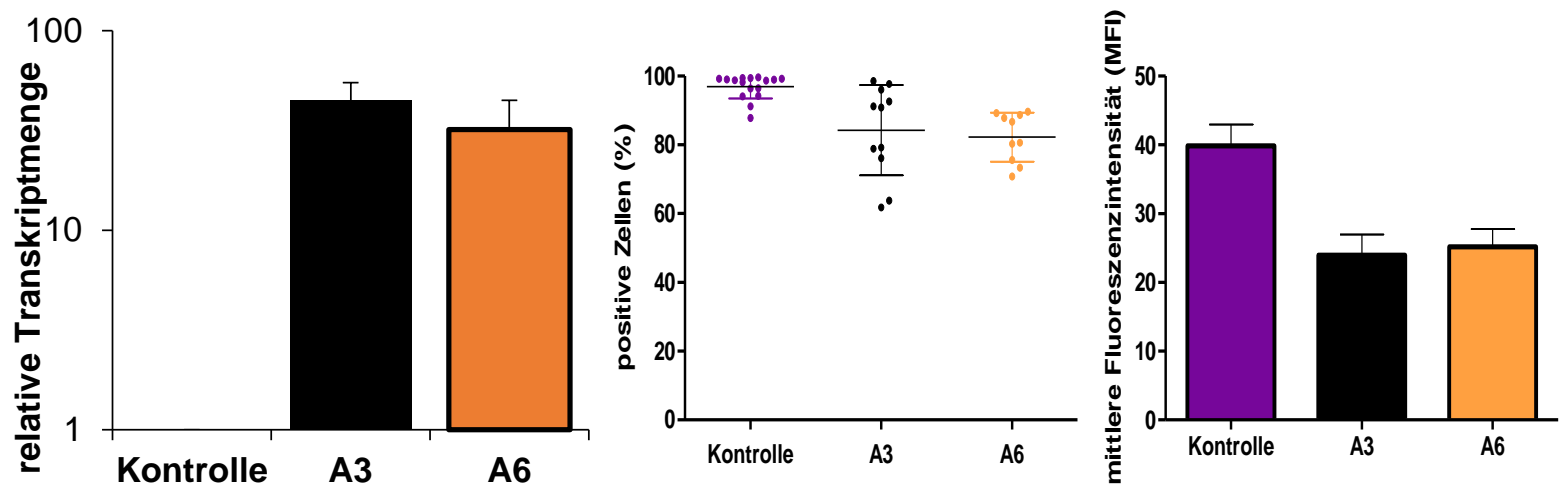

Abb. 3.7 Expression NK-Zell-aktivierender Liganden auf PSC: DNAM-1

A Bindung an DNAM-1 Kontrolle (YAC-1) $n=13, A 3 n=10, A 6 n=5$. Die Messung erfolgte nach Zugabe von FITC-gebundenen Sekundärantikörpern, die an zuvor zugegebenes, rekombinantes DNAM-1 banden. Dargestellt ist der prozentuale Anteil DNAM-1-bindender Zellen abzüglich der Werte des Sekundärantikörpers. Ein Punkt entspricht einer Messung, angegeben sind zudem der Mittelwert (MW) sowie die Standardabweichung (SD).

B CD112 Durchflusszytometrie: Kontrolle (YAC-1): $n=16$, A3 $n=16, A 6 n=9 ;$ rtPCR: $n=3$.

In der quantitativen rtPCR wurden die Zellinien $A 3$ und $A 6$ auf die Expression von mRNA zu CD112 untersucht. Die Berechnung der Daten der rtPCR erfolgte mithilfe der ${ }^{\triangle \triangle} \mathrm{CT}$-Methoden nach Pfaffl, die Werte sind als relative Transkriptionsmenge in Bezug auf die Kontrollzelllinien als $2^{-\Delta \Delta C T}$ dargestellt. Die Normalisierung erfolgte auf HPRT.

C CD155 Durchflusszytometrie: Kontrolle (YAC-1): $n=16, A 3 n=11, A 6 n=10 ;$ rtPCR: $n=3$.

Die Berechnung der Daten der rtPCR erfolgte wie in Abb. 3.6. Die Ergebnisse sind logarithmisch dargestellt. 
Während sowohl die Kontrollzellinie (YAC-1) als auch die PSC in den einzelnen durchflusszyometrischen Experimenten unterschiedlich stark an DNAM-1 banden, zeigten sich sich die PSC in den durchflusszytometrischen Messungen deutlich positiv für CD155 und in einzelnen Messungen positiv für CD112. Für beide Liganden zeigte sich, normalisiert auf HPRT, eine erhöhte Expression von mRNA im Vergleich zu YAC1-Zellen. 


\section{A Bindung an NKG2D}

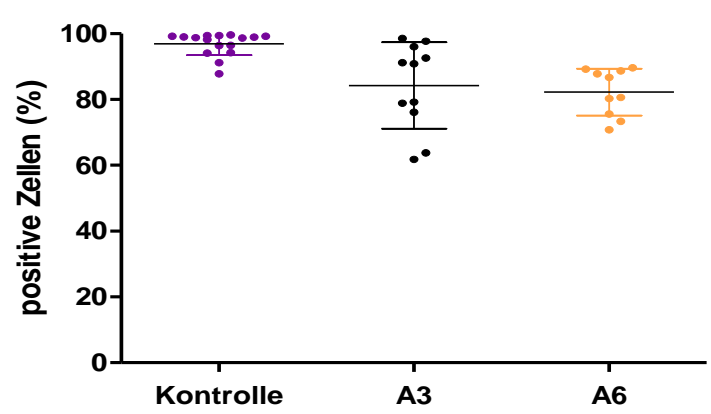

\section{B Liganden NKG2D}
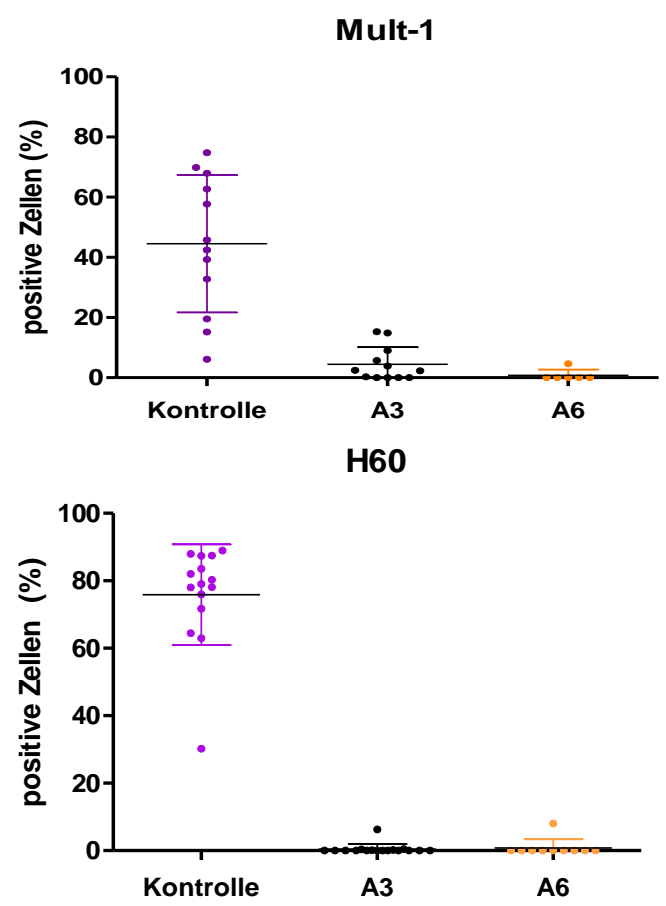
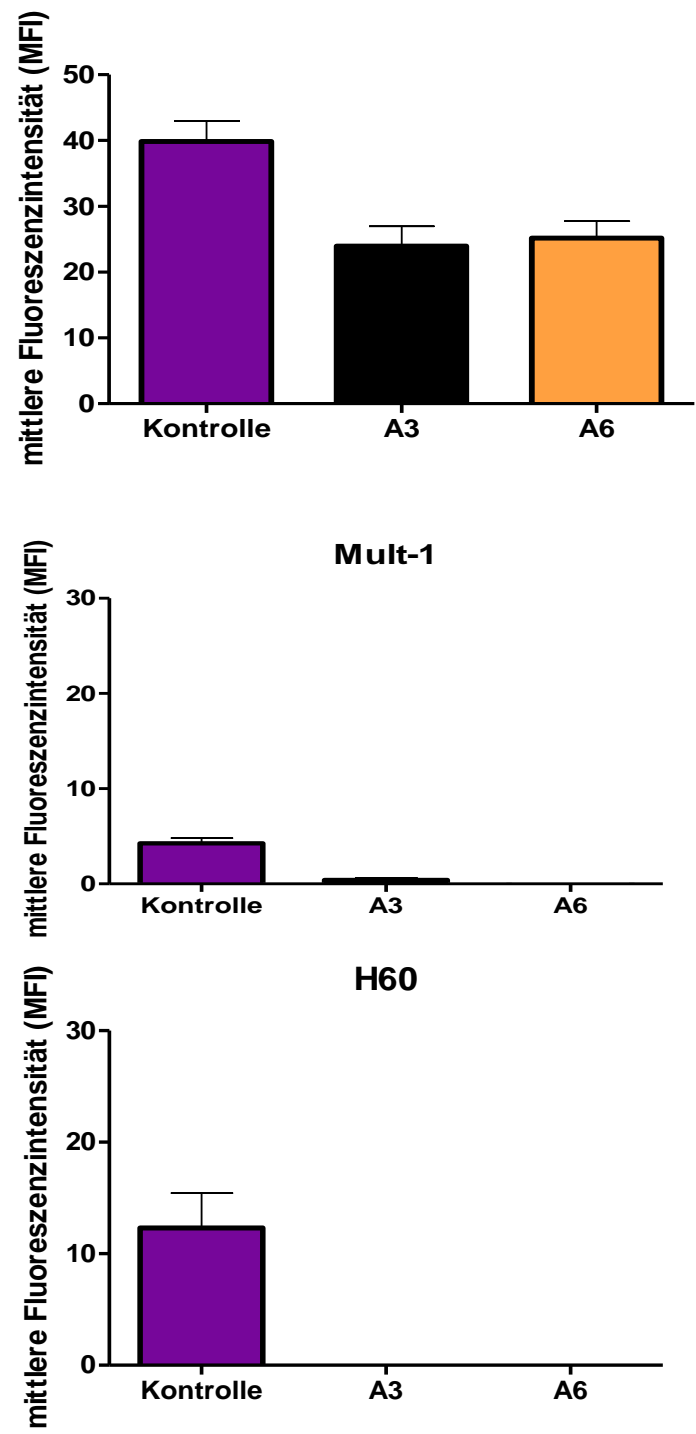

Rae-1

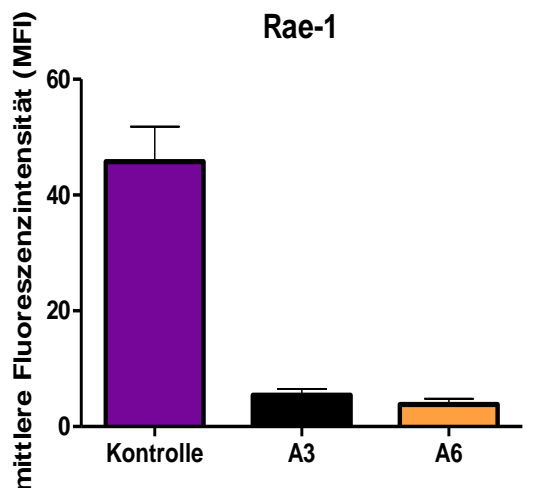

Abb. 3.8 Expression NK-Zell-aktivierender Liganden auf parthenogenetischen Stammzellen: NKG2D

A Bindung an NKG2D. Die Messung erfolgte nach Zugabe von FITC-gebundenen Sekundärantikörpern, die an zuvor zugegebenes rekombinantes NKG2D banden. Die Zusammenstellung der Ergebnisse erfolgte wie in Abb. 3.7. Kontrolle $n=12, A 3 n=10, A 6 n=6$

B Liganden von NKG2D. Durchflusszytometrie: Mult-1 Kontrolle $n=12$, A3 $n=12$, A6 $n=6$; H60 Kontrolle $n=15, A 3 n=15, A 6 n=10$; Rae-1 Kontrolle $n=17$, A3 $n=17, A 6 n=10$

rtPCR: $n=3$. Die Berechnung der Daten erfolgte mithilfe der ${ }^{\Delta \Delta}$ CT-Methode, die Werte sind als $2-\triangle \Delta C T$ dargestellt. Die Normalisierung erfolgte auf HPRT. 
Die PSC zeigten eine Interaktion mit rekombinanten NKG2D, einem der wichtigsten aktivierenden NK-Zell-Rezeptoren. Murine Zellen können H60, Mult1 und Rae-1 als Liganden von NKG2D exprimieren. Die PSC wurden daher auf die Expression dieser drei Liganden getestet und es konnte eine Expression von Rae-1, jedoch keine wesentliche Expression von $\mathrm{H} 60$ oder Mult1 in der Durchflusszytometrie gezeigt werden (vgl. Abb. 3.8 B).

In der rtPCR zeigte sich, dass die Linien A3 und A6 mehr mRNA von Rae-1 als die Kontrollzellen (YAC-1) exprimierten.

Die Zellen wurden weiterhin auf eine Interaktion mit 2B4 und NKp46, zwei aktivierenden NK-Zell-Rezeptoren, untersucht. Diese ließen sich jedoch nicht nachweisen. Auch konnte keine Expression von CD48, welches über eine Interaktion mit 2B4 die NK-Zell-Antwort beeinflusst, auf den parthenogenetischen Linien gezeigt werden.

3.2 Auswirkungen Peptid-spezifischer CTL auf parthenogenetische Stammzellen

\subsubsection{Lyse parthenogenetischer Stammzellen durch CTL aus OT-I-Mäusen}

Zur Bestimmung der Lyse der PSC durch CTL aus OT-I-Mäusen wurde der ${ }^{51} \mathrm{Chrom-}$ Freisetzungstest eingesetzt. OT-I-Mäuse sind transgen für einen Rezeptor, welcher auf $\mathrm{H}_{2} \mathrm{~K}^{\mathrm{b}}$ präsentiertes SIINFEKL erkennt. Als Kontrollzellen dienten RMA-Zellen, von denen eine gute Lysierbarkeit durch CTL aus OT-I-Mäusen bekannt ist. Die Experimente beinhalteten zudem eine Negativkontrolle, welcher kein SIINFEKL zugegeben wurde und somit die Peptidspezifität sichern sollte. Als Nachweis, dass die Lyse über den Granula-Exozytose-Weg vermittelt und somit kalziumabhängig war, wurde zu einem Triplett zudem ein $\mathrm{Ca}^{2+-}$ Chelator, EDTA, gegeben (s. Abb 3.9). 
A

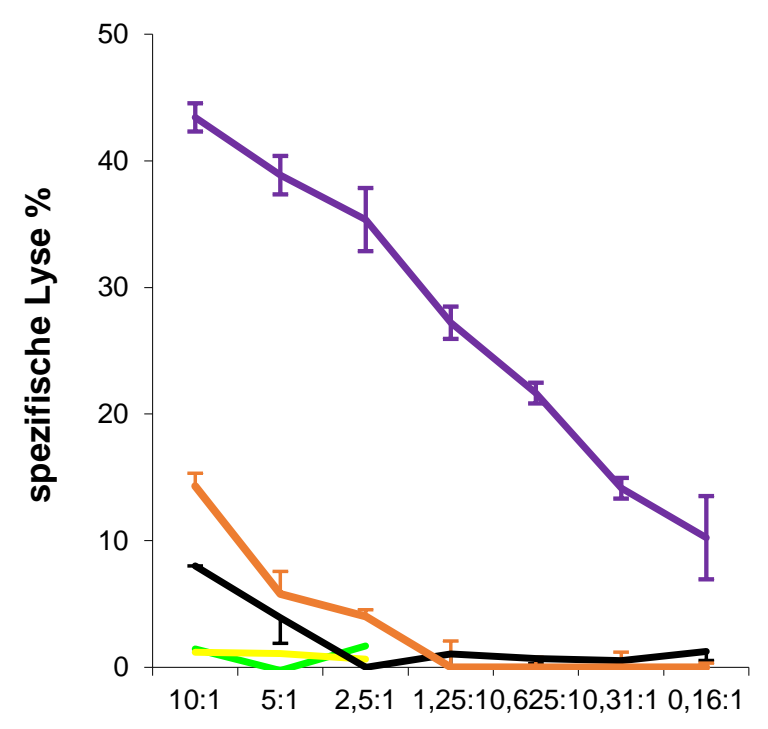

B

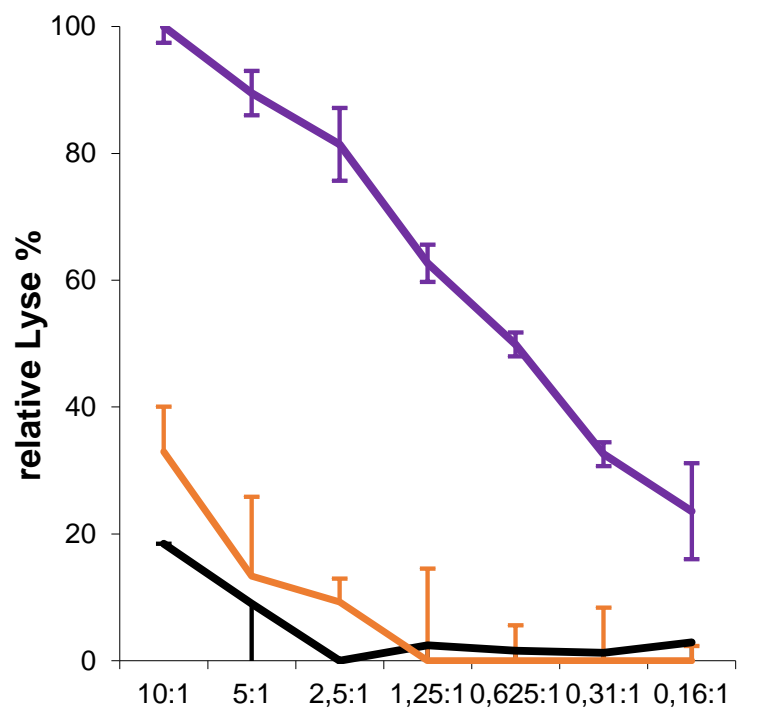

Abb. 3.9 Exemplarischer ${ }^{51}$ Chrom-Freisetzungstest

A spezifische Lyse. Exemplarisch ist ein Experiment dargestellt. Die Kontrollen zeigen die Peptidspezifität (Negativkontrolle I: RMA + SIINFEKL) sowie eine Abhängigkeit der Lyse von Kalzium (Negativkontrolle II: RMA + SIINFEKL + EGTA). Sowohl der Positivkontrolle, als auch den Messungen mit A3- und A6-Zellen wurde SIINFEKL hinzugefügt. Dargestellt sind die Mittelwerte (MW) der einzelnen Messungen. Die Balken geben die jeweilige Standardabweichung (SD) der Tripletts an.

$B$ relative Lyse. Die Abbildung zeigt dasselbe Experiment wie Abb. 3.9A, dargestellt ist hier jedoch die relative Lyse in Bezug auf die Positivkontrolle. Diese Darstellung macht eine bessere Vergleichbarkeit der Testreihen untereinander möglich.

Die Ergebnisse der Experimente sind in Abb. 3.10 zusammengefasst. Dargestellt ist zum einen die spezifische, zum anderen die relative Lyse, bezogen auf die Kontrollzellen (RMA). Die Berechnung der relativen Lyse erfolgte dabei ähnlich wie zuvor bei den ${ }^{51}$ Chrom-Freisetzungstests, zu welchen LAK-Zellen als Effektorzellen eingesetzt worden waren: bei einem Effektor- zu Zielzellverhältnis von 10:1 wurde die Lyse der Kontrollzelllinie als 100\% festgesetzt und die Lyse der Zielzelllinien in Relation gesetzt. 
A

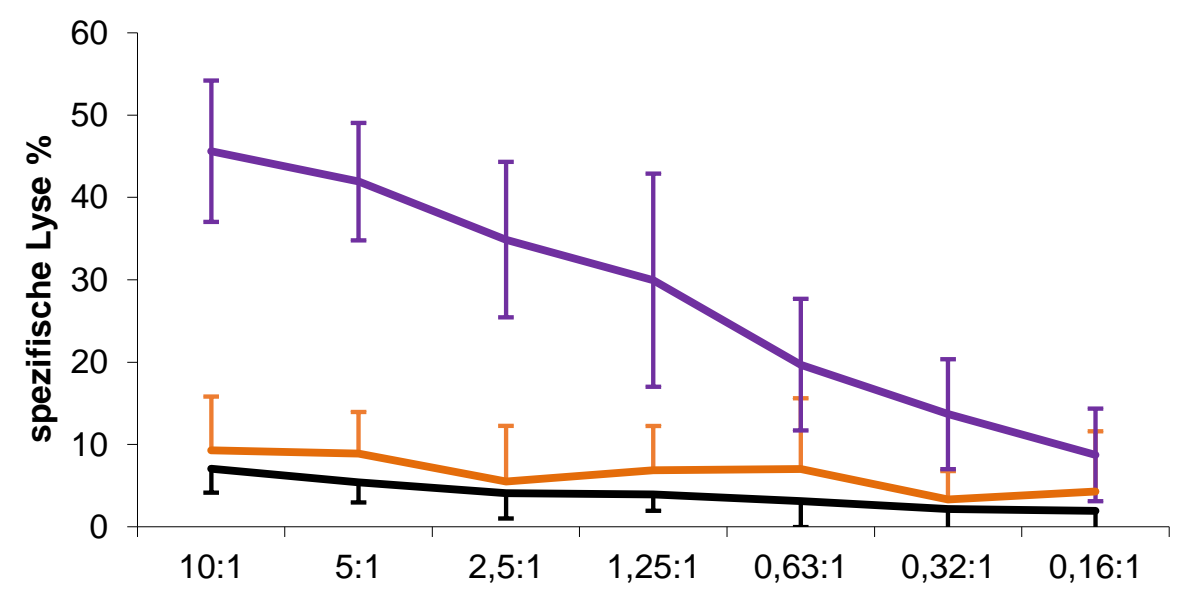

Effektor-: Zielzellverhältnis

B
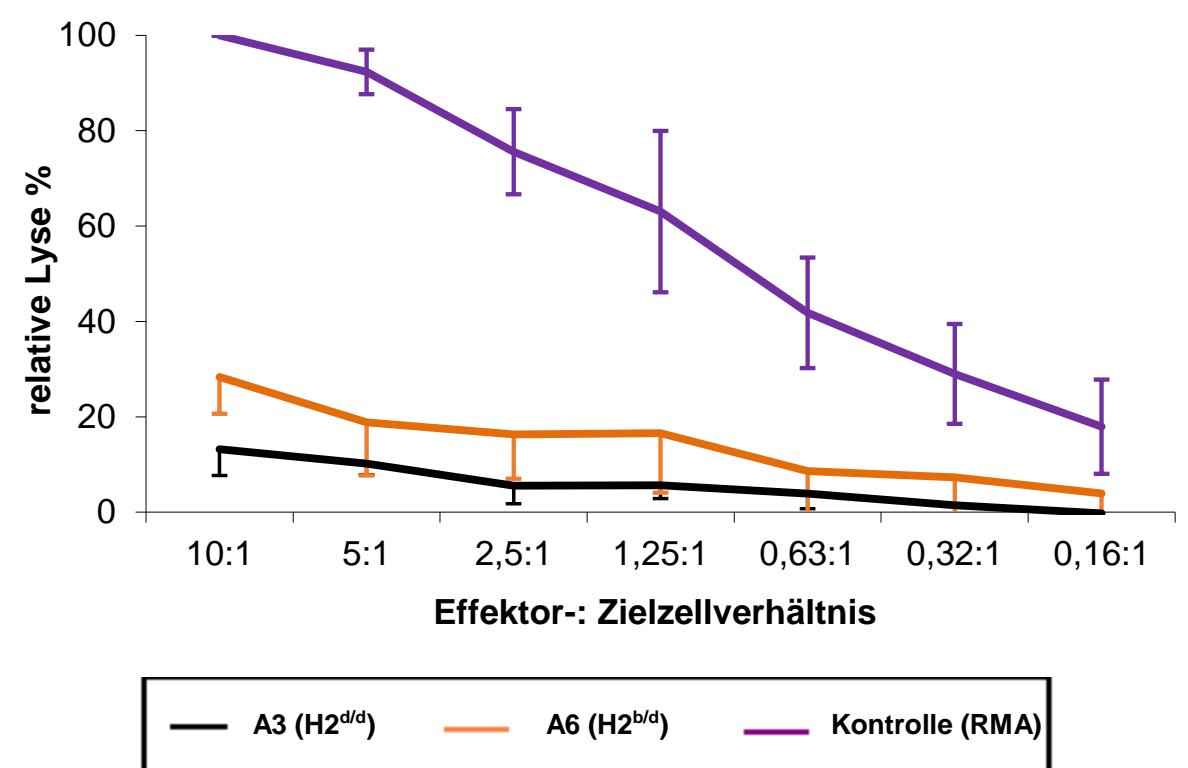

Abb. 3.10 Lyse von PSC durch CTL aus OT-I-Mäusen

A spezifische Lyse. Die Abbildung zeigt die Mittelwerte der spezifischen Lyse der durchgeführten Experimente. Zusätzlich angegeben ist die Standardabweichung. Kontrolle: $n=6, A 3: n=4, A 6: n=4$ $B$ relative Lyse. Um eine Vergleichbarkeit der Tests untereinander zu gewährleisten, wurde die relative Lyse der Zielzellen in Bezug auf die Kontrollzellen (RMA) berechnet. Hierbei wurde der Wert der spezifischen Lyse von RMA-Zellen des höchsten Effektor-: Zielzellverhältnises von 10:1 100\% gleichgesetzt.

Die homologen PSC (A3), welche aufgrund ihres Hintergrundes $\left(\mathrm{H} 2^{d / d}\right)$ kein $\mathrm{H}_{2} \mathrm{~K}^{\mathrm{b}}$ exprimieren und somit von peptidspezifischen CTL aus OT-I-Mäusen nicht erkannt werden, wurden nicht lysiert. Allerdings zeigten auch die heterologen PSC $\left(\mathrm{A} 6: \mathrm{H} 2^{\mathrm{b} / \mathrm{d}}\right)$ im Vergleich zur Kontrolle (RMA) nur eine geringe Lysierbarkeit. Dies warf die Frage auf, ob sich PSC gegen Lyse durch CTL zu schützen vermögen und ob die niedrige 
Lyse beispielsweise durch die geringe Expression von MHC-Klasse-I-Molekülen zu erklären sei.

\subsubsection{Lyse parthenogenetischer Stammzellen durch OT-I-Zellen nach Behandlung mit Interferon- $\gamma$}

Es ist bekannt, dass Interferon-y die Expression von MHC-Klasse-I-Molekülen steigern kann. Da die geringe Lyse parthenogenetischer Stammzellen in Zusammenhang mit der niedrigen Expression von MHC-Klasse-I-Molekülen stehen könnte, wurde versucht, die MHC-Klasse-I-Expression durch Behandlung mittels Applikation von Interferon-y über $48 \mathrm{~h}$ zu steigern und den Effekt mittels durchflusszytometrischer

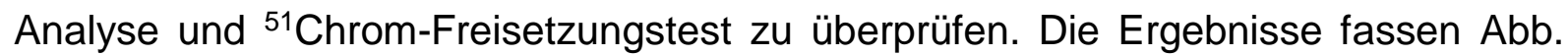
3.11 und 3.12 zusammen.

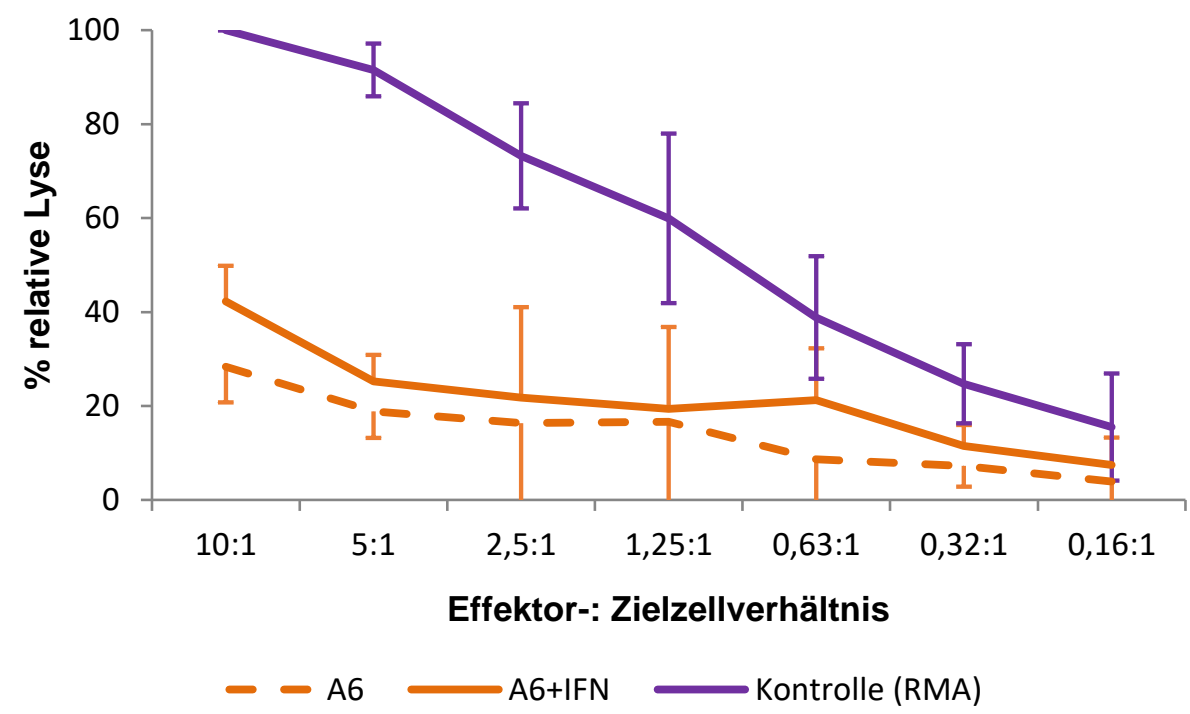

Abb. 3.11 Auswirkungen von Behandlung mit IFN-y über 48 Stunden $A$ relative Lyse der mit Interferon-y behandelten im Vergleich zu unbehandelten Zellen der Linie A6.

$\mathrm{n}=3$. Die Abbildung zeigt die Mittelwerte (MW) der relativen Lyse der durchgeführten Experimente. Die Zielzellen wurden über 48 Stunden mit Interferon- $y$ inkubiert und anschließend im ${ }^{51} \mathrm{Chrom}$ Freisetzungstest getestet. Angegeben ist zudem die Standardabweichung (SD). Die gestrichelten Linien zeigen unbehandelte, während die durchgezogenen Linien mit Interferon- $\gamma$ behandelte Zellen darstellen.

Die mit Interferon- $y$ behandelten Zellen scheinen im Vergleich zu den unbehandelten Zellen leicht vermehrt lysiert zu werden. Jedoch konnte sich durchflusszytometrisch 
keine Steigerung der Expression von MHC-Klasse-I-Molekülen nachweisen lassen (vgl. Abb. 3.12).
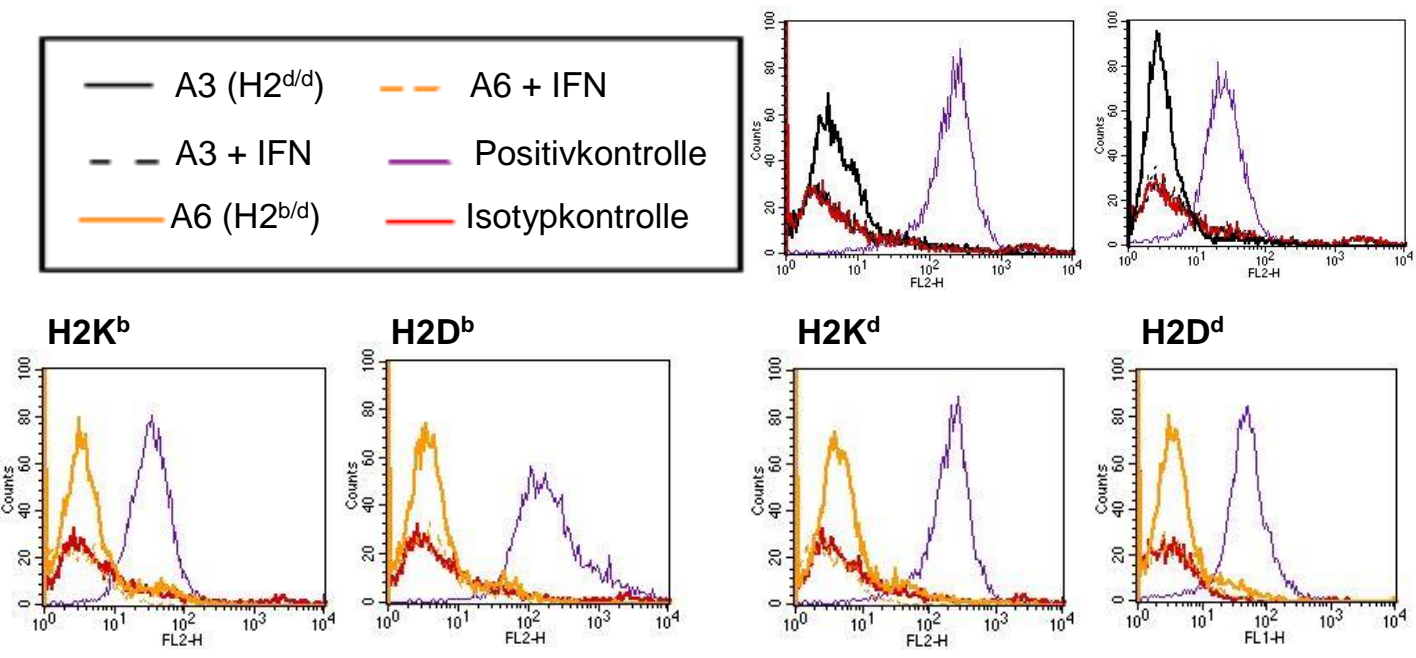

Mittlere Fluoreszenzintensität (MFI)

Abb. 3.12 Expression von MHC-Klasse-I-Molekülen auf mit Interferon-y behandelten parthenogenetischen Stammzellen, exemplarische Darstellung durchflusszytometrischer Messungen.

Die Abbildung zeigt einen Vergleich der durchflusszytometrisch gemessenen MHC-Klasse-I-Expression auf parthenogenetischen Stammzellen und solchen, die über 48 Stunden mit Interferon-y behandelt wurden. Es lässt sich keine vermehrte Expression von MHC-Klasse-I-Molekülen erkennen.

\subsubsection{Hinweise auf protektive Faktoren parthenogenetischer Stammzellen gegen} CTL

Aufgrund der geringen Lysierbarkeit der PSC durch CTL stellte sich die Frage, ob sich die parthenogenetischen Stammzellen gegen die Zytotoxizität der CD8+-Zellen zu schützen vermögen. Bekannte Mechanismen hierzu sind z. B. die Expression von SPI6/Serpinb9, Arginase oder TGF $\beta$. Die Zellen wurden daher im Westernblot auf eine Expression von SPI6/Serpinb9 hin untersucht. Hierbei konnte keine Expression nachgewiesen werden (vgl. Abb. 3.13A). Mittels rtPCR wurde die Expression von Arginase, TGF $\beta$ und SPI6 auf Ebene der mRNA untersucht. Als Kontrolle für die Expression von Arginase dienten murine Leberzellen, für TGF $\beta$ RMA-Zellen und für SPI6 OTI-Zellen. Auch hier ließ sich keine Expression nachweisen (Abb. 3.13B). 
A

A3

A6

Kontrolle

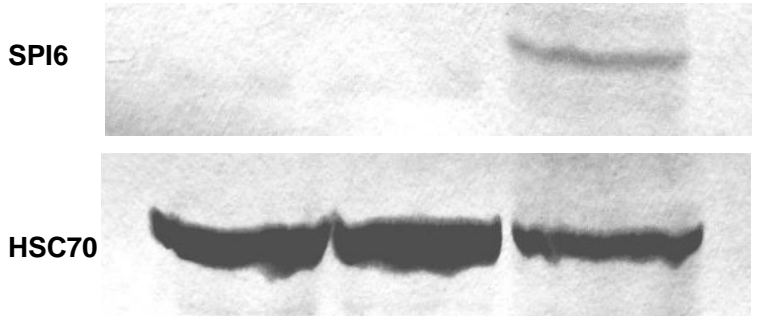

B

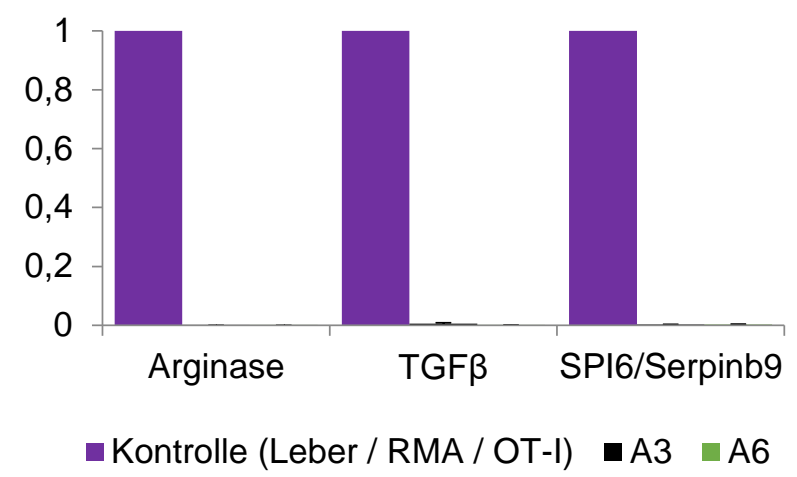

Abb. 3.13 Hinweise auf protektive Faktoren der PSC gegen CTL

A Westernblot. Im Westernblot konnte keine Expression von SPI6 für A3- oder A6-Zellen nachgewiesen werden. Als Kontrolle dienten CTL aus OT-I-Mäusen, welche Serpinb9/SPI6 zum Schutz gegen ihre eigene Zytotoxizität exprimieren. HSC70 diente als Ladekontrolle.

B rtPCR. $n=3$. cDNA zur Kontrolle der Ergebnisse wurde aus Leber (für Arginase), RMA-Zellen (für TGF $\beta$ ) und OT-I-Mäusen (für SPI6) gewonnen. Die Berechnung der Daten erfolgte nach Pfaffl mithilfe

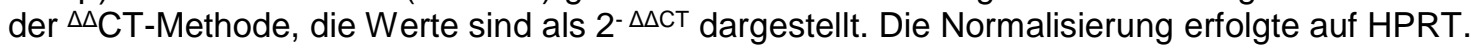

3.3 Auswirkungen von CTL und NK-Zellen auf parthenogenetische Stammzellen im Vergleich zu differenzierten Zellen

Im Hinblick auf die Transplantierbarkeit differenzierter parthenogenetischer Stammzellen rückten auch die immunologischen Eigenschaften dieser Zellen in den Fokus. Zur Gewinnung differenzierter PSC wurden die Zellen über 12 Tage in einem Differenzierungsmedium gehalten. Um einen Eindruck von dem Grad ihrer Differenzierung zu bekommen, wurden die Zellen in der durchflusszytometrischen Analyse auf die Expression von SSEA-1 getestet, einem murinen Stammzellmarker (s. Abb. 3.14). 
A

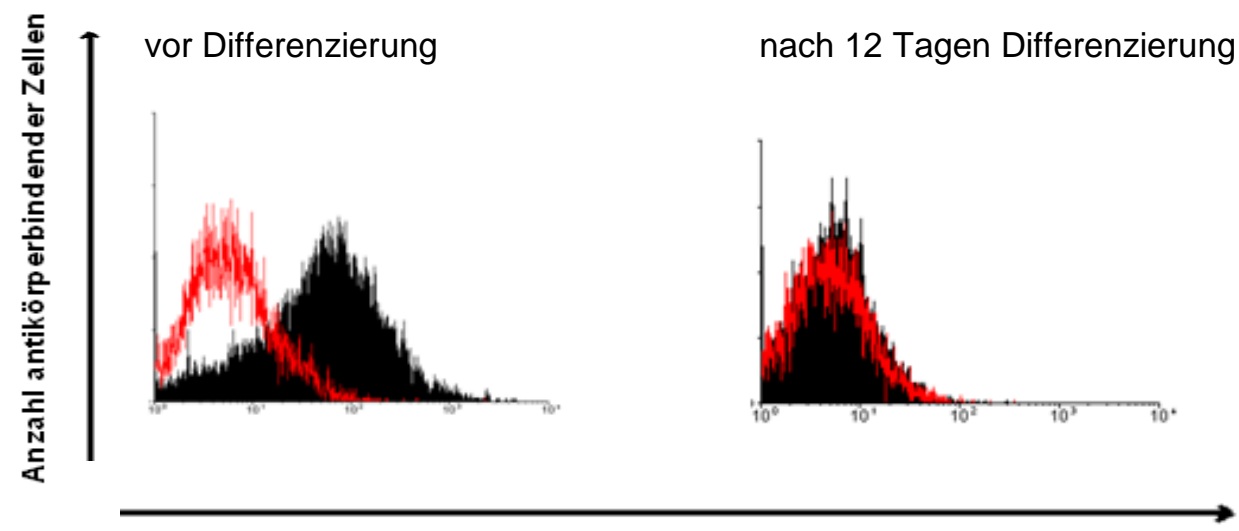

Mittlere Fluoreszenzintensität (MFI)

B
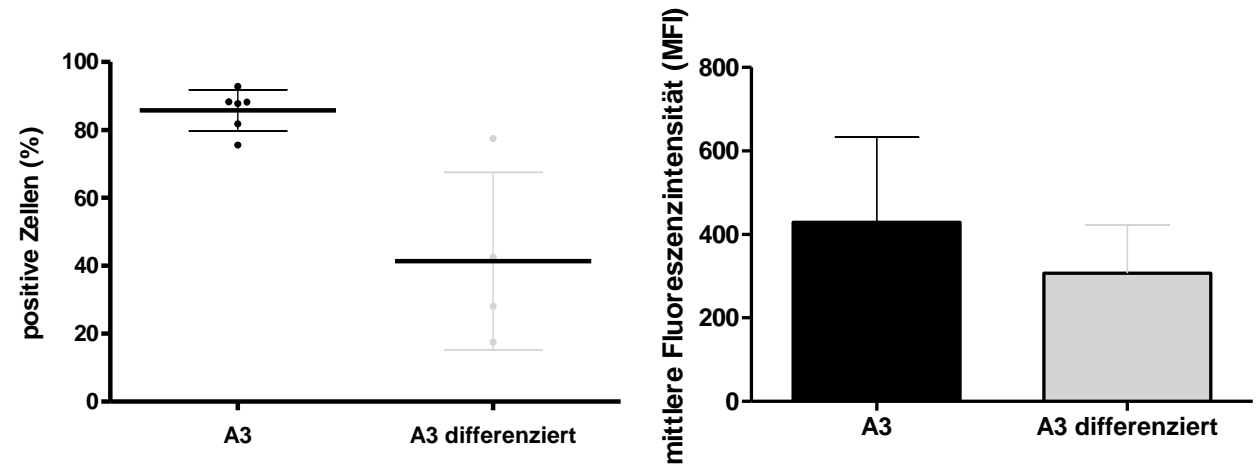

Abb. 3.14 Expression von SSEA-1 in der Durchflusszytometrie

A exemplarische Messung von SSEA-1 in der Durchflusszytometrie. Die Grafik zeigt die durchflusszytometrisch gemessene Expression von SSEA-1 auf A3-Zellen zu Beginn und nach 12 Tagen Differenzierung. In rot ist die Isotypkontrolle, in schwarz die mit SSEA-1-Antikörper behandelten Zellen dargestellt.

B Zusammenschau der Messungen von SSEA-1 auf undifferenzierten und differenzierten A3Zellen. A3 $n=6, A 3$ differenziert $n=4$. Angegeben ist der Mittelwert, sowie die Standardabweichung. Die Ergebnisse ergeben sich aus den prozentualen Anteilen positiv gemessener Zellen sowie der durchschnittlichen mittleren Fluoreszenzintensität

3.3.1 Lysierbarkeit undifferenzierter parthenogenetischer Stammzellen durch LAKZellen im Vergleich zur Lysierbarkeit differenzierter parthenogenetischer Stammzellen

Zum Vergleich der Lysierbarkeit undifferenzierter und differenzierter parthenogenetischer Stammzellen diente erneut der ${ }^{51}$ Chrom-Freisetzungstest. Zur Differenzierung der parthenogenetischen Stammzellen wurden diese für 12 Tage in Differenzierungsmedium gehalten und anschließend - wie bereits die undifferenzierten PSC (s. Abb. 3.1 und 3.2) zuvor - auf ihre Lysierbarkeit durch LAK-Zellen aus Milzen 
von Mäusen gleichen (129Sv, C57BL/6, DBA) und unterschiedlichen Haplotyps (FVB) getestet (vgl. Abb. 3.16).
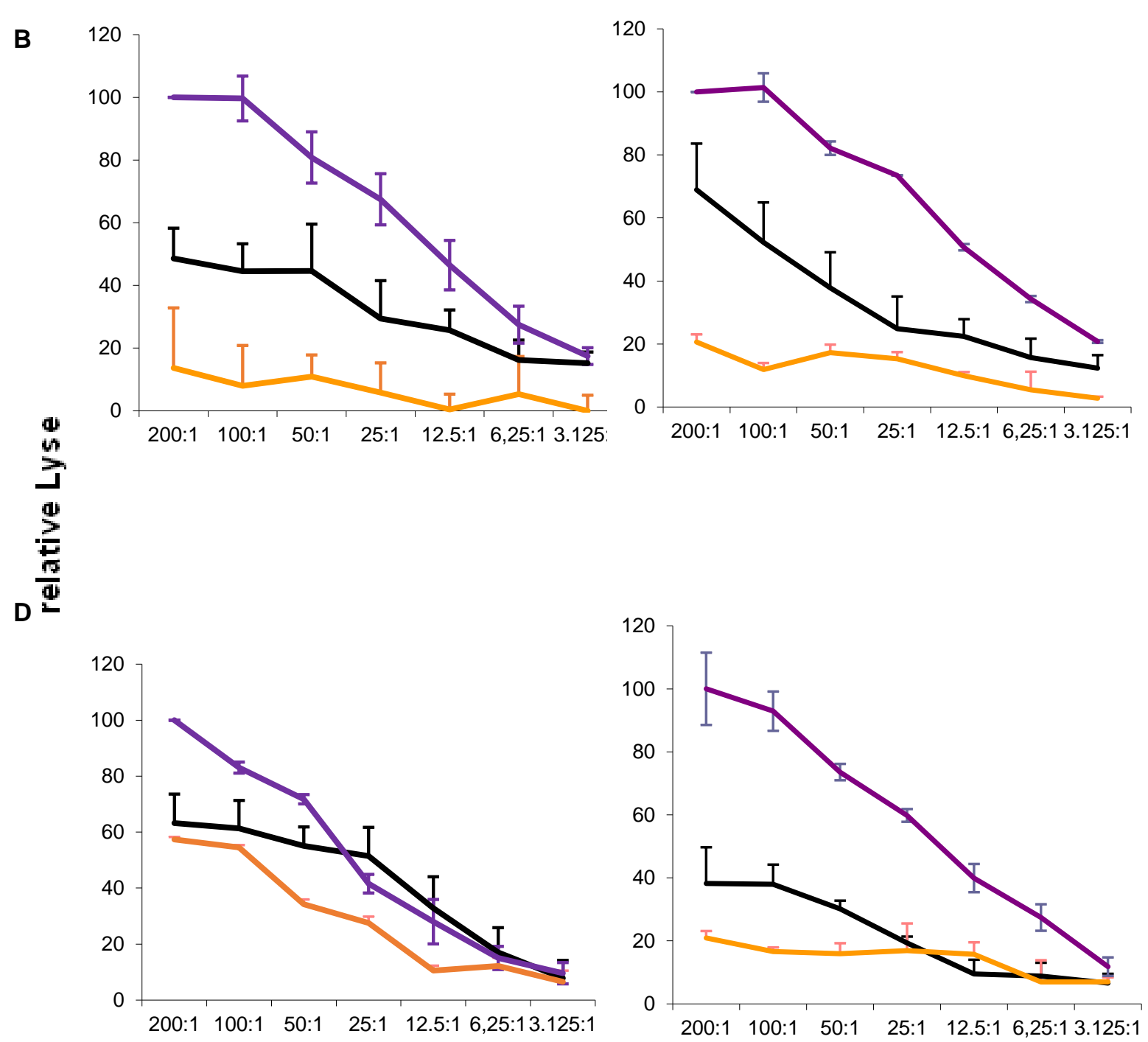

Abb. 3.15 relative Lyse differenzierter PSC durch LAK-Zellen

Dargestellt sind die Mittelwerte der relativen Lyse der einzelnen Experimente der PSC, welche zuvor 12 Tage mit Differenzierungsmedium behandelt wurden. Die Balken geben die jeweilige Abweichung vom Mittelwert an.

A 129Sv. A3 $n=6, A 6 n=6$. A6-Zellen. Die absolute spezifische Lyse lag bei einem Effektor- zu Zielzellverhältnis von 200:1 für A3-Zellen durchschnittlich bei 30,71\% (SD: 7,42), für A6-Zellen bei 9,66 $\%$ (SD: 16,41)

B C57BL/6. A3 $n=3, A 6 n=2$. Die spezifische Lyse für A3-Zellen lag durchschnittlich bei $54,24 \%$ (SD: 15,5), für A6-Zellen bei 16,33\% (SD: 2,72).

C DBA. A3 $n=3, A 6 n=2$. Die spezifische Lyse für A3-Zellen lag durchschnittlich bei 36,45\% (SD: 15,73), für A6-Zellen bei $32,17 \%$ (SD: 6,83)

D FVB. A3 n=4, A6 n=2 Spezifische Lyse A3: 26,39\% (SD: 12,43), A6: 14,79\% (SD: 7,12) 
Es zeigte sich eine deutliche Abnahme der Lysierbarkeit durch LAK-Zellen mit steigendem Grad der Differenzierung (s. Abb 3.17, in zweifaktorieller ANOVA, für alle Tests $\mathrm{p}<0,01)$. Auffällig ist zudem, dass A6-Zellen $\left(\mathrm{H} 2^{\mathrm{b} / \mathrm{d}}\right)$ deutlich weniger als A3Zellen lysiert werden, obwohl sie zuvor unter gleichen Bedingungen gehalten wurden (s. Abb. 3.15 und 3.16).
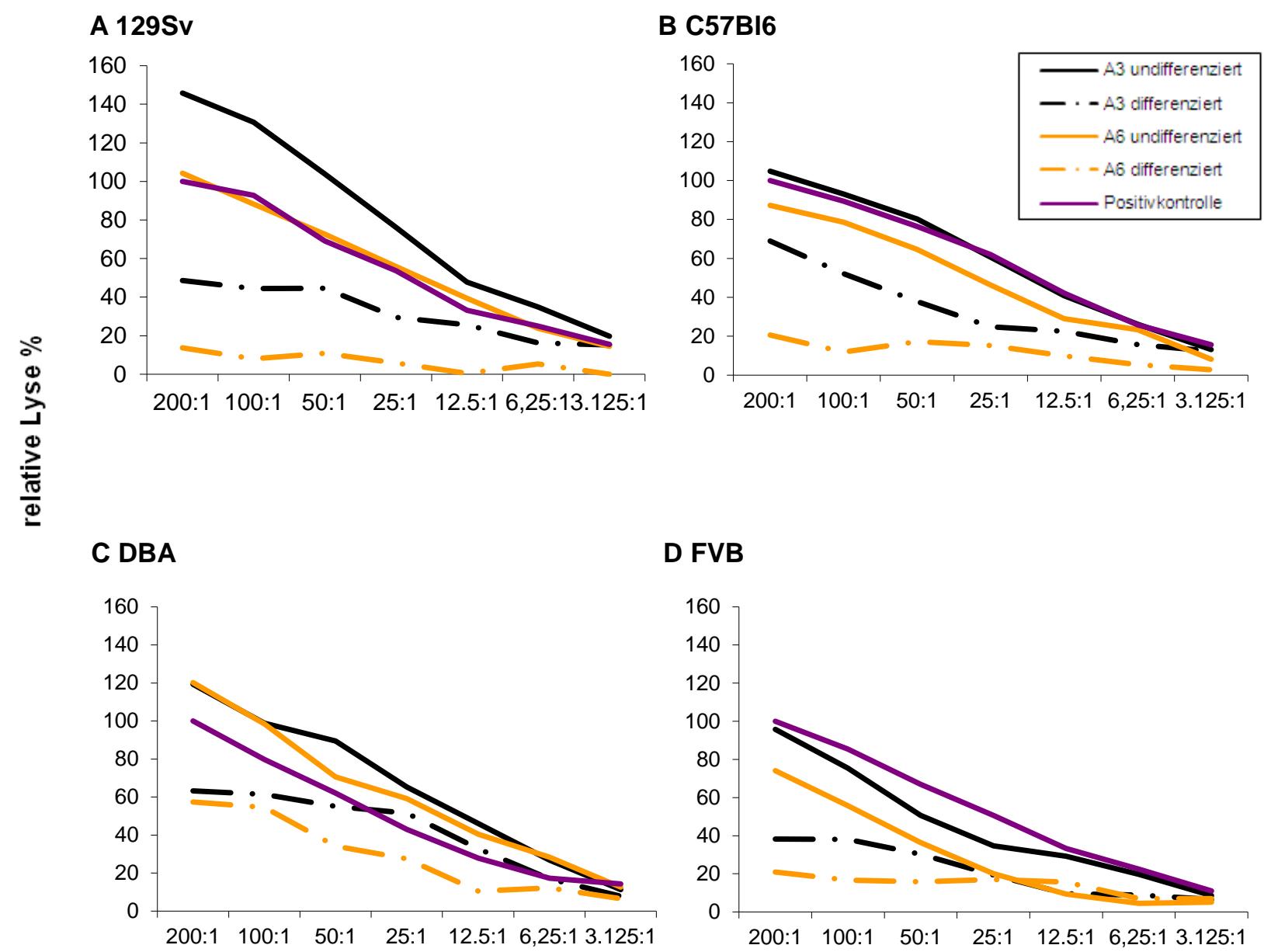

Effektor-: Zielzellverhältnis

Abb. 3.16 Vergleich der Lysierbarkeit undifferenzierter und differenzierter PSC durch LAK-Zellen Dargestellt ist die relative Lyse undifferenzierter und differenzierter PSC gegenüber einer Kontrollzelllinie (YAC-1) durch LAK-Zellen. Auf Standardabweichungen wurde aus Gründen der Übersichtlichkeit verzichtet, sie sind jedoch den Abb. 3.2 und 3.15 zu entnehmen.

A Lyse durch LAK- Zellen aus 129Sv-Mäusen. A3 undifferenziert $n=5, A 3$ differenziert $n=6, A 6$ undifferenziert $n=5, A 6$ differenziert $n=6$. Deutlich erkennbar ist die mit steigender Differenzierung der Zellen abnehmende Lysierbarkeit.

B Lyse durch LAK- Zellen aus C57BL-Mäusen. A3 undifferenziert $n=4, A 3$ differenziert $n=3, A 6$ undifferenziert $n=6, A 6$ differenziert $n=2$. Wie auch in den anderen Experimenten scheint die Abnahme der Lysierbarkeit bei den Zellen der Linie A6 stärker ausgeprägt als bei den Zellen der Linie A3.

C Lyse durch LAK- Zellen aus DBA-Mäusen. $A 3$ undifferenziert $n=4, A 3$ differenziert $n=3, A 6$ undifferenziert $n=3, A 6$ differenziert $n=2$

D Lyse durch LAK- Zellen aus FVB-Mäusen. A3 undifferenziert $n=5, A 3$ differenziert $n=4, A 6$ undifferenziert $n=6, A 6$ differenziert $n=2$ 
3.3.2 Lysierbarkeit undifferenzierter parthenogenetischer Stammzellen durch CTL im Vergleich zur Lysierbarkeit ihrer differenzierten Derivate

Im Vergleich mit undifferenzierten PSC zeigten differenzierte PSC im ${ }^{51} \mathrm{Chrom}$ Freisetzungstest eine kaum veränderte Lysierbarkeit durch aus OT-I-Mäusen gewonnenen CTL (Abb. 3.17; $p=0,29$; zweifaktorielle ANOVA). Zu beachten ist, dass A3-Zellen kein $\mathrm{H}_{2} \mathrm{~K}^{\mathrm{b}}$ exprimieren und daher durch CTL aus OT-I-Mäusen nicht Peptidabhängig lysiert werden können.

A

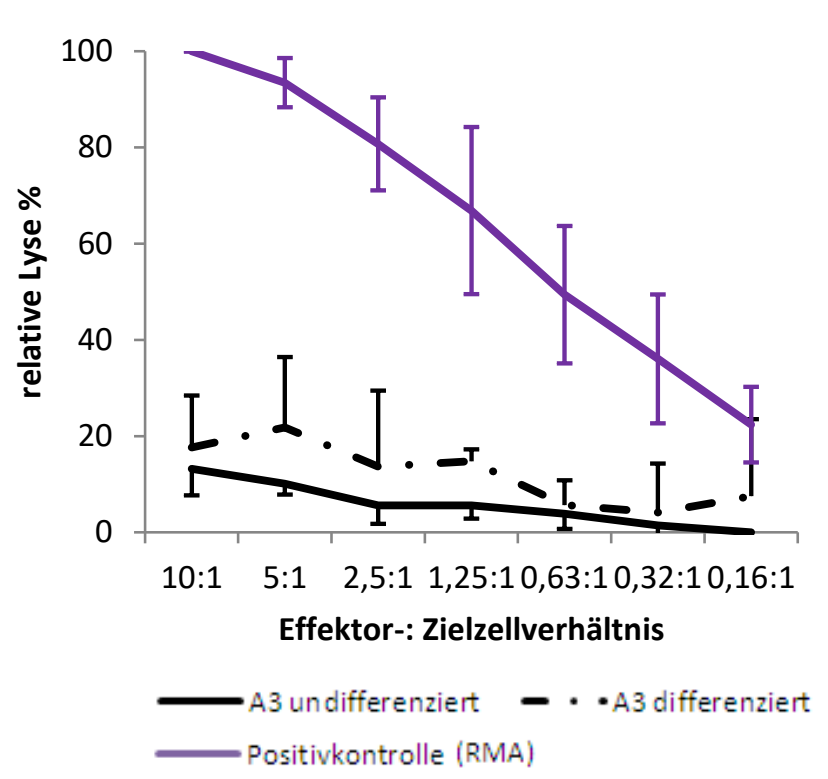

B

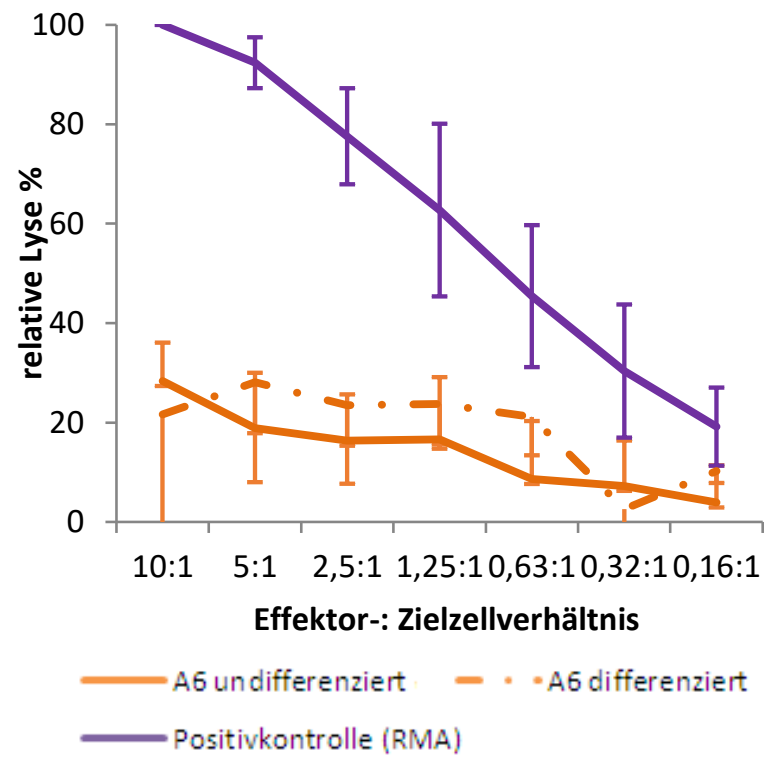

Abb. 3.17 Vergleich der Lysierbarkeit undifferenzierter und differenzierter PSC durch CTL aus OT-I-Mäusen

Ergebnisse der ${ }^{51}$ Chrom-Freisetzungstest mit CTL aus OT-I-Mäusen. Dargestellt ist die relative Lyse undifferenzierter und differenzierter PSC gegenüber einer Kontrollzelllinie (RMA) als Mittelwerte der einzelnen Messungen. Angegeben ist zudem die Standardabweichung.

A Linie A3. A3 undifferenziert $n=4$; A3 differenziert $n=2$; Positivkontrolle (RMA) $n=6$

B Linie A6. A6 undifferenziert $n=4$; $A 6$ differenziert $n=3$; Positivkontrolle (RMA) $n=6$

\subsubsection{MHC-Klasse-I-Expression differenzierter Zellen}

Zur inhaltlichen Einordnung der Daten aus den ${ }^{51}$ Chrom-Freisetzungstests wurden auch die differenzierten PSC hinsichtlich der Expression verschiedener Moleküle untersucht. Abb. 3.18 zeigt die Expression von MHC-I-Molekülen nach 12 Tagen Differenzierung. Trotz der starken Reduktion der Lysierbarkeit durch LAK im ${ }^{51} \mathrm{Chrom}$ Freisetzungstest ist die durchflusszytometrisch nachweisbare Expression von MHCKlasse-I-Molekülen auf der Oberfläche der Zielzellen kaum gestiegen. 

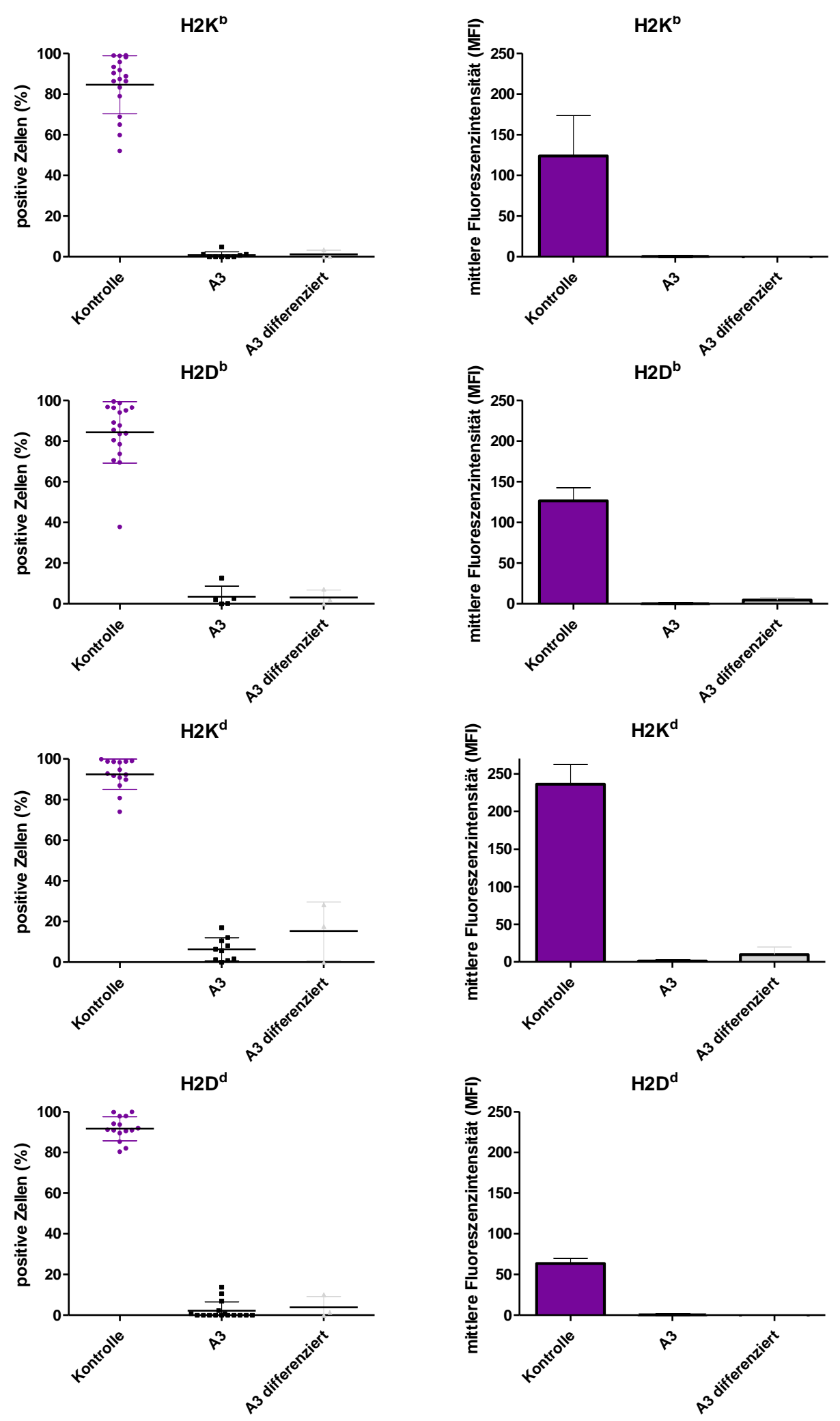

Abb. 3.18 Durchflusszytometrische Messungen der Expression von MHC-Klasse-I-Molekülen auf differenzierten PSC

Kontrolle für $\mathrm{H}_{2} \mathrm{~K}^{\mathrm{b}}$ und $\mathrm{H}_{2} \mathrm{D}^{\mathrm{b}}$ : RMA-Zellen; für $\mathrm{H}_{2} \mathrm{~K}^{\mathrm{d}}$ und $\mathrm{H} 2 \mathrm{D}^{\mathrm{d}}$ : $653-Z e l l e n$. Auf der linken Seite dargestellt ist jeweils die mittlere Anzahl positiv gefärbter Zellen einschließlich der Standardabweichung (SD) der einzelnen Messungen. Rechts wird die mittere Fluoreszenzintensität der Messungen einschließlich der Abweichung vom Mittelwert (SEM) angegeben.

H2K : Kontrolle: $n=18, A 3: n=9$, A3 differenziert: $n=3$; H2D : Kontrolle: $n=18, A 3: n=5$, A3 differenziert: $n=3$; H2Kd: Kontrolle: $n=15$, A3: $n=10$, A3 differenziert: $n=3$; H2D ${ }^{d}$ : Kontrolle: $n=15, A 3: n=15, A 3$ differenziert: $n=3$ 
3.3.4 Veränderung der Expression NK-Zell-aktivierender Liganden während der Differenzierung der parthenogenetischen Stammzellen

Auch die Expression verschiedener NK-Zell-Liganden, insbesondere Rae-1 und CD155 der differenzierten Derivate wurde mit der Expression der Stammzellen verglichen. Die Ergebnisse fasst Abb. 3.19 graphisch zusammen.
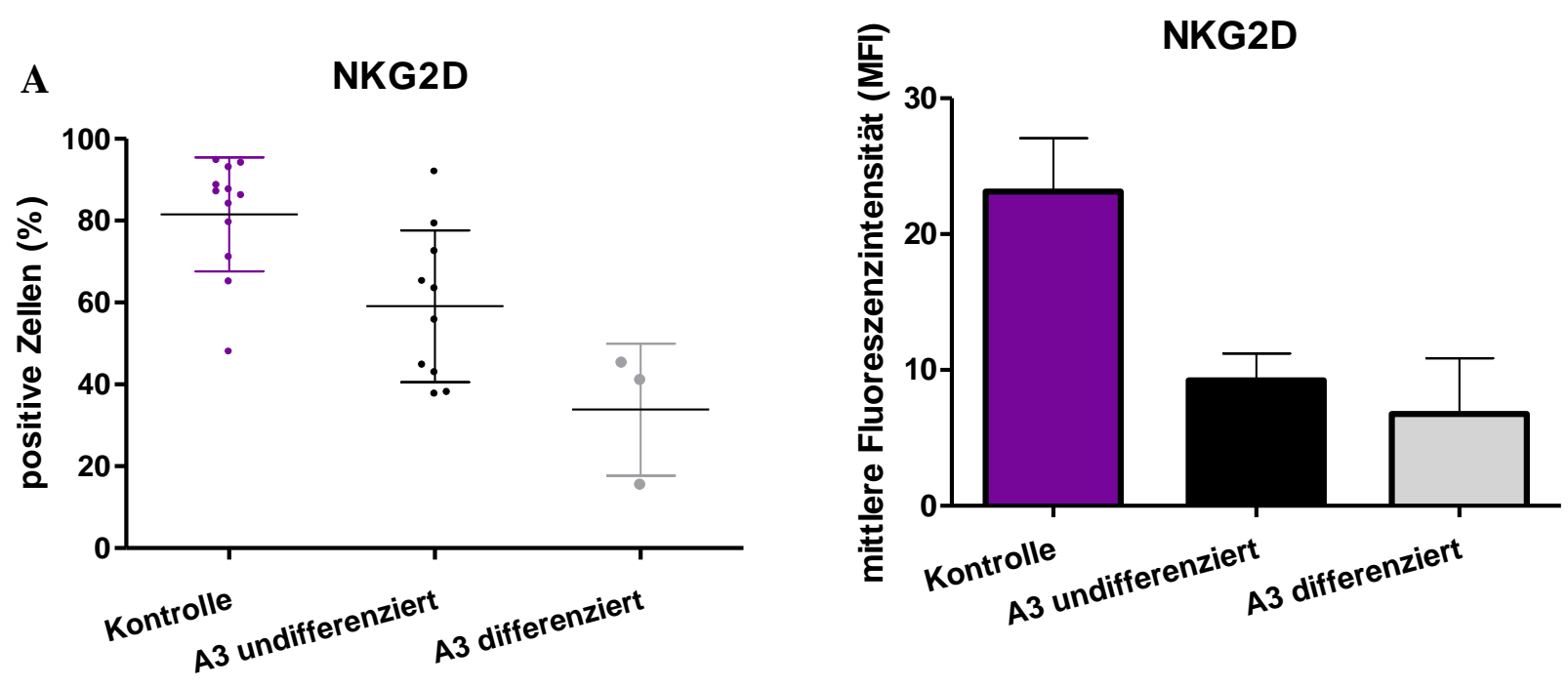

Rae-1
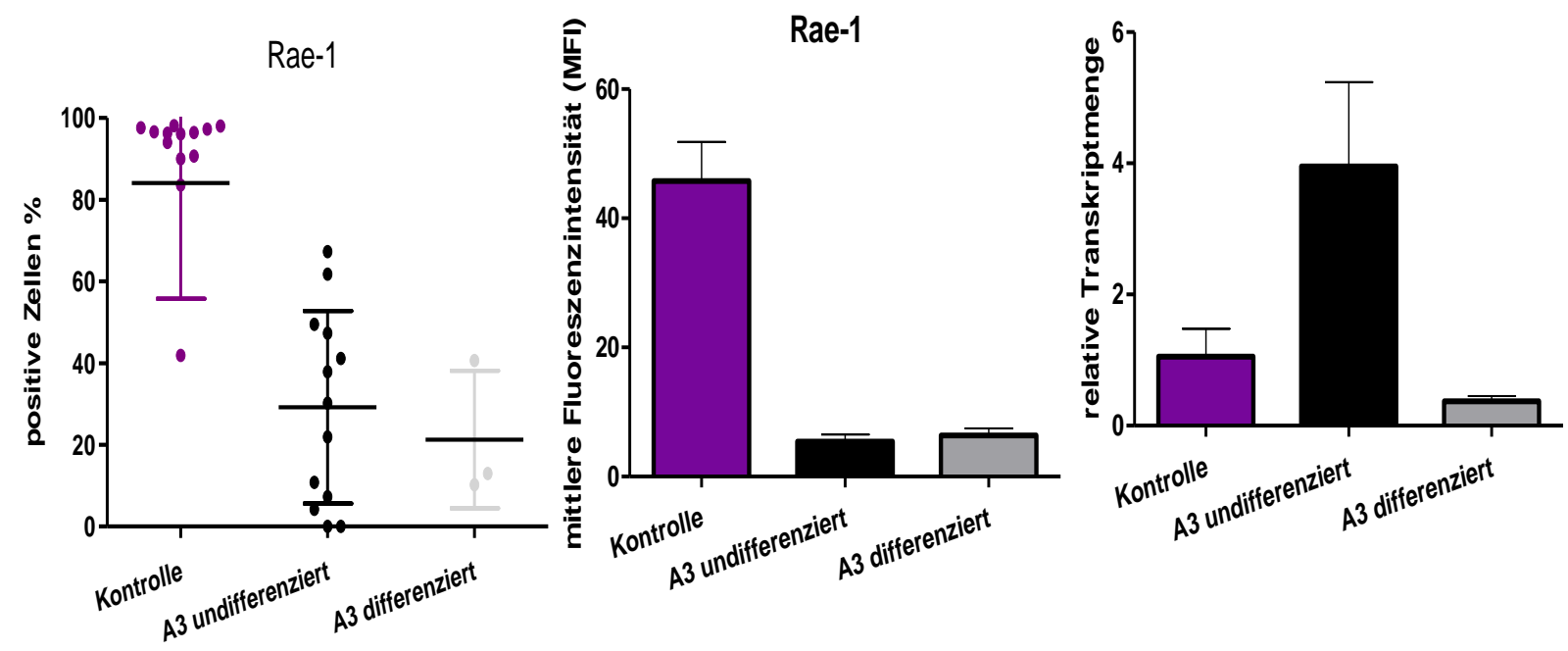


\section{B CD155}
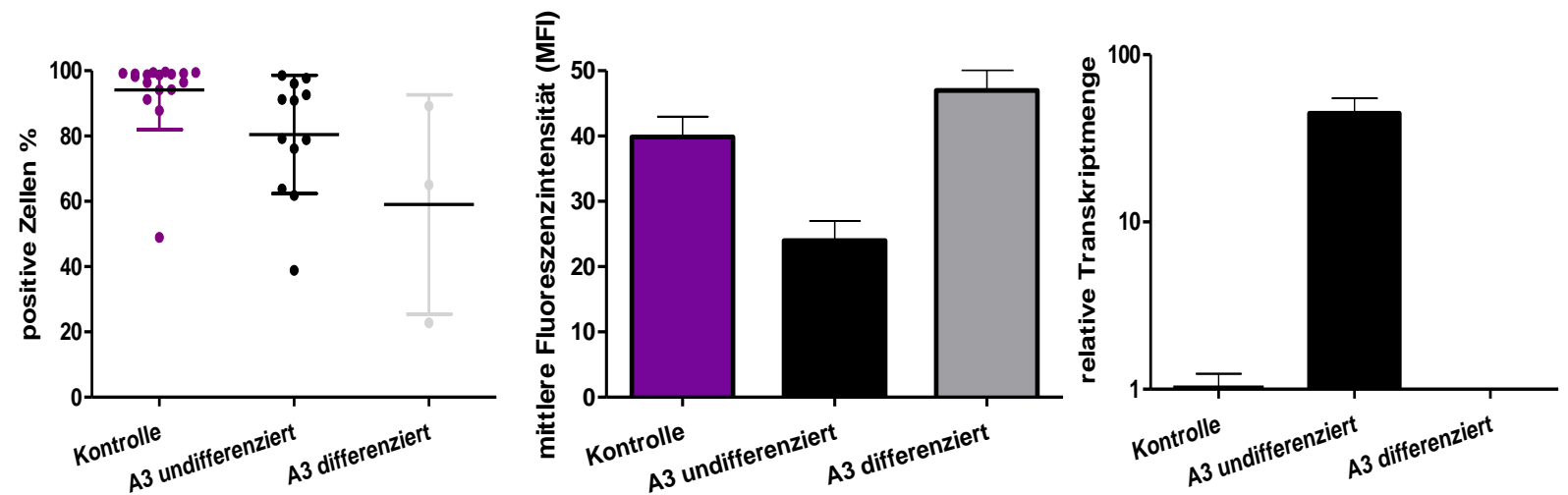

Abb. 3.19 Vergleich der Expression NK-Zell-aktivierender Liganden auf differenzierten und undifferenzierten PSC

Dargestellt sind verschiedene Messungen aus rtPCR und Durchflusszytometrie

A NKG2D und Rae-1 rtPCR: $n=3$. FACS: NKG2D: Kontrolle (YAC-1: $n=12), A 3(n=10), A 3$ differenziert $(n=3)$; Rae-1: Kontrolle (YAC-1: $n=17)$, A3 $(n=17)$, A3 differenziert $(n=3)$

$B$ Expression von CD155 auf undifferenzierten und differenzierten PSC. rtPCR: $n=3$. FACS: Kontrolle (YAC-1; $n=17), A 3$ ( $n=12), A 3$ differenziert $(n=3)$

Es zeigte sich eine Abnahme der Bindung an NKG2D, die jedoch knapp nicht signifikant war ( $p=0,058$; t-test). Die Reduktion der Expression von Rae-1 war in der Durchflusszytometrie nicht signifikant ( $p=0,59$; $t$-Test), jedoch zeigte sich ein Trend in der rtPCR ( $p=0,09 ; t-T e s t)$. CD155 zeigte zwar eine durchschnittlich geringere Anzahl positiver Zellen, doch war die mittlere Fluoreszenzintensität der differenzierten Zellen höher als jene der undifferenzierten. In der rtPCR zeigte sich jedoch eine deutlich höhere relative Transkriptmenge der undifferenzierten Zellen sowohl gegenüber der Kontrollzelllinie als auch gegenüber der differenzierten Linie. 


\section{Diskussion}

Stammzellen wecken als Modell für Medikamenten-Effekte und embryonale Entwicklung, vor allem aber als Quelle verschiedenster Gewebe große Erwartungen (Zimmermann 2011).

Während in den letzten Jahren Fortschritte im Hinblick auf die gerichtete Differenzierung und Gewebeintegration bei verschiedenen Stammzellinien erreicht werden konnten, stellt die zeitgerechte Verfügbarkeit von patientenspezifischen, also bestenfalls kaum immunogenen, Stammzellen und ihrer Derivate ein nicht hinreichend gelöstes Problem dar. So konnte zuletzt von induzierten pluripotenten Stammzellen (iPSC) gezeigt werden, dass das Immunsystem eines syngenen

Empfängers diese weitestgehend akzeptiert (Araki et al. 2013). Allerdings bleibt fraglich, ob die Zeit und die Kosten, welche für die Gewinnung, Reprogrammierung und Differenzierung von Stammzellen im Falle einer klinischen Anwendung benötigt würden, eine praktikable Anwendung erlauben.

Parthenogenetische Stammzellen (PSC) könnten Lösungen für einige dieser Problemfelder bieten. Sie weisen prinzipiell einen homologen Chromosomensatz auf, sodass die Variabilität ihres MHC-Lokus stark reduziert ist. Hochrechnungen besagen, dass nur wenige MHC-haploidentische Zellllinien genügen müssten, um den Großteil einer Bevölkerung mit immunkompatiblen Zellen versorgen zu können (Taylor et al. 2005, Nakajima et al. 2007). Der Aufbau von PSC-Banken könnte dementsprechend die zeitnahe Verfügbarkeit wenig immunogener Stammzellen deutlich vereinfachen. Trotz der immunologische Vorteile, die parthenogenetische Stammzellen demnach bieten könnten, existieren bisher nur wenige Studien, die sich mit den tatsächlichen Auswirkungen des Immunsystems auf PSC auseinandergesetzt haben. Die vorliegende Arbeit hatte daher zum Ziel, Effektormechanismen von zytotoxischen TZellen (CTL) und Natürlichen Killer-Zellen (NK-Zellen) auf parthenogenetische Stammzellen zu untersuchen und einen Ausblick auf die immunologischen Eigenschaften ihrer differenzierten Derivate zu geben. Die für die Experimente eingesetzten PSC entstammten den murinen Linien A3 und A6, welche von einer Arbeitsgruppe um Michael Didié etabliert wurden (Didié et al. 2013). Die Zellen der Linie $A 3$ wiesen einen homologen $\left(\mathrm{H} 2^{\mathrm{d} / \mathrm{d}}\right)$, diejenigen der Linie $\mathrm{A} 6$ aufgrund eines Crossing-Overs einen heterologen MHC-Lokus $\left(\mathrm{H}^{\mathrm{b} / \mathrm{d}}\right)$ auf. 
Didié und Kollegen hatten zuvor nachweisen können, dass die untersuchten Zelllinien sich zu ekto-, ento- und mesodermalen Zellen (in vitro und in vivo) und im Vergleich zu embryonalen Stammzellen ebenso gut zu Kardiomyozyten differenzieren ließen. Diese waren nach Injektion in das Myokard adulter Mäuse in der Lage, sich funktionell zu integrieren (Didié et al. 2013).

\subsection{Parthenogenetische Stammzellen und NK-Zellen}

Um die Lysierbarkeit der PSC durch NK-Zellen zu quantifizieren, wurde der ${ }^{51} \mathrm{Chrom}$ Freisetzungstest eingesetzt. Als Kontrolle wurden YAC-1-Zellen eingesetzt, von denen eine gute Lysierbarkeit durch LAK-Zellen bekannt ist.

Es zeigte sich, dass die untersuchten PSC-Linien von LAK-Zellen sehr gut lysiert wurden, häufig sogar stärker als die Kontrollzelllinien (vgl. Abb. 3.2). Der Haplotyp der lysierenden Zellen wirkte sich dabei nicht signifikant auf die Lyse der Zielzellen aus. Es scheint demnach zunächst keinen Unterschied zu machen, ob die lysierenden Zellen die gleichen Allele für den MHC-Klasse-I-Lokus wie die untersuchten Zellen besitzen oder nicht.

Um zu überprüfen, ob die Lyse der Stammzellen tatsächlich durch NK-Zellen vermittelt wurde, führten wir die Experimente erneut mit aufgereinigten NK-Zellen durch (Abb. 3.3). Auch hier zeigte sich eine gute Lysierbarkeit der parthenogenetischen Linien.

Vergleicht man unsere Ergebnisse mit der bereits publizierten Literatur, fält auf, dass verschiedene Arbeitsgruppen in Bezug auf die Lysierbarkeit von Stammzellen durch NK-Zellen zu teils sehr unterschiedlichen Ergebnissen gekommen sind (vgl. 1.3.4). So kam eine Arbeitsgruppe zu dem Schluss, dass sich murine embryonale Stammzellen (ESC) nicht durch aktivierte syngene oder allogene NK-Zellen lysieren ließen (Koch et al. 2008). In der Nachfolge wurden diverse Stammzellinien hinsichtlich ihrer Lysierbarkeit durch NK-Zellen untersucht und bis dato zeigten sich die meisten Linien - ebenso wie die aktuell für diese Dissertation getesteten Zellen - gut von NK-Zellen lysierbar (vgl. z. B. Frenzel et al. 2009). Wie die Diskrepanz zwischen den Ergebnissen zu erklären ist, bleibt letztlich unklar und bedürfte eventuell weiterer Testung der von Koch et al. untersuchten Zellen.

Didié et al. konnten zeigen, dass nach Injektion der untersuchten PSC in MHCidentische Empfänger (z. B. A3 $\left(H 2^{d / d}\right)$ in DBA-Mäuse $\left.\left(H 2^{d / d}\right)\right)$ und solche mit einem 
fehlenden, aber nicht unterschiedlichen MHC-Genotyp (z. B. A3 $\left(H 2^{\mathrm{d} / \mathrm{d}}\right)$ in B6D2Mäuse $\left.\left(\mathrm{H} 2^{\mathrm{b} / \mathrm{d}}\right)\right)$, Teratome gebildet wurden, das Immunsystem der Empfänger die PSC also weitestgehend akzeptierte. Dementsprechend scheint die in dieser Arbeit in vitro nachgewiesene NK-Zell-Antwort nicht auszureichen, um eine Abstoßung der Zellen in vivo zu erreichen. Im Einklang hierzu stehen Ergebnisse, nach denen NK-Zellen in vivo zwar beispielsweise in der Lage waren, ein langsameres Teratom-Wachstum zu verursachen, es letztlich jedoch nicht vollständig verhindern konnten (vgl. Tian et al. 2006; Dressel et al. 2010).

Eine mögliche Erklärung der guten Lysierbarkeit verschiedener Stammzellinien durch NK-Zellen ist die geringe bis nicht messbare Expression von MHC-Klasse-I-Molekülen auf ihren Oberflächen im Sinne der missing-self-Hypothese (Kärre 1985). Passend hierzu konnten wir durchflusszytometrisch keine Expression von MHC-Klasse-IMolekülen auf den Stammzelllinien zeigen (Abb. 3.4 und 3.5). Auch auf Ebene der mRNA konnten wir relativ zu den Kontrollzelllinien kaum Expression nachweisen (Abb. 3.6).

Zum anderen scheint die Expression von NK-Zell-aktivierenden Liganden eine Rolle zu spielen. In der Durchflusszytometrie zeigte sich eine Bindung des NK-Zellaktivierenden Rezeptor NKG2D an die untersuchten PSC (Abb. 3.8A). Wir untersuchten die PSC dementsprechend auf die murinen NKG2D-Liganden Rae-1, Mult-1 und H60. Wir konnten zeigen, dass Antikörper gegen Rae-1 sowohl in der Durchflusszytometrie an die Stammzellen banden, wie auch dessen mRNA - im Vergleich zu den Kontrollzelllinien - vermehrt exprimiert wurde (vgl. Abb. 3.8B). Mult1 und $\mathrm{H} 60$ wurden hingegen nicht exprimiert. Auch auf anderen Stammzelllinien sowie Zellen einer embryonalen Karzinomlinie (Dressel et al. 2008, Nomura et al. 1996) konnte Rae-1 als Ligand von NKG2D nachgewiesen werden. Wie bedeutend der Einfluss von Rae-1 bezüglich der NK-Zell-Lyse genau ist, ist noch nicht abschließend geklärt.

Neben Rae-1 konnten wir in Durchflusszytometrie und rtPCR CD155 und CD112 auf den beiden untersuchten parthenogenetischen Zelllinien nachweisen (Abb. 3.7). Beide Moleküle stimulieren über Interaktion mit CD226 (DNAM-1) die Aktivität von NK-Zellen und könnten so - wie auch Rae-1 - zur Lyse der PSC beigetragen haben. CD115 und CD112 wurden ebenfalls bereits auf anderen Stammzellinien nachgewiesen (Dressel et al. 2010). 
In der rtPCR zeigte sich zudem, dass die parthenogenetischen Stammzellen sowohl deutlich mehr mRNA von CD155 als auch von Rae-1 exprimieren als die jeweiligen Kontrollzelllinien, dennoch zeigte sich durchflusszytometrisch eine im Vergleich geringere Expression dieser Moleküle. Es wäre zu erwägen, ob die Stammzellen nicht im gleichen Maße wie die Kontrollzelllinien in der Lage sind, mRNA zu translatieren oder gebildete Moleküle an die Oberfläche der Zellen zu transportieren.

Zusammenfassend ist davon auszugehen, dass die Expression NK-Zell-aktivierender Liganden, insbesondere Rae-1 und CD155, sowie der Mangel an MHC-Klasse-IMolekülen auf der Oberfläche der untersuchten Zellen die gute Lysierbarkeit der untersuchten Stammzellinien bedingt.

\subsection{Parthenogenetische Stammzellen und CTL}

CTL erkennen andere Zellen über die Interaktion inres T-Zell-Rezeptors mit MHCKlasse-I-Molekülen. Erkennen sie ein dort präsentiertes Antigen als körperfremd, lysieren sie die präsentierende Zelle.

Um die Lysierbarkeit der PSC durch zytotoxische T-Zellen (CTL) zu untersuchen, wurde ebenfalls der ${ }^{51} \mathrm{Chrom}$-Freisetzungstest eingesetzt.

$\mathrm{Da}$ die CTL-vermittelte Lyse in diesen Experimenten $\mathrm{H}^{2} \mathrm{~K}^{\mathrm{b}}$-abhängig erfolgte, war davon auszugehen, dass Zellen der Linie $\mathrm{A} 3$, welche kein Gen für $\mathrm{H} 2 \mathrm{~K}^{\mathrm{b}}$ besitzen, nicht lysiert werden konnten und tatsächlich zeigte sich hier keine Lyse der Zellen (Abb. 3.10). Die Zellen der Linie A6 wurden dagegen in geringem Maße lysiert, sodass es scheint, als könnten CTL PSC prinzipiell lysieren und die dafür notwendigen MHCKlasse-I-Molekülen doch exprimieren.

Zwar konnten diese in der Durchflusszytometrie nicht nachgewiesen werden (Abb. 3.4), doch wäre eine mögliche Erklärung, dass parthenogenetische Stammzellen MHC-Klasse-I-Moleküle in so geringem Maße exprimieren, dass sie durchflusszytometrisch nicht nachweisbar sind. Es ist bekannt, dass bereits eine sehr geringe Anzahl von MHC-Klasse-I-Molekülen genügt, um CTL zu aktivieren (Brower et al. 1994, Sykulev et al. 1996). Hiermit im Einklang stehen Experimente, bei denen verschiedene Stammzellinien aus maGSC, ESC und iPSC trotz durchflusszytometrisch nicht nachweisbarer Expression von MHC-I-Molekülen durch aktivierte CTL in vitro lysierbar und dementsprechend nicht generell gegen CTL-vermittelte Lyse 
geschützt waren (Dressel et al. 2009, vgl. auch Bonde und Zavazava 2006, Yachomovik-Cohen et al. 2010). Zudem konnte gezeigt werden, dass die allogene Abwehr von Stammzellen mit ihrer Infiltration durch $\mathrm{CD}^{+}{ }^{+}$und $\mathrm{CD} 8^{+}$-Zellen sowie Makrophagen einherging und dass das Teratom-Wachstum durch CTL unterbunden werden konnte, wenn diese durch APC aktiviert wurden (Wu et al. 2008). Dies unterstützt die Vermutung, dass CTL eine entscheidende Rolle in der Abwehr allogener Stammzellen spielen.

Um zu überprüfen, ob ein Anstieg der MHC-I-Moleküle auf den PSC ihre Lysierbarkeit beeinflusst, schlossen wir einige Experimente an. IFN-y steigert die Expression von MHC-Klasse-I-Molekülen auf verschiedenen Zelllinien. Wir inkubierten die PSC über $48 \mathrm{~h}$ mit IFN-y. Obwohl durchflusszytometrisch keine Steigerung der Expression von MHC-Klasse-I-Molekülen gezeigt werden konnte, war ein leichter Anstieg der Lyse durch CTL aus OT-I-Mäusen (Abb. 3.11 und 3.12) zu messen.

Aufgrund der im Vergleich geringen Lysierbarkeit der parthenogenetischen Stammzellen im Vergleich mit anderen Stammzellinien stellte sich die Frage, ob sie sich auf eine andere Art und Weise als durch die niederige Expression von MHCKlasse-I-Molekülen vor CTL zu schützen vermögen. Bisher gab es einige wenige Publikationen, die nahelegten, dass sich einzelne Stammzellinien durch Expression von SPI-6 (Serpinb9), TGF- $\beta$ oder Arginase I gegen CTL schützen. Dies ließ sich bisher jedoch nicht auf andere Linien übertragen (Yachimovich-Cohen et al. 2010, Koch et al. 2008, Abdullah et al. 2007).

Wir untersuchten die Zellen mittels Westernblot und rtPCR auf die Expression dieser Moleküle. Es konnte jedoch keine Expression nachgewiesen werden (Abb. 3.13), weshalb davon auszugehen ist, dass zumindest die untersuchten parthenogenetischen Stammzellinien sich nicht durch deren Expression zu schützen vermögen. Inwiefern und ob PSC sich durch andere Mechanismen gegen CTL zu schützen vermögen, bleibt weiter zu untersuchen.

\subsection{Differenzierte Derivate}

Neben den Eigenschaften der Stammzelllinien selbst sind gerade für die Transplantationsmedizin ihre differenzierten Derivate von Interesse. Es stellte sich demnach die Frage, ob und inwiefern sich die Antwort der T- und NK-Zellen auf die 
untersuchten Stammzelllinnien im Laufe einer weiterführenden Differenzierung verändern würde.

Zur Gewinnung differenzierter Derivate der PSC wurden diese für 12 Tage in einem Differenzierungsmedium gehalten. Die Zellen wurden anschließend in der durchflusszytometrischen Analyse auf die Expression von SSEA-1 getestet, einem murinen Stammzellmarker, wobei es zu einer deutlichen Abnahme der Expression von SSEA-1 kam (vgl. Abb. 3.13).

Es ist bekannt, dass die Expression von MHC-Klasse-I-Molekülen auf anderen Stammzelllinien im Laufe ihrer Differenzierung ansteigt, wobei das Ausmaß dieser Zunahme in einzelnen Studien sehr unterschiedlich ausfiel (z. B. Drukker et al. 2002, v.d. Brink und Burakoff 2002, Frenzel et al. 2009). Es wird daher davon ausgegangen, dass CD8+-T-Zellen die Derivate im Laufe des Differenzierungsprozesses besser erkennen und deren Lyse vermehrt hervorrufen können (Nussbaum et al. 2007), während die Antwort der NK-Zellen im Einklang mit der missing-self-Hypothese typischerweise sinkt (Koch et al. 2006, Dressel et al. 2008, Frenzel et al. 2009).

Der Anstieg der Expression der MHC-Klasse-I-Moleküle auf den partheno-genetischen Stammzelllinien fiel in den meisten durchflusszytometrischen Messungen nach 12 Tagen Inkubationszeit gering bis negativ aus (Abb.3.19). Dennoch kam es im ${ }^{51} \mathrm{Chrom}-$ Freisetzungstest zu einer deutlichen Reduktion der Lysierbarkeit durch NK-Zellen (Abb. 3.15 und Abb. 3.16), sodass davon auszugehen ist, dass bereits ein geringer Anstieg der MHC-I-Expression auf den Stammzellen genügte, um die PSC weitgehend vor NK-Zell vermittelter Lyse zu schützen (vgl. Kap. 4.2).

Ebenfalls einen Einfluss auf die Immunogenität der Zellen hat vermutlich die Tatsache, dass die Derivate andere Moleküle als ihre Vorläuferzellen exprimieren (z. B. Swijnenburg et al. 2005). Die durchschnittliche Bindung an NKG2D sank in unseren Experimenten in der Durchflusszytometrie ebenso wie die Expression von Rae-1 mit zunehmender Differenzierung. Auch die Expression von CD155 reduzierte sich. Diese - allerdings nicht signifikanten - Ergebnisse fanden sich auch in der rtPCR wieder (vgl. Abb. 3.20) und könnten die geringere Lyse differenzierter Derivate im Vergleich zu ihren Vorläuferzellen erklären.

Auffällig war, dass differenzierte Zellen der Linie A6 meist geringer lysiert wurden als die Zellen der Linie A3. Daher ließe sich überlegen, ob Zellen der Linie A6 anfänglich besser differenzierbar waren als die Zellen der Linie A3 (Abb. 3.15). Weiterführende 
Experimente der Arbeitsgruppe um Didié zeigten jedoch keine signifikanten Unterschiede in der Differenzierbarkeit (Didié et al. 2013).

Die Lysierbarkeit durch CTL stieg geringfügig, jedoch nicht signifikant (Abb. 3.18), was dem geringen Anstieg der MHC-Klasse-I-Expression geschuldet sein könnte. In diesem Fall wäre es sehr interessant, die Lysierbarkeit weiter differenzierter Derivate durch CTL zu untersuchen. Eventuell könnten differenzierte Derivate auch protektive Mechanismen gegen CTL aufweisen, wir konnten allerdings bei Überprüfung keine der vermuteten Protektionsmechanismen (z. B. durch SPI-1 oder Arginase) nachweisen. 


\section{Zusammenfassung}

Parthenogenetische Stammzellen sind aus adulten Eizellen gewonnene Stammzellen. Ihr homologer Chromosomensatz könnte für die Einführung von Stammzellbanken ein entscheidender Vorteil sein. In der vorliegenden Arbeit haben wir untersucht, wie sich NK-Zellen und CTL auf parthenogenetische Stammzellen und deren Derivate in vitro auswirken.

Zusammenfassend konnten wir zeigen, dass PSC sich ähnlich wie andere Stammzelllinien von NK-Zellen sehr gut und von CTL vergleichsweise gering lysieren lassen. Dies lässt sich am ehesten mit der geringen Expression von MHC-Klasse-IMolekülen und der Expression einiger NK-Zell-aktivierender Liganden, insbesondere Rae-1 und CD155, erklären. Im Laufe der Differenzierung konnten wir nur eine geringe Steigerung der Expression von MHC-Klasse-I-Molekülen zeigen, während die Zahl der NK-Zell-aktivierenden Liganden deutlich abnahm. Im Einklang mit diesen Ergebnissen wurden die differenzierten Derivate der Zellen deutlich geringer durch NK-Zellen lysiert als inre Vorläuferzellen, der Anstieg der Lyse durch CTL war dagegen nur geringfügig ausgeprägt.

Parthenogenetische Stammzellen verhalten sich aus immunologischer Sicht somit weitgehend ähnlich wie andere Stammzellinien. Für die Zukunft wäre eine weitergehende Untersuchung der differenzierten Derivate in Bezug auf ihre Lyse durch CTL, aber auch hinsichtlich der Relevanz von CD155 und Rae-1 bezüglich der NKZell-vermittleten Lyse undifferenzierter Zellen wünschenswert. 


\section{Literaturverzeichnis}

Abdullah Z, Saric T, Kashkar H, Baschuk N, Yazdanpanah B, Fleischmann BK, Hescheler J, Krönke M, Utermöhlen O (2007): Serpin-6 expression protects embryonic stem cells from lysis by antigen-specific CTL. J Immunol 178, 3390-9

Ackerman AL, Cresswell P (2004): Cellular mechanisms governing crosspresentation of exogenous antigens. Nat Immunol $\underline{5}, 678-84$

Amariglio N, Hirshberg A, Scheithauer BW, Cohen Y, Loewenthal R, Trakhtenbrot L, Paz N, Koren-Michowitz M, Waldman D, Leider-Trejo Let al. (2009): Donor-derived brain tumor following neural stem cell transplantation in an ataxia telangiectasia patient. PLoS Med $\underline{6}$, e1000029

Amit M, Itskovitz-Eldor J (2006): Feeder-free culture of human embryonic stem cells. Methods Enzymol 420, 37-49

Anderson G, Moore NC, Owen JJ, Jenkinson EJ (1996): Cellular interactions in thymocyte development. Annu Rev Immunol 14, 73-99

Araki R, Uda M, Hoki Y, Sunayama M, Nakamura M, Ando S, Sugiura M, Ideno H, Shimada A, Nifuji A et al. (2013): Negligible immunogenicity of terminally differentiated cells derived from induced pluripotent or embryonic stem cells. Nature $\underline{494}, 100-4$

Balaji KN, Schaschke N, Machleidt W, Catalfamo M, Henkart PA (2002): Surface cathepsin B protects cytotoxic lymphocytes from self-destruction after degranulation. $\mathrm{J}$ Exp Med 196, 493-503

Balakier H, Tarkowski AK (1976): Diploid parthenogenetic mouse embryos produced by heat-shock and Cytochalasin B. J Embryol Exp Morph 35, 25-39.

Ben-Hur T, Idelson M, Khaner H, Pera M, Reinhartz E, Itzik A, Reubinoff BE (2004): Transplantation of human embryonic stem cell-derived neural progenitors improves behavioral deficit in Parkinsonian rats. Stem Cells $\underline{22}, 1246-55$

Bernstein HS, Hyun WC (2012): Strategies for enrichment and selection of stem cellderived tissue precursors. Stem Cell Res Ther $\underline{3}, 17$

Bevan MJ (1976): Minor $\mathrm{H}$ antigens introduced on $\mathrm{H}-2$ different stimulating cells crossreact at the cytotoxic T cell level during in vivo priming. J Immunol 117, 2233-8

Bhandoola A, Sambandam A (2006): From stem cell to T cell: one route or many? Nat Rev Immunol $\underline{6}$, $117-26$

Bissonnette CJ, Lyass L, Bhattacharyya BJ, Belmadani A, Miller RJ, Kessler JA (2011): The controlled generation of functional basal forebrain cholinergic neurons from human embryonic stem cells. Stem Cells $\underline{29}, 802-11$

Blum B, Benvenisty N (2009): The tumorigenicity of diploid and aneuploid human pluripotent stem cells. Cell Cycle $\underline{8}, 3822-30$

Bonde S, Zavazava N (2006): Immunogenicity and engraftment of mouse embryonic stem cells in allogeneic recipients. Stem Cells $\underline{24}, 2192-201$ 
Bonnevie L, Bel A, Sabbah L, Al Attar N, Pradeau P, Weill B, Le Deist F, Bellamy V, Peyrard S, Ménard C et al. (2007): Transplantation 83, 333-5

Brower RC, England R, Takeshita T, Kozlowski S, Margulies DH, Berzofsky JA, Delisi C (1994): Minimal requirements for peptide mediated activation of CD8+ CTL. Mol Immunol 31,1285-93

Bryceson YT, Ljunggren HG, Long EO (2009): Minimal requirement for induction of natural cytotoxicity and intersection of activation signals by inhibitory receptors. Blood $\underline{114}, 2657-66$

Bryceson YT, Chiang S, Darmanin S, Fauriat C, Schlums H, Theorell J, Wood S (2011): Molecular Mechanisms of Natural Killer Cell Activation. J Innate Immun 2011 $\underline{3}, 216-26$

Burshtyn DN, Shin J, Stebbins C, Long EO (2000): Adhesion to target cells is disrupted by the killer cell inhibitory receptor. Curr Biol $10,777-80$

Buta C, David R, Dressel R, Emgård M, Fuchs C, Gross U, Healy L, Hescheler J, Kolar $R$, Martin U et al. (2013): Reconsidering pluripotency tests: do we still need teratoma assays? Stem Cell Research 11, 552-62

Caspi O, Lesman A, Basevitch Y, Gepstein A, Arbel G, Habib ICH, Gepstein L, Levenberg $S$ (2007): Tissue engineering of vascularized cardiac muscle from human embryonic stem cells. Circ Res $\underline{100}, 263-72$

Chen Z, Liu Z, Huang J, Amano T, Li C, Cao S, Wu C, Liu B, Zhou L, Carter MG et al. (2009): Birth of parthenote mice directly from parthenogenetic embryonic stem cells. Stem Cells $\underline{9}, 2136-45$

Christalla P (2010): Entwicklung von bioartifiziellem Herzgewebe aus parthenogenetischen Stammzellen der Maus. SUB Univ Hamburg EDiss 2011/4821

Cibelli JB, Grant KA, Chapman KB, Cunniff K, Worst T, Green HL, Walker SJ, Gutin $\mathrm{PH}$, Vilner L, Tabar $\mathrm{V}$ et al. (2002): Parthenogenetic stem cells in nonhuman primates. Science 295, 819

Cowan CA, Atienza J, Melton DA, Eggan K (2005): Nuclear reprogramming of somatic cells after fusion with human embryonic stem cells. Science $\underline{309}$, 1369-73

Davis M, Boniface J, Reich Z, Lyons D, Hampl J, Arden B, Chien Y (1998): Ligand Recognition by T Cell Receptors. Ann Rev Immunol 트, 523-44

Deguine J, Breart B, Lemaitre F, Di Santo JP, Bousso P (2010): Intravital imaging reveals distinct dynamics for natural killer and CD8(+) T cells during tumor regression. Immunity $\underline{33}, 632-44$

Didié M, Christalla P, Rubart M, Muppala V, Döker S, Unsöld B, El-Armouche A, Rau T, Eschenhagen T, Schwoerer APet al. (2013): Parthenogenetic stem cells for tissueengineered heart repair. J Clin Invest 123, 1285-98

Draper JS, Pigott C, Thomson JA, Andrews PW (2002): Surface antigens of human embryonic stem cells: changes upon differentiation in culture. J Anat $\underline{200}, 249$ 
Dressel R (2011): Effects of histocompatibility and host immune responses on the tumorigenicity of pluripotent stem cells. Sem Immunopath $\underline{33}, 573-91$

Dressel R, Schindehütte J, Kuhlmann T, Elsner L, Novota P, Baier PC, Schillert A, Bickeböller H, Herrmann T, Trenkwalder C et al. (2008): The tumorigenicity of mouse embryonic stem cells and in vitro differentiated neuronal cells is controlled by the recipients' immune response. PLoS One $\underline{3}, 2622$

Dressel R, Nolte J, Elsner L, Novota P, Guan K, Streckfuss-Bömeke K, Hasenfuss G, Jaenisch R, Engel W (2010): Pluripotent stem cells are highly susceptible targets for syngeneic, allogeneic, and xenogeneic natural killer cells. FASEB J 24, 2164-77

Dressel R, Guan K, Nolte J, Elsner L, Monecke S, Nayernia K, Hasenfuss G, Engel W (2009): Biol Direct $\underline{4}, 31$

Drukker M, Katchman H, Katz G, Even-Tov Friedman S, Shezen E, Hornstein E, Mandelboim O, Reisner Y, Benvenisty N (2006): Human embryonic stem cells and their differentiated derivatives are less susceptible to immune rejection than adult cells. Stem Cells $\underline{24}, 221-9$

Drukker M, Katz G, Urbach A, Schuldiner M, Markel G, Itskovitz-Eldor J, Reubinoff B, Mandelboim O, Benvenisty N (2002): Characterization of the expression of $\mathrm{MHC}$ proteins in human embryonic stem cells. Proc Natl Acad Sci USA 99, 9864-9

Eckardt S, Dinger T C, Kurosaka S, Leu NA, Müller AM, McLaughlin KJ (2008): In vivo and in vitro differentiation of uniparental embryonic stem cells into hematopoietic and neural cell types. Organogenesis $\underline{4}, 33-41$

Erdö F, Buhrle C, Blunk J, Hoehn M, Xia Y, Fleischmann B, Focking M, Kustermann E, Kolossov E, Hescheler J et al. (2003): Host-dependent tumorigenesis of embryonic stem cell transplantation in experimental stroke. J Cereb Blood Flow Metab 23, 780-5

Evans MJ, Kaufman MH (1981): Establishment in culture of pluripotential cells from mouse embryos. Nature 292, 154-6

Fändrich F, Lin X, Chai GX, Schulze M, Ganten D, Bader M, Holle J, Huang DS, Parwaresch R, Zavazava N et al. (2002): Preimplantation-stage stem cells induce longterm allogeneic graft acceptance without supplementary host conditioning. Nat Med $\underline{8}$, 171-8

Fauriat C, Long EO, Ljunggren HG, Bryceson YT (2010): Regulation of human NK cell cytokine and chemokine production by target cell recognition. Blood $\underline{115}$, 2167-76

Flodström-Tullberg M, Bryceson YT, Shi FD, Hoglund P, Ljunggren HG (2009): Natural killer cells in human autoimmunity. Curr Opin Immunol 21, 634-40

Frenzel LP, Abdullah Z, Kriegeskorte AK, Dieterich R, Lange N, Busch DH, Krönke M, Utermöhlen O, Hescheler J, Saric T (2009): Role of NKG2D-ligands and ICAM-1 in NK cellmediated lysis of murine embryonic stem cells and embryonic stem cell-derived cardiomyocytes. Stem Cells 27, 307-16 
Fu RH, Wang YC, Liu SP, Huang CM, Kang YH, Tsai CH, Shyu WC, Lin SZ (2011): Differentiation of stem cells: strategies for modifying surface biomaterials. Cell Transplant 므, 37-47

Gao GF, Jakobsen BK (2000): Molecular interactions of coreceptor CD8 and MHC class I: the molecular basis for functional coordination with the T-cell receptor. Immunol Today $\underline{21}, 630-6$

Garcia KC, Teyton L, Wilson IA. (1999): Structural basis of T cell recognition. Annu Rev Immunol 17, 369-97

Glaser T, Opitz T, Kischlat T, Konang R, Sasse P, Fleischmann BK, Engel W, Nayernia $\mathrm{K}$, Brüstle O (2008): Adult germ line stem cells as a source of functional neurons and glia. Stem Cells $\underline{26}, 2434-43$

Gore A, Li Z, Fung HL, Young JE, Agarwal S, Antosiewicz-Bourget J, Canto I, Giorgetti A, Israel MA, Kiskinis $E$ et al. (2011): Somatic coding mutations in human induced pluripotent stem cells. Nature $\underline{471}, 63-7$

Grakoui A, Bromley SK, Sumen C, Davis MM, Shaw AS, Allen PM, Dustin ML (1999): The immunological synapse: a molecular machine controlling T cell activation. Science $\underline{285}, 221-7$

Green JM, Noel PJ, Sperling AI, Walunas TL, Gray GS, Bluestone JA, Thompson CB (1994): Absence of B7-dependent responses in CD28-deficient mice. Immunity 1, 5018

Gregoire C, Chasson L, Luci C, Tomasello E, Geissmann F, Vivier E, Walzer T (2007): The trafficking of natural killer cells. Immunol Rev $\underline{220}, 169-82$

Grinnemo KH, Kumagai-Braesch M, Månsson-Broberg A, Skottman H, Hao X, Siddiqui A, Andersson A, Strömberg AM, Lahesmaa R, Hovatta $O$ et al. (2006): Human embryonic stem cells are immunogenic in allogeneic and xenogeneic settings. Reprod Biomed Online 13, 712-24

Grommé M, Neefjes J (2002): Antigen degradation or presentation by MHC class I molecules via classical and non-classical pathways. Mol Immunol $\underline{39}$, 181-202

Groscurth P, Filgueira L (1998): Killing Mechanisms of Cytotoxic T Lymphocytes. News Physiol Sci $\underline{13}, 17-21$

Guan K, Nayernia K, Maier LS, Wagner S, Dressel R, Lee JH, Nolte J, Wolf F, Li M, Engel W, Hasenfuss G (2006): Pluripotency of spermatogonial stem cells from adult mouse testis. Nature $\underline{440}, 1199-1203$

Guan K, Wagner S, Unsöld B, Maier LS, Kaiser D, Hemmerlein B, Nayernia K, Engel W, Hasenfuss $G$ (2007): Generation of functional cardiomyocytes from adult mouse spermatogonial stem cells. Circ Res $\underline{100}, 1615-25$

Hassin D, Garber OG, Meiraz A, Schiffenbauer YS, Berke G (2011): Cytotoxic T lymphocyte perforin and Fas ligand working in concert even when Fas ligand lytic action is still not detectable. Immunology $\underline{133}, 190-6$ 
Hentze H, Soong PL, Wang ST, Phillips BW, Putti TC, Dunn NR (2009): Teratoma formation by human embryonic stem cells: evaluation of essential parameters for future safety studies. Stem Cell Res $\underline{2}, 198-210$

Hewitt EW (2003): The MHC class I antigen presentation pathway: strategies for viral immune evasion. Immunology 110, 163-9

Ho PJ, Yen ML, Yet SF, Yen BL (2012): Current applications of human pluripotent stem cells: possibilities and challenges. Cell Transplant 21, 801-14

Kägi D, Ledermann B, Bürki K, Seiler P, Odermatt B, Olsen KJ, Podack ER, Zinkernagel RM, Hengartner $H$ (1994): Cytotoxicity mediated by $T$ cells and natural killer cells is greatly impaired in perforin-deficient mice. Nature $\underline{369}, 31-7$

Kappler JW, Roehm N, Marrack P. (1987): T cell tolerance by clonal elimination in the thymus. Cell $\underline{49}, 273-80$

Karabekian Z, Posnack NG, Sarvazyan N (2011): Immunological barriers to stem-cell based cardiac repair. Stem Cell Rev $\underline{7}, 315-25$

Kärre K (1985): Role of target histocompatibility antigens in regulation of natural killer activity: a reevaluation and a hypothesis. In: Mechanisms of NK cell mediated cytotoxicity. Academic Press Orlando, 81-91

Kaufman MH, Robertson EJ, Handyside AH, Evans MJ (1983) Establishment of pluripotential cell lines from haploid mouse embryos. J Embryol Exp Morphol 73, 24961

Kim K, Lerou P, Yabuuchi A, Lengerke C, Ng K, West J, Kirby A, Daly MJ, Daley GQ (2007): Histocompatible embryonic stem cells by parthenogenesis. Science $\underline{315}$, $482-6$

Klimanskaya I, Rosenthal N, Lanza R (2007): Derive and Conquer: sourcing and differentiating stem cells for clinical purposes. Nat Rev Drug Discov $\underline{7}, 131-42$

Ko K, Arauzo-Bravo MJ, Tapia N, Kim J, Lin Q, Bernemann C, Han DW, Gentile L, Reinhardt P, Greber B et al. (2010): Human adult germline stem cells in question. Nature $\underline{465}$, E1

Koch CA, Jordan CE, Platt JL (2006): Complement-dependent control of teratoma formation by embryonic stem cells. J Immunol 177, 4803-9

Koch CA, Geraldes P, Platt JL (2008): Immunosuppression by embryonic stem cells. Stem Cells $\underline{26}, 89-98$

Kubiak J, Paldi A, Weber M, Maro B (1991): Genetically identical parthenogenetic mouse embryos produced by inhibition of the first meiotic cleavage with cytochalasin D. Development 111, 763-9

Kuhn JR, Poenie M (2002): Dynamic polarization of the microtubule cytoskeleton during CTL-mediated killing. Immunity $\underline{16}, 111-21$

Laflamme MA, Chen KY, Naumova AV, Muskheli V, Fugate JA, Dupras SK, Reinecke H, Xu C, Hassanipour M, Police S et al. (2007). Cardiomyocytes derived from human 
embryonic stem cells in pro-survival factors enhance function of infarcted rat hearts. Nature Biotech $\underline{25}, 1015-24$

Lawrenz B, Schiller H, Willbold E, Ruediger M, Muhs A, Esser S (2004): Highly sensitive biosafety model for stem-cell-derived grafts. Cytotherapy $\underline{6}, 212-22$

Lee H, Shamy GA, Elkabetz Y, Schofield CM, Harrsion NL, Panagiotakos G, Socci ND, Tabar V, Studer L (2007): Directed differentiation and transplantation of human embryonic stem cell-derived motoneurons. Stem Cells $\underline{25}$, 1931-9

Lenschow DJ, Walunas TL, Bluestone JA. (1996): CD28/B7 system of $T$ cell costimulation. Annu Rev Immunol 14, 233-58

Lettau M, Schmidt H, Kabelitz D, Janssen O (2007): Secretory lysosomes and their cargo in T and NK cells. Immunol Lett $\underline{108}, 10-19$

Lieberman J (2003): The ABCs of granule-mediated cytotoxicity: new weapons in the arsenal. Nat Rev Immunol $\underline{3}, 361-70$

Lin H, Lei J, Wininger D, Nguyen MT, Khanna R, Hartmann C, Yan WL, Huang SC (2003): Multilineage potential of homozygous stem cells derived from metaphase II oocytes. Stem Cells $\underline{21}, 152-61$

Lister R, Pelizzola M, Kida YS, Hawkins RD, Nery JR, Hon G, Antosiewicz-Bourget J, O'Malley R, Castanon R, Klugman S et al. (2011): Hotspots of aberrant epigenomic reprogramming in human induced pluripotent stem cells. Nature $\underline{471}, 68-73$

Long EO (2008): Negative signaling by inhibitory receptors: the NK cell paradigm. Immunol Rev 224, 70-84

Lowin B, Hahne M, Mattmann C, Tschopp J (1994): Cytolytic T-cell cytotoxicity is mediated through perforin and Fas lytic pathways. Nature $\underline{370}, 650-2$

Lui KO, Boyd AS, Cobbold SP, Waldmann H, Fairchild PJ (2010): A role for regulatory $T$ cells in acceptance of ESC-derived tissues transplanted across an major histocompatibility complex barrier. Stem Cells $\underline{28}$, 1905-14

Ma T, Xie M, Laurent T, Ding S (2013): Progress in the reprogramming of somatic cells. Circ Res $\underline{112}, 562-74$

Mai Q, Yu Y, Li T, Wang J, Chen M, Huang S, Zhou C, Zhou Q (2007): Derivation of human embryonic stem cell lines from parthenogenetic blastocysts. Cell Res $\underline{17}, 1008-$ 19

Martin GR (1981): Isolation of a pluripotent cell line from early mouse embryos cultured in medium conditioned by teratocarcinoma stem cells. Procl Natl Acad Sci USA $\underline{78}$, 7634-8

Martins-Taylor K, Xu RH (2012): Concise review: Genomic stability of human induced pluripotent stem cells. Stem Cells $\underline{30}, 22-7$

Mistry AR, O'Callaghan CA (2007): Regulation of ligands for the activating receptor NKG2D. Immunology 121, 439-47 
Nakajima F, Tokunaga K, Nakatsuji N (2007): Human leukocyte antigen matching estimations in a hypothetical bank of human embryonic stem cell lines in the Japanese population for use in cell transplantation therapy. Stem Cells $\underline{25}, 983-5$

Nomura M, Zou Z, Joh T, Takihara Y, Matsuda Y, Shimada K (1996): Genomic structures and characterization of Rae1 family members encoding GPI-anchored cell surface proteins and expressed predominantly in embryonic mouse brain. J Biochem 120, 987-95

Nussbaum J, Minami E, Laflamme MA, Virag JA, Ware CB, Asino A, Muskheli V, Pabon L, Reinecke H, Murry CE (2007): Transplantation of undifferentiated murine embryonic stem cells in the heart: teratoma formation and immune response. FASEB $\mathrm{J} \underline{21}, 1345-57$

Okita K, Nakagawa M, Hyenjong H, Ichisaka T, Yamanaka S (2008): Generation of mouse induced pluripotent stem cells without viral vectors. Science $322,949-53$

Park IH, Arora N, Huo H, Maherali N, Ahfeldt T, Shimamura A, Lensch MW, Cowan C, Hochedlinger K, Daley GQ (2008): Disease-specific induced pluripotent stem cells. Cell $\underline{134}, 877-86$

Pawelec G (2004): Tumour escape from the immune response. Cancer Immunol Immunother $\underline{53}, 843$

Pegram HJ, Andrews DM, Smyth MJ, Darcy PK, Kershaw MH (2011): Activating and inhibitory receptors of natural killer cells. Immunol Cell Biol $\underline{89}, 216-24$

Puri MC, Nagy A (2012): Concise review: Embryonic stem cells versus induced pluripotent stem cells: the game is on. Stem Cells $\underline{30}, 10-14$

Raya A, Rodríguez-Pizà I, Guenechea G, Vassena R, Navarro S, Barrero MJ, Consiglio A, Castellà M, Río P, Sleep E et al. (2009): Disease-corrected haematopoietic progenitors from Fanconi anaemia induced pluripotent stem cells. Nature $\underline{460}, 53-9$

Revazova ES, Turovets NA, Kochetkova OD, Kindarova LB, Kuzmichev LN, Janus JD, Pryzhkova MV (2007): Patient-specific stem cell lines derived from human parthenogenetic blastocysts. Cloning Stem Cells $\underline{9}$, 432-49

Rideout WM, Hochedlinger K, Kyba M, Daley GQ, Jaenisch R (2002): Correction of a genetic defect by nuclear transplantation and combined cell and gene therapy. Cell $\underline{109}, 17$

Robertson NJ, Brook FA, Gardner RL, Cobbold SP, Waldmann H, Fairchild PJ (2007): Embryonic stem cell-derived tissues are immunogenic but their inherent immune privilege promotes the induction of tolerance. Proc Natl Acad Sci USA 104, 20920-5

Rohwedel J, Sehlmeyer U, Shan J, Meister A, Wobus AM (1996): Primordial germ cellderived mouse embryonic germ (EG) cells in vitro resemble undifferentiated stem cells with respect to differentiation capacity and cell cycle distribution. Cell Biol Int 20, 57987

Schwartz RH (2003): T cell anergy. Annu Rev Immunol 21, 305-34 
Shiba Y, Fernandes S, Zhu WZ, Filice D, Muskheli V, Laflamme MA (2012): Human ES-cell-derived cardiomyocytes electrically coule and suppress arrhythmias in injured hearts. Nature $\underline{489}, 322-5$

Sinai P, Roybal KT, Wülfing C (2010): Tentative and transient natural killer cell polarization balances the requirements for discriminatory recognition and cytolytic efficacy. Commun Integr Biol $\underline{3}, 545-8$

Stadtfeld M, Nagaya M, Utikal J, Weir G, Hochedlinger K (2008): Induced pluripotent stem cells generated without viral integration. Science $\underline{322}, 945-9$

Stinchcombe JC, Griffiths GM (2007): Secretory Mechanisms in Cell-Mediated Cytotoxicity. Annu Rev Cell Dev Biol 23, 495-517

Streckfuss-Bömeke K, Vlasov A, Hülsmann S, Yin D, Nayernia K, Engel W, Hasenfuss G, Guan K (2008): Generation of functional neurons and glia from multipotent adult mouse germ-line stem cells. Stem Cell Res 2 , 139-54

Suárez-Alvarez B, Rodriguez RM, Calvanese V, Blanco-Gelaz MA, Suhr ST, Ortega F, Otero J, Cibelli JB, Moore H, Fraga MF et al. (2010): Epigenetic mechanisms regulate $\mathrm{MHC}$ and antigen processing molecules in human embryonic and induced pluripotent stem cells. PLoS One $\underline{5}$, e10192

Swijnenburg RJ, Tanaka M, Vogel H, Baker J, Kofidis T, Gunawan F, Lebl DR, Caffarelli AD, de Bruin JL, Fedoseyeva EV et al. (2005): Embryonic stem cell immunogenicity increases upon differentiation after transplantation into ischemic myocardium. Circulation 112, I166-72

Swijnenburg RJ, Schrepfer S, Cao F, Pearl JI, Xie X, Connolly AJ, Robbins RC, Wu JC (2008): In vivo imaging of embryonic stem cells reveals patterns of survival and immune rejection following transplantation. Stem Cells Dev 17, 1023-9

Sykulev Y, Joo M, Vturina I, Tsomides TJ, Eisen HN (1996): Evidence that a single peptide-MHC complex on a target cell can elicit a cytolytic $T$ cell response. Immunity 4 , 565-71

Tada M, Takahama Y, Abe K, Nakatsuji N, Tada T (2001): Nuclear reprogramming of somatic cells by in vitro hybridization with ES cells. Curr Biol 11, 1553-8

Takahashi K, Yamanaka S (2006): Induction of pluripotent stem cells from mouse embryonic and adult fibroblast cultures by defined factors. Cell $\underline{126}, 663-76$

Taylor CJ, Bolton EM, Pocock S, Sharples LD, Pedersen RA, Bradley JA. (2005): Banking on human embryonic stem cells: estimating the number of donor cell lines needed for HLA matching. Lancet 366, 2019-25.

Thomas RJ, Anderson D, Chandra A, Smith NM, Young LE, Williams D, Denning C (2009): Automated, scalable culture of human embryonic stem cells in feeder-free conditions. Biotechnol Bioeng 102, 1636-44.

Thomson JA, Itskovitz-Eldor J, Shapiro SS, Waknitz MA, Swiergiel JJ, Marshall VS, Jones JM (1998): Embryonic stem cell lines derived from human blastocysts. Science 282, 1145-7 
Tian X, Woll PS, Morris JK, Linehan JL, Kaufman DS (2006): Hematopoietic engraftment of human embryonic stem cell derived cells is regulated by recipient innate immunity. Stem Cells $\underline{24}$, 1370-80

Topham NJ, Hewitt EW (2009): Natural killer cell cytotoxicity: how do they pull the trigger? Immunology $\underline{128}, 7-15$

Trinchieri G, Valiante N (1993): Receptors for the Fc fragment of IgG on natural killer cells. Nat Immun $\underline{12}$, 218-34

Uchida T, Tomita Y, Anzai K, Zhang QW, Yoshikawa M, Kishihara K, Nomoto K, Yasui $\mathrm{H}$ (1999): Roles of CD4+ and CD8+ T cells in discordant skin xenograft rejection. Transplantation $\underline{68}, 1721-7$

Van den Brink MR, Burakoff SJ (2002): Cytolytic pathways in haematopoietic stem-cell transplantation. Nat Rev Immunol 2, 273

Vivier E, Tomasello E, Baratin M, Walzer T, Ugolini S (2008): Functions of natural killer cells. Nat Immunol $\underline{9}, 503-10$

Voskoboinik I, Dunstone MA, Baran K, Whisstock JC, Trapani JA (2010): Perforin: structure, function, and role in human immunopathology. Immunol Rev $\underline{235}$, 35-54

Wajant $\mathrm{H}$ (2002): The Fas signaling pathway: more than a paradigm. Science $\underline{296}$, 1635-6

Wernig M, Zhao JP, Pruszak J, Hedlund E, Fu D, Soldner F, Broccoli V, ConstantinePaton M, Isacson O, Jaenisch R (2008): Neurons derived from reprogrammed fibroblasts functionally integrate into the fetal brain and improve symptoms of rats with Parkinson's disease. Proc Natl Acad Sci USA 105, 5856-61

Wilmut I, Schnieke AE, McWhir J, Kind AJ, Campbell KH (1997): Viable offspring derived from fetal and adult mammalian cells. Nature $\underline{385}, 810-3$

Wu DC, Boyd AS, Wood KJ (2008): Embryonic stem cells and their differentiated derivatives have a fragile immune privilege but still represent novel targets of immune attack. Stem Cells $\underline{26}, 1939-50$

Wulfing C, Purtic B, Klem J, Schatzle JD (2003): Stepwise cytoskeletal polarization as a series of checkpoints in innate but not adaptive cytolytic killing. Proc Natl Acad Sci USA $\underline{100}, 7767-72$

Yachimovich-Cohen N, Even-Ram S, Shufaro Y, Rachmilewitz J, Reubinoff B (2010): Human embryonic stem cells suppress $T$ cell responses via arginase I-dependent mechanism. J Immunol 184, 1300-8

Ye L, Zimmermann WH, Garry DJ, Zhang J (2013): Patching the heart: cardiac repair from within and outside. Circ Res $113,922-32$

Zimmermann WH (2011): Embryonic and embryonic-like stem cells in heart muscle engineering. J Mol Cell Cardiol 50, 320-6

Zhang D, Pan L, Yang LH, He XK, Huang XY, Sun FZ (2005): Strontium promotes calcium oscillations in mouse meiotic oocytes and early embryos through InsP3 
receptors and requires activation of phospholipase and the synergistic action of InsP3. Human Reproduction 20, 3053-61

Zhao T, Zhang ZN, Rong Z, Xu Y (2011): Immunogenicity of induced pluripotent stem cells. Nature $\underline{13}, 212-5$

Zhou H, Wu S, Joo JY, Zhu S, Han DW, Lin T, Trauger S, Bien G, Yao S, Zhu Y et al. (2009): Generation of induced pluripotent stem cells using recombinant proteins. Cell Stem Cell $\underline{4}, 381-4$ 


\section{Danksagung}

Insbesondere möchte ich Prof. Ralf Dressel für die freundliche Überlassung des Themas, die gute Betreuung und die fortwährende Motivation während des gesamten Projektes danken.

Ebenso geht mein Dank an die Mitarbeiter im Labor - insbesondere an Leslie Elsner für die stete Unterstützung und Rat bei der praktischen Arbeit.

Dank auch der Abteilung für Pharmakologie der Universitätsmedizin Göttingen und insbesondere Vijaykumar Muppala, der einen Teil der untersuchten Zellen zur Verfügung stellte. 


\section{Lebenslauf}

Ich wurde am 17. August 1987 als erste Tochter von Hartmut Johannsen und Dagmar Derendorf geboren.

Bis 2006 besuchte ich das „Gymnasium am Kothen“ in Wuppertal und das "Colegio San Luis de Alba" in Valdivia, Chile. 2007 begann ich mit dem Studium der Humanmedizin an der Georgia Augusta. Seit April 2014 befinde ich mich in der Weiterbildung zur Fachärztin für Innere Medizin.

Im Februar 2010 begann ich mit den Arbeiten an der vorliegenden Dissertation. 